\title{
WestVirginiaUniversity
}

THE RESEARCH REPOSITORY @ WVU

Graduate Theses, Dissertations, and Problem Reports

2006

\section{Software application for emergency responders, SAFER 2.0}

Saritha Reddy Potula

West Virginia University

Follow this and additional works at: https://researchrepository.wvu.edu/etd

\section{Recommended Citation}

Potula, Saritha Reddy, "Software application for emergency responders, SAFER 2.0" (2006). Graduate Theses, Dissertations, and Problem Reports. 1784.

https://researchrepository.wvu.edu/etd/1784

This Thesis is protected by copyright and/or related rights. It has been brought to you by the The Research Repository @ WVU with permission from the rights-holder(s). You are free to use this Thesis in any way that is permitted by the copyright and related rights legislation that applies to your use. For other uses you must obtain permission from the rights-holder(s) directly, unless additional rights are indicated by a Creative Commons license in the record and/ or on the work itself. This Thesis has been accepted for inclusion in WVU Graduate Theses, Dissertations, and Problem Reports collection by an authorized administrator of The Research Repository @ WVU. For more information, please contact researchrepository@mail.wvu.edu. 


\title{
Software Application for Emergency Responders, SAFER 2.0
}

\author{
Saritha Reddy Potula
}

Thesis submitted to the College of Engineering and Mineral Resources at

West Virginia University

in partial fulfillment of the requirements for the degree of

\author{
Master of Science \\ In \\ Mechanical Engineering \\ Dr. Jacky C. Prucz, Co-chair \\ Dr. Rashpal S. Ahluwalia, Co-chair \\ Dr. James E. Smith \\ Department of Mechanical Engineering \\ Morgantown, West Virginia \\ 2006
}

Keywords: First Responders, Hazardous Materials, Emergency, DOT, NIOSH Copyright 2006 Saritha Reddy Potula 


\section{ABSTRACT \\ Software Application for Emergency Responders, SAFER 2.0

\author{
Saritha Reddy Potula
}

The SAFER 2.0 was developed as a web based information system for the First Responders involved in dealing with the hazardous materials incidents. The software tool enables First Responders to view and identify the substances involved in a hazard via a secure Internet connection. The tool also aids in identifying the unknown substances based on the physical description (color, odor, texture, gas / liquid, etc.), symptoms and other information available at the site of the incident. The system is based on the 2004 North American Emergency Response Guidebook (ERG2004) and NIOSH Pocket Guide (NPG). ERG2004 was developed for use by firefighters, police, and other emergency services personnel who may be the first to arrive at the scene of a transportation incident involving a hazardous material. The NPG presents key information and data for 677 chemicals.

The software tool was implemented using the latest technology available i.e. ASP.NET 2.0 as the front-end and SQL Server 2005 as the database. The key features of the system are:

- Easy to use,

- Easy and rapid access to information during a critical incident,

- Identification of unknown substances, and

- Protection of First Responders and general public. 
I dedicate this thesis to my beloved parents

P. KrishnaReddy and P.Kalavathi 


\section{ACKNOWLEDGEMENTS}

I am greatly thankful to my research advisor Dr. Rashpal Ahluwalia for his guidance and continued support. The advice and insight provided by Dr. Ahluwalia has been extremely valuable. I would like to express special thanks to him for his valuable time and co-operation.

I would like to thank, Dr. Jacky Prucz for his continued support, comments, suggestions and review of my thesis. I also wish to thank, Dr. James Smith for the guidance and encouragement provided. The suggestions, reviews and encouragement provided by Dr. Ahluwalia, Dr. Prucz and Dr. Smith helped me in shaping my thesis.

I thank my parents, aunt and uncle for their encouragement, unyielding support, unconditional love and sacrifices. I am greatly thankful to my friends for their continuous support and encouragement, who made this possible. I also thank my brothers and other family members for their valuable support. I would also like to thank Mr. Bruce Palmer and Mr. Jeffrey Altemus, Neurobiology and Anatomy Department, Health Sciences Center, for their continued support.

Last but not the least, my heartfelt thanks to the Mechanical Engineering department, West Virginia University for giving me an opportunity to pursue my higher education, their continued financial support, which was of great help to me in pursuit for completion of my Master of Science degree program. 


\section{TABLE OF CONTENTS}

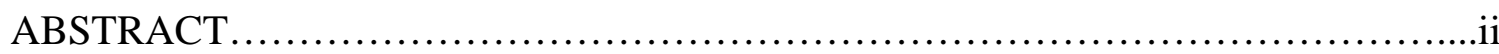

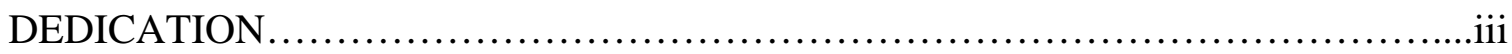

ACKNOWLEDGEMENTS.............................................................

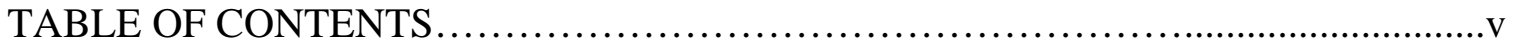

LIST OF FIGURES.............................................................

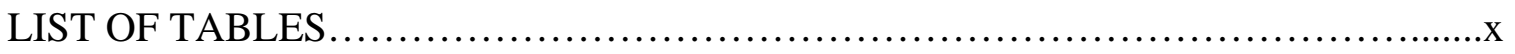

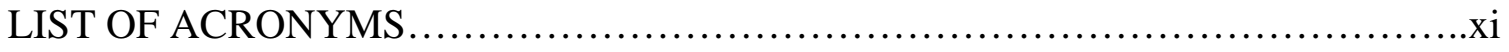

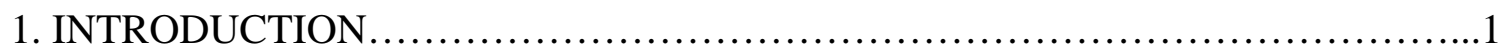

1.1 Hazardous materials.......................................................

1.2 Hazardous materials incidents and reporting requirements......................

1.3 Hazardous materials shipments....................................................

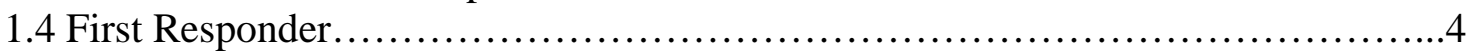

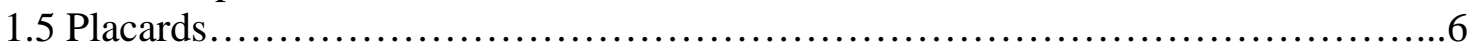

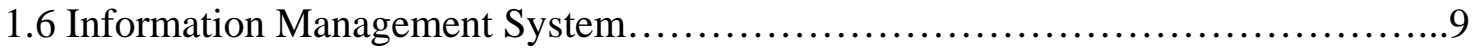

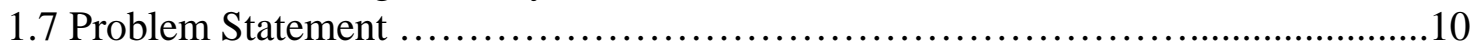

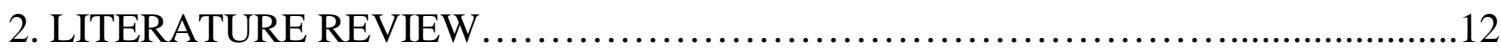

2.1 Existing Data Sources and Applications........................................12

2.2 Sources Used to Populate SAFER Database..................................26

3. SOFTWAREDESIGN AND IMPLEMENTATION .............................37

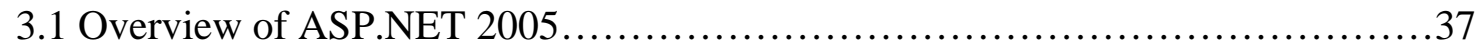

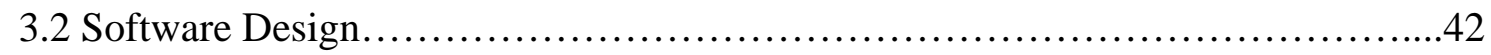

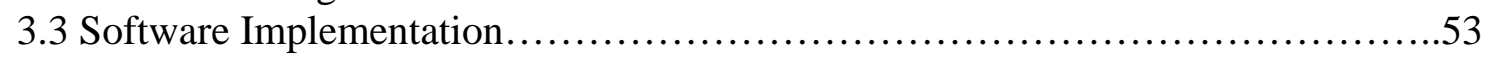

4. DATABASE DESIGN AND IMPLEMENTATION...............................55

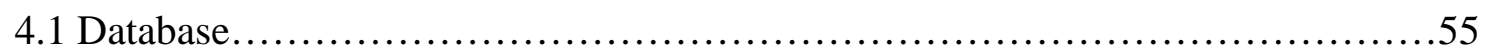

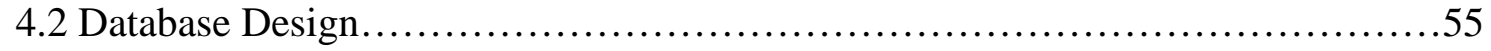

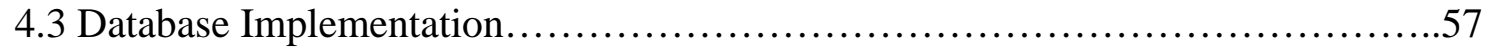




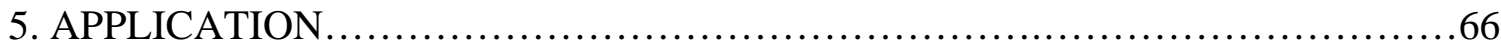

5.1 Shipping document........................................................66

5.2 Emergence Response Telephone Number.....................................68

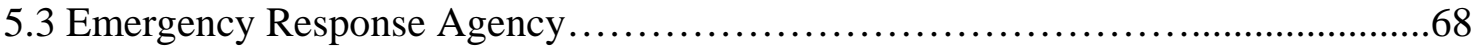

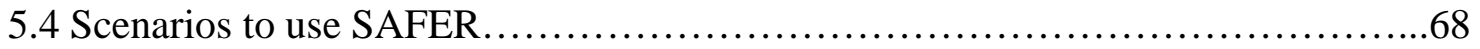

6. CONCLUSIONS AND FUTURE WORK......................................108

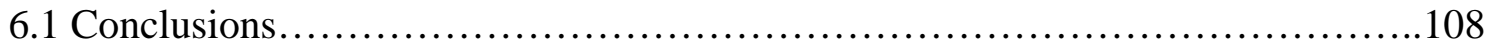

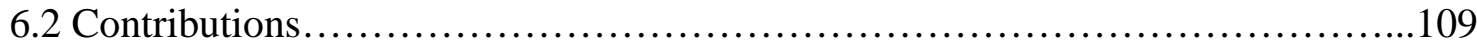

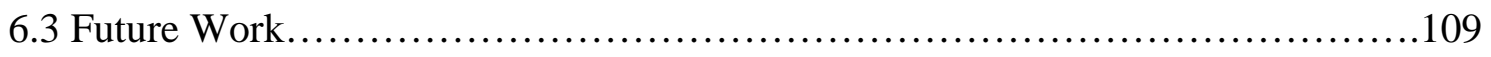

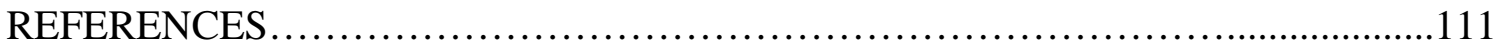

APPENDIX

Appendix 1: Safety Precautions..................................................113

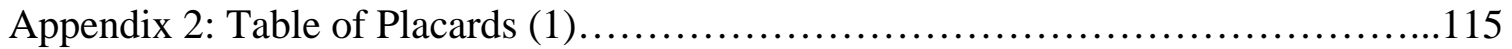

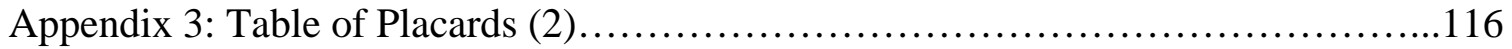

Appendix 4: Rail Car Identification Chart......................................117

Appendix 5: Road Trailer Identification Chart.....................................118 


\section{LIST OF FIGURES}

Figure 1.1: Hazardous Materials Incidents

Figure 1.2: First Responders

Figure 1.3: Placard Indicating Flammable Gas

Figure 2.1: Key information and data for Allyl Alcohol

Figure 2.2: Satellite-based Vehicle Tracking

Figure 2.3: Emergency Response Index

Figure 2.4: Emergency Response Guide

Figure 3.1: Screen shot of creating a new project in VS.NET 2005 IDE

Figure 3.2: Screen shot of creating a new non web-based project in VS.NET 2005

Figure 3.3: Screen shot of creating a new web-based project in VS.NET 2005

Figure 3.4: 3.Tier Architecture

Figure 3.5(a): SAFER Architecture Overview

Figure 3.5(b): SAFER Architecture Details

Figure 3.6: SAFER Flowchart

Figure 3.7: Class Diagram of SAFER

Figure 3.8: Sequence Diagram of SAFER

Figure 4.1: Database Schema

Figure 4.2: Emergency Response Index table view (ERGuide)

Figure 4.3: Emergency Response Guide table view (Actions)

Figure 4.4: NIOSH Pocket Guide table view (fnames)

Figure 4.5: Hazardous Chemicals table view 
Figure 5.1: Placard and Panel with ID number

Figure 5.2: Home page of SAFER website

Figure 5.3: Known substance page

Figure 5.4: Dropdown menu for substance list

Figure 5.5: Option ‘h’ highlighted

Figure 5.6: Hypochlorite solution highlighted

Figure 5.7: Chemical ID and Guide No. associated with Hypochlorite Solution

Figure 5.8: Hypochlorite data page

Figure 5.9: Potential Hazards

Figure 5.10: Public safety

Figure 5.11: Emergency Response page (Fire, Spill or Leak)

Figure 5.12: First aid option on the data page

Figure 5.13: First aid

Figure 5.14: Unknown substance page

Figure 5.15: Physical description highlighted

Figure 5.16: Physical properties

Figure 5.17: Option 'c’ highlighted

Figure 5.18: Colorless liquid with persistent banana-like odor

Figure 5.19: Ethylamine data page

Figure 5.20: 118 Gases, Flammable, Corrosive

Figure 5.21: Symbol 
Figure 5.22: Symptoms

Figure 5.23: Selecting the appropriate symptoms

Figure 5.24: Oxygen, Compressed data page

Figure 5.25: 122 Gases-Oxidizing (Including refrigerated liquids)

Figure 5.26: Data on Spill or Leak

Figure 5.27: Data for Spill or Leak

Figure 5.28: Change Criteria option

Figure 5.29: Unknown substance start page

Figure 5.30: Placards option highlighted

Figure 5.31: Placards page

Figure 5.32: Data page based on Placard search

Figure 5.33: Guide number link highlighted

Figure 5.34: Select another Placard button

Figure 5.35: Placards homepage 


\section{LIST OF TABLES}

Table 2.1: Physical and Chemical Properties of Substances

Table 2.2: Recommended Practices

Table 4.1: Emergency Response Index fields (ERGuide)

Table 4.2: Emergency Response Guide fields (Actions)

Table 4.3: NIOSH Pocket Guide Fields (fnames)

Table 4.4: Hazardous Chemicals fields (Hazardous Chemicals) 


\section{LIST OF ACRONYMS}

\begin{tabular}{ll} 
HAZMAT & Hazardous Material \\
DOT & Department of Transportation \\
OSHA & Occupational Safety and Health Administration \\
RSPA & Research and Special Programs Administration \\
HMR & Hazardous Materials Regulations \\
ERG & Emergency Response Guidebook \\
SCT & Secretariat of Communications and Transportation of Mexico \\
WWW & World Wide Web \\
CoBRA & Chemical Biological Response Aide \\
DGI & Defense Group Inc. \\
CANUTEC & Canadian Transport Emergency Centre \\
TC & Transport Canada \\
WISER & Wireless Information System for Emergency Responders \\
HSDB & Hazardous Substances Data Bank \\
NLM & National Library of Medicine \\
TOXNET & Toxicology Data Network \\
NPG & NIOSH Pocket Guide \\
MSDS & Material Safety Data Sheets \\
HazCom & Current Intelligence Bulletin \\
CIB & Hardous Communication \\
\hline &
\end{tabular}




$\begin{array}{ll}\text { CAS } & \text { Chemical Abstracts Service } \\ \text { RTECS } & \text { Registry of Toxic Effects of Chemical Substances } \\ \text { REL } & \text { Recommended Exposure Limit } \\ \text { IDLH } & \text { Immediately Dangerous to Life and Health } \\ \text { PEL } & \text { Permissible Exposure Limit } \\ \text { PDA } & \text { Personal Digital Assistant } \\ \text { PC } & \text { Personal Computer } \\ \text { IT } & \text { Information Technology } \\ \text { UML } & \text { Unified Modeling Language } \\ \text { BP } & \text { Boiling Point } \\ \text { MP } & \text { Melting Point } \\ \text { SQL } & \text { Structured Query Language }\end{array}$




\section{CHAPTER 1}

\section{INTRODUCTION}

\subsection{Hazardous Materials:}

Hazardous materials are defined and regulated in the United States primarily by laws and regulations administered by the U.S. Environmental Protection Agency (EPA), the U.S. Occupational Safety and Health Administration (OSHA), the U.S. Department of Transportation (DOT), and the U.S. Nuclear Regulatory Commission (NRC). Each has its own definition of a "hazardous material" [1].

The Occupational Safety \& Health Administration, OSHA defines hazardous material as any substance or chemical which is a "health hazard" or "physical hazard," including: chemicals which are carcinogens, toxic agents, irritants, corrosives, sensitizers; agents which act on the hematopoietic system; agents which damage the lungs, skin, eyes, or mucous membranes; chemicals which are combustible, explosive, flammable, oxidizers, pyrophorics, unstable-reactive or water-reactive; and chemicals which in the course of normal handling, use, or storage may produce or release dust, gases, fumes, vapors, mists or smoke which may have any of the previously mentioned characteristics. (Full definitions can be found at 29 Code of Federal Regulations (CFR) 1910.1200.)

EPA incorporates the OSHA definition, and adds any item or chemical which can cause harm to people, plants, or animals when released by spilling, leaking, pumping, pouring, emitting, emptying, discharging, injecting, escaping, leaching, dumping or 
disposing into the environment (40 CFR 355 contains a list of over 350 hazardous and extremely hazardous substances).

DOT defines a hazardous material as any item or chemical which, when being transported or moved, is a risk to public safety or the environment, and is regulated as such under the: Hazardous Materials Regulations (49 CFR 100-180); International Maritime Dangerous Goods Code; Dangerous Goods Regulations of the International Air Transport Association; Technical Instructions of the International Civil Aviation Organization; U.S. Air Force Joint Manual, Preparing Hazardous Materials for Military Air Shipments.

The NRC regulates items or chemicals which are "special nuclear source" or byproduct materials or radioactive substances. (See 10 CFR 20).

In Federal law, a hazardous material is defined as a substance or material that the Secretary of Transportation has determined is capable of posing an unreasonable risk to health, safety, and property when transported in commerce, and has designated as hazardous under Federal hazardous materials transportation law [19].

Mitigating the risks associated with hazardous materials may require the application of safety precautions during their transport, usage, storage and disposal. Most countries regulate hazardous materials by law, and are subject to several International treaties as well. The most widely applied regulatory scheme is that for the transportation of hazardous materials.

The United States Department of Transportation (DOT) regulates hazmat transportation within the territory of the US. The U.S. Occupational Safety and Health 
Administration (OSHA) regulates the handling of hazardous materials in the workplace as well as response to hazardous materials-related incidents.

\subsection{Hazardous Material Incidents and Reporting Requirements:}

The following figure 1.1 contains the hazardous materials incident summary statistics for the period of 1983 to 2004 [2].

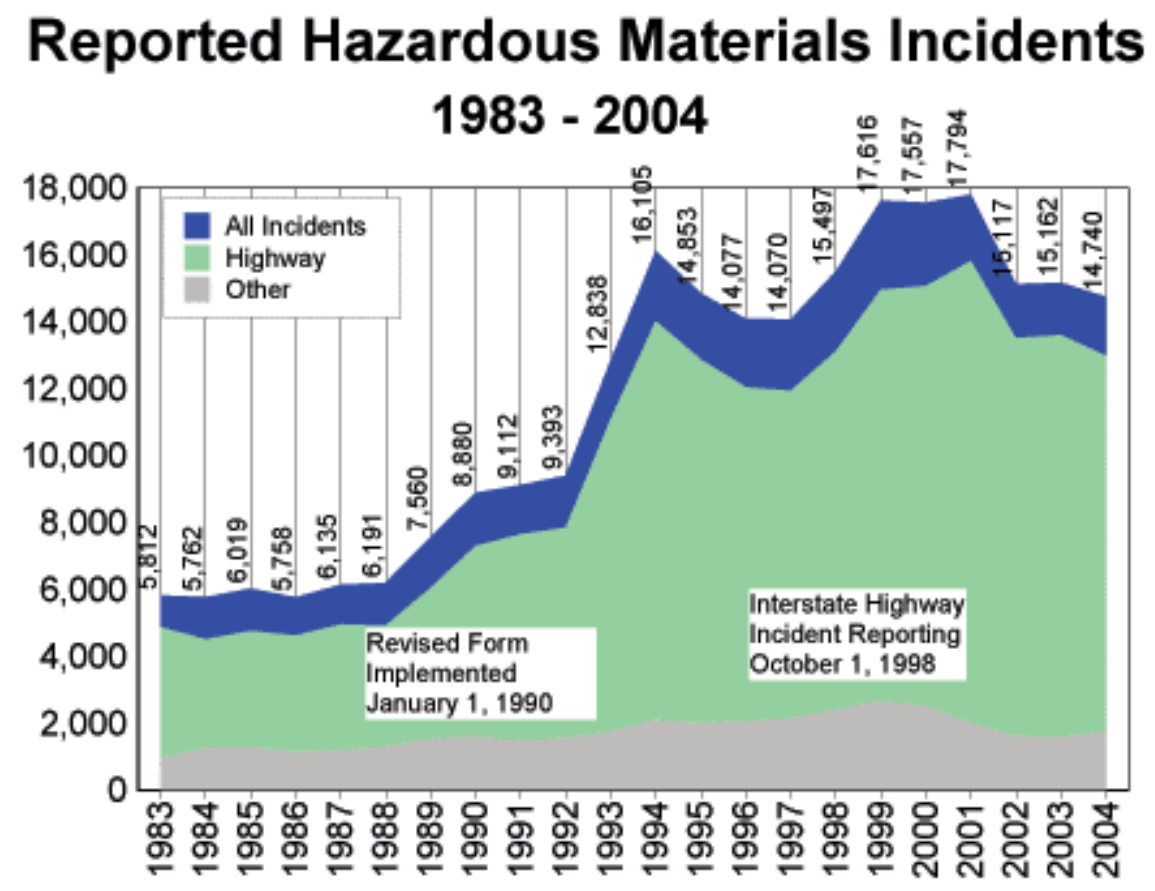

Figure 1.1: Hazardous Materials Incidents

A hazardous material is most dangerous when it is released into atmosphere. The regulations in 49 CFR 171.15 and 171.16 govern the situations where a release or a suspected release of a hazardous material has taken place in transportation. Two phases 
of incident reporting are required in the regulations. Section 171.15 covers immediate telephonic notification following an incident and Section 171.16 outlines written reporting procedures [2].

\subsection{Hazardous Materials Shipments:}

Ensuring the safe transport of hazardous materials within the United States is primarily the responsibility of the U.S. Department of Transportation (DOT). Within DOT, the Research and Special Programs Administration (RSPA) issues the Hazardous Materials Regulations (HMR) and provides training, enforcement, technical support, information and policy guidance to protect the transportation community and the general public against the safety risks inherent in transporting hazardous materials [3].

Hazardous materials (hazmat) shipment information plays an important role in RSPA's ability to achieve its mission. Developing cost-effective regulations and helping emergency responders plan for hazmat transport risks are among the activities that rely on information about hazmat shipments occurring in the U.S.

The Office of Hazardous Materials Safety presently estimates the number of hazardous materials shipments in the United States at more than 800,000 per day. Approximately 500,000 daily shipments involve chemical and allied products (SIC 28); about 300,000 involve petroleum products; and at least 10,000 other shipments involve waste hazardous materials, medical wastes and various other hazardous materials [1]. 


\subsection{First Responder:}

The service personnel first on the scene, such as police officers, firefighters and industrial health professionals are the First Responders. A First Responder is expected to recognize the presence of dangerous goods, protect oneself and the public, secure the area, and call for assistance of trained personnel as soon as conditions permit. Properly trained and equipped first responders as shown in figure 1.2 have the greatest potential to save lives and limit casualties after an incident.

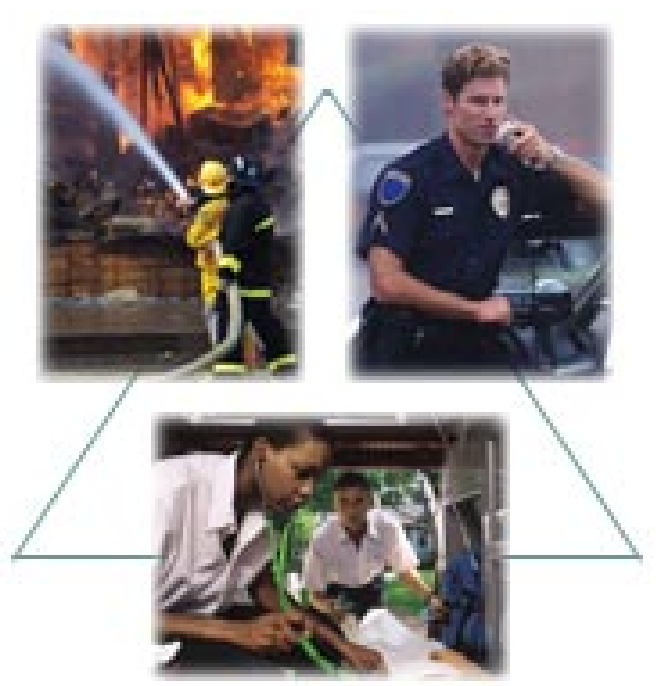

Figure 1.2: First Responders

Facts about First Responders [4]:

- There are over 1 million firefighters in the United States, of which approximately 750,000 are volunteers. 
- Local police departments have an estimated 556,000 full-time employees including about 436,000 sworn enforcement personnel.

- Sheriffs' offices reported about 291,000 full-time employees, including about 186,000 sworn personnel.

- There are over 155,000 nationally registered emergency medical technicians (EMT).

\subsection{Placards [19]:}

In the United States, approximately 800,000 shipments of hazardous materials are transported each day in bulk and in smaller shipment configurations. In regard to bulk rail shipments, the industry uses roughly 200,000 rail tank cars. A subset of these cars moves over 275,000 shipments of chlorine, anhydrous ammonia, propane gas, and gasoline every year. The motor carrier industry dedicates more than 400,000 large trucks to the transportation of hazardous materials. A subset of this fleet participates in approximately 18,000,000 shipments of gasoline and 125,000 shipments of explosives a year.

Placards are currently required on these and other conveyances used in the transportation of hazardous materials. The placards serve as an easily identifiable, visual source of information used by millions of workers in the transportation, public safety, and hazmat industries. Placards identify the general type of hazard associated with the hazardous materials and may also identify the specific hazardous material. Placards are part of a well-established international hazmat communication system. They help regulators working in compliance and enforcement to ensure that hazardous materials 
shipments are transported in a safe manner consistent with the regulations, help transportation workers identify hazmat shipments so that they can be handled appropriately, and help emergency responders quickly ascertain the nature of the hazard that they face in the case of an accident or spill.

The primary function of placards is to provide initial warning information in the event of an incident involving a shipment of hazardous materials. The prominent display of the diamond-shaped placard is intended to immediately warn responders, handlers, and bystanders that hazards are present and reduce the chance of someone inadvertently entering an incident site.

When required, placards must be placed on both ends and both sides of trucks, railcars, and intermodal containers that carry hazardous materials. They are coded by color and contain symbols and numbers that designate the hazard class or division of the hazardous material that is being shipped. For bulk and certain non-bulk shipments, a four digit hazardous material identification number may be on the placard or on an accompanying orange panel or a white square-on-point sign. Figure 1.3 shows the placard for flammable gas (white letters on a red background). The single digit at the bottom of the placard shown in Figure 1.3 is the hazard class. 


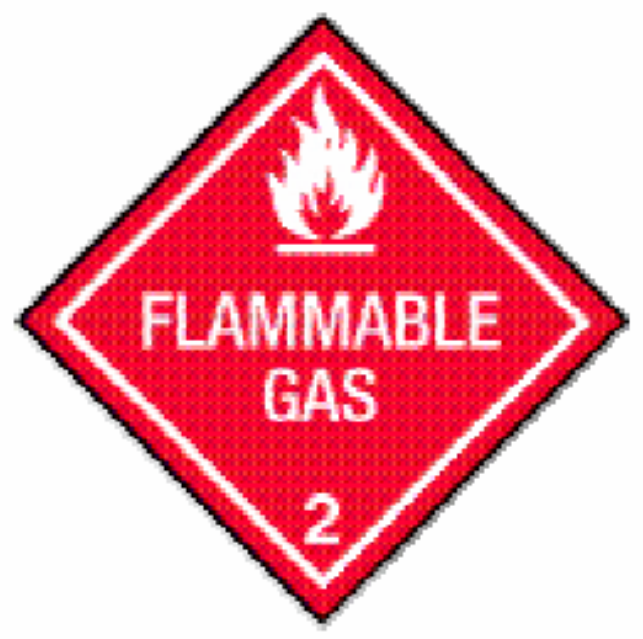

Figure 1.3: Placard indicating flammable gas

Hazardous materials are categorized into nine hazard classes:

1. Explosives

2. Gases

3. Flammable and combustible liquids

4. Flammable solids, spontaneously combustible materials, and dangerous when wet materials

5. Oxidizers and organic peroxides

6. Toxic (poison or poisonous) material and infectious substances

7. Radioactive materials

8. Corrosive materials

9. Miscellaneous dangerous goods. 
Placards usually give fire fighters, police, and other emergency responders at an incident the first indication that a hazardous material is present. Visible placards allow the emergency personnel to assess the situation from a distance and reduce the possibility that these responders will be exposed unnecessarily to a dangerous material. Emergency responders use the information provided by the placard in conjunction with the ERG2004, to decide on their course of action for handling an incident involving a hazardous material.

\subsection{Information Management System:}

Information Management has been defined as the organization-wide capability of creating, maintaining, retrieving, and making available the right information, in the right place, at the right time, in hands for the right people, at the lowest possible cost, in the best media, for use in decision making [5].

The rapid evolution of computer technology is expanding man's ability to convert data into useful information and to utilize the information to solve complex problems. The need to obtain, access conveniently, quickly, and economically makes it imperative to devise procedures for the creation, management, and utilization of databases [6].

Recent advances in web technology have made the focus of the information technology field to move towards development for the World Wide Web (WWW). More users have access to web information, and information providers are able to store information of various types on the web easily. The web has now become one of the most 
important medium for information interchange. Web based systems maximize information sharing and enable comprehensive management of data [7].

Information systems using the web technology are prevalent throughout the world. Advancements in web technology have made it possible to move documentation

and data management away from paper based systems [8]. New web programming languages take advantage of a high-end database technology to deliver the promise of a paperless society. Maintaining electronic documents are easy and require less storage space. It reduces the cost of printing, copying and distributing. The key feature of a webbased system is its time saving ability to easily search vast amounts of information in a short period of time.

Development of a web-based information system for the Emergency Responders is relatively new and Software Application for Emergency Responders (SAFER) is an application developed in that direction.

\subsection{Problem Statement:}

A review of the previously published work indicates that there a few software tools to aid First Responders in dealing with hazardous materials incidents. The existing tools are windows based and focus on limited areas. A user needs to search quickly to determine the chemical properties of suspect substances. There exists a need for a streamlined information system that can aid the First Responders to quickly identify the specific or generic hazards of the materials involved in the incident, and protect themselves and the general public during the initial response phase of the incident. This 
thesis presents a design and implementation of such a system. Such a system will provide First Responders with:

- Critical information

- Comprehensive decision support, including assistance in identification of an unknown substance.

- Guidance on immediate actions necessary to save lives and protect the environment.

- Expedite the ability to transition from observation to action, when seconds really count.

- Literally replace a stack of books, so you can always have the information you need.

- A comprehensive database of information drawn from multiple sources, which is easy to use and fast.

- A wide range of information on hazardous substances, including substance identification, properties and health information.

- $\quad$ Easy access to the system. 


\section{CHAPTER 2}

\section{LITERATURE REVIEW}

\subsection{Existing Data Sources and Applications:}

\subsubsection{Chemical Companion:}

Chemical Companion operates on a Windows CE-based personal digital assistants, provides detailed information on 130 of the most common chemicals associated with hazmat incidents. The characteristics of a chemical, such as its boiling point or density, tell different things about how to approach the scene of the incident. This project is being sponsored by the federal government's Technical Support Work Group. It helps first responders to make decisions about Protective equipment, Chemical reactivity, Isolation and protective zones. The Chemical Companion will be offered free to the military, law enforcement officers and fire departments. Beta-testing for the Chemical Companion began in fall of 2005, and is expected to be distributed this year [9].

Major Drawbacks:

Chemical Companion provides information only about the most common chemicals associated with hazmat incidents. It helps responders to make decisions about only some of the categories. It is being developed only on a handheld device. Moreover, it is expected to be distributed sometime later this year. 


\subsubsection{CoBRA ${ }^{\circledR}$ (Chemical Biological Response Aide):}

Emergency Response Solutions is a division of Defense Group Inc. (DGI), is the leading provider of crisis management systems solutions to military, civilian government and commercial entities. The CoBRA ${ }^{\circledR}$ line of products and services including software, hardware and training provides first responders and emergency management authorities with decision support systems for all incidents. This system gives specific emphasis to chemical, biological, radiological, nuclear, general hazard, and all explosive related events. This tool runs on almost any desktop or laptop PC running on Microsoft ${ }^{\circledR}$ Windows $^{\text {TM }}$ 2000, XP or XP Tablet PC Edition operating systems. CoBRA ${ }^{\circledR}$ is scalable to the requirements of small or large organizations and supports the full spectrum of response including planning, training, exercising, and response. It gives users the capability to organize all the information needed during an emergency response with an easy to use software program [10].

Major Drawbacks:

CoBRA 4.0 costs around $\$ 2500.00$ and is not available on a web based platform. It does not provide exclusive information about the steps to be taken during a hazardous materials incident such as public safety, evacuation distance, medical treatment, etc.

\subsubsection{CANUTEC:}

It is the Canadian Transport Emergency Centre operated by Transport Canada to assist emergency response personnel in handling dangerous goods emergencies.: The 
2004 Emergency Response Guidebook (ERG2004) was developed jointly by Transport Canada (TC), the U.S. Department of Transportation (DOT) and the Secretariat of Transport and Communications of Mexico (SCT) for use by fire fighters, police, and other emergency services personnel who may be the first to arrive at the scene of a transportation incident involving dangerous goods.

CANUTEC's ERGO 2004 (a software version of the 2004 Emergency Response Guidebook (ERG2004)) was made available for free download as of August 1, 2005. The most recent revision is version 1.0. The file size is $2776 \mathrm{~KB}$ and is self-extracting. The interface of ERGO was designed to have a look and feel similar to the Guidebook so that familiarity with the ERG2004 would translate effortlessly to the software version [11].

Major Drawback: It is the guidebook made available online and the user has to search for the information.

2.1.4 WISER (Wireless Information System for Emergency Responders):

WISER has been developed by US National Library of Medicine. WISER is a system designed to assist first responders in hazardous material incidents. It provides a wide range of information on hazardous substances. It is available for the Palm, PocketPC, and Windows. The operational version of WISER provides a highly functional solution with information and substance identification capabilities on more than 400 substances from the HSDB (Hazardous Substances Data Bank). HSDB is a toxicology 
data file on the National Library of Medicine's (NLM) Toxicology Data Network (TOXNET®). It contains information on human exposure, industrial hygiene, emergency handling procedures, environmental fate, regulatory requirements, and related areas [12].

Major Drawbacks:

It is based on the 2000 Emergency Response Guidebook and has substance identification capabilities on about 400 substances only.

\subsubsection{Pocket Mobility Inc.:}

Pocket Mobility Inc. provides mobile technology for emergency responders, training solutions, and educational applications. The Hazmat Toolkit by Pocket Mobility Inc. is an essential tool for first responders and hazmat personnel. The Hazmat Toolkit runs on a handheld PDA (Palm or Pocket PC), or a Windows computer [13]. It is not available on a web based platform and the tool is not very user friendly.

\subsubsection{NIOSH Pocket Guide to Chemical Hazards (NPG):}

It is intended as a source of general industrial hygiene information on several hundred chemicals/classes for workers, employers, and occupational health professionals. The NPG does not contain an analysis of all pertinent data, rather it presents key information and data in abbreviated or tabular form for chemicals or substance groupings (e.g. cyanides, fluorides, manganese compounds) that are found in the work environment. The information found in the NPG should help users recognize and control occupational chemical hazards [14]. 
The Pocket Guide includes the following:

- Chemical names, synonyms, trade names, conversion factors, CAS, RTECS, and DOT numbers

- NIOSH Recommended Exposure Limits (NIOSH RELs)

- Occupational Safety and Health Administration (OSHA) Permissible Exposure Limits (PELs)

- NIOSH Immediate Dangerous to Life and Health values (NIOSH IDLHs)

- A physical description of the agent with chemical and physical properties

- Measurement methods

- Personal protection and sanitation recommendations

- Respirator recommendations

- Information on health hazards including route, symptoms, first aid and target organ information.

Figure 2.1 shows the sample information available in NIOSH pocket guide for the chemical Allyl Alcohol. 


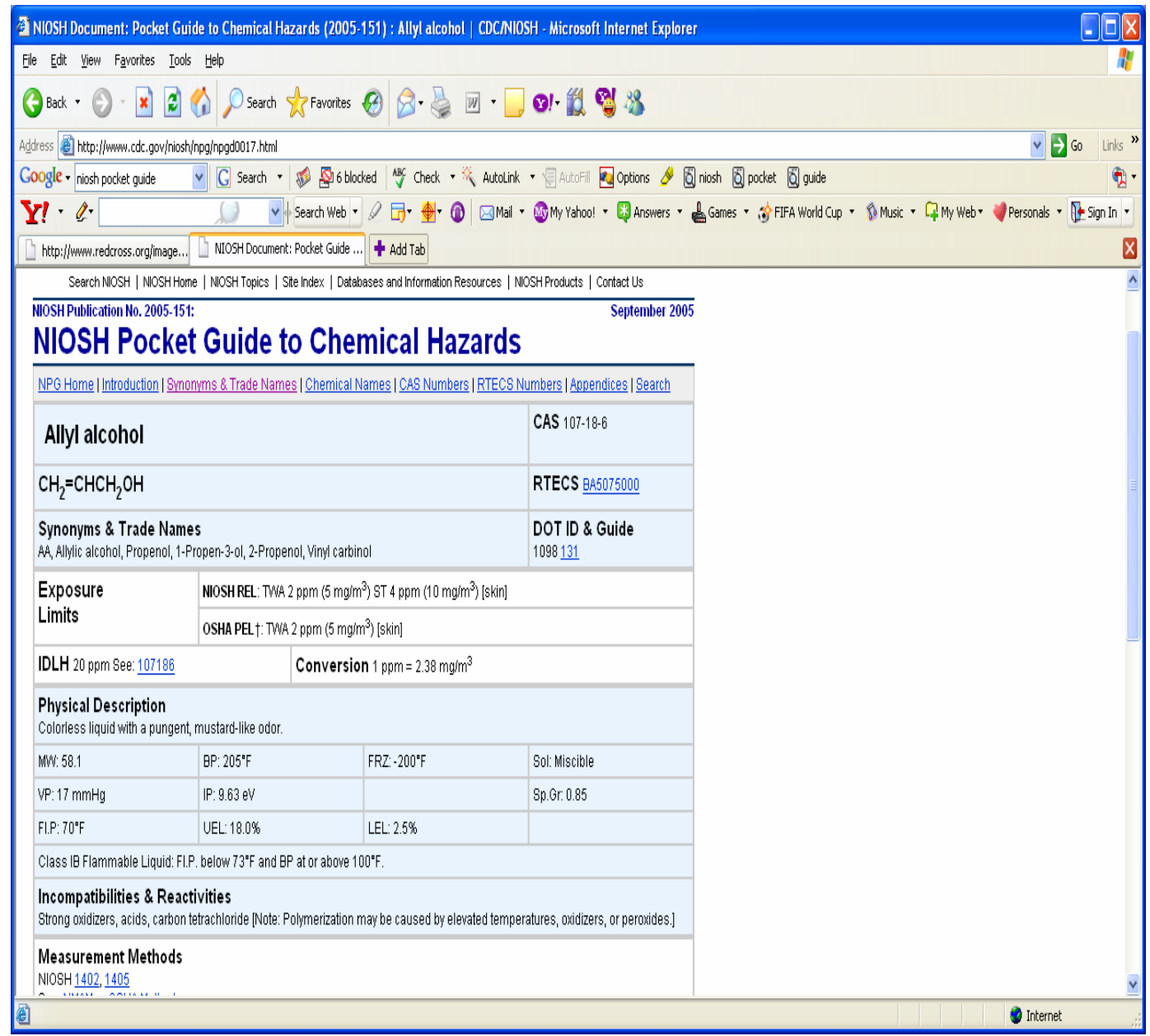

Figure 2.1: Key information and data from NIOSH

\subsubsection{NIOSH's HazCom Helper:}

NIOSH's HazCom Helper provides those responsible for creating an OSHA HazCom written program with software to aid in writing their program and for identifying hazardous chemicals on site. OSHA's HazCom rule (29 CFR 1910.1200) requires all mines to determine which chemicals are hazardous, write a Hazard Communication Program, label all containers containing hazardous chemicals, keep 
MSDS's for all hazardous chemicals, provide HazCom training to employees, and to make the HazCom information available to employees.

Chemicals in industry pose a range of hazards to exposed employees, from mild health effects to death. Some chemicals cause or contribute to chronic health problems, such as heart or kidney disease or cancer. Others cause acute injuries or illnesses such as dermatitis, burns, and poisonings. Some chemicals pose hazards by contributing to fires and explosions. The toll of chemically-related injuries and illnesses in industry can be obscured by years of latency between an exposure to a chemical and the onset of an illness.

OSHA's Hazard Communication Standard, called HazCom, expresses two safety and health principles: employees have a right to know about the chemical hazards where they work and you have a responsibility to know about the chemical hazards at a location. HazCom requires employees to be informed about chemical hazards.

NIOSH's HazCom Helper also provides those responsible for creating a MSHA HazCom written program with software to aid in writing their program and for identifying hazardous chemicals on site. MSHA's HazCom rule (30 CFR Part 47) requires all mines to determine which chemicals are hazardous, write a Hazard Communication Program, label all containers containing hazardous chemicals, keep MSDS's for all hazardous chemicals, provide HazCom training to employees, and to make the HazCom information available to employees [15]. 


\subsubsection{Industrial Fire Hazards Handbook:}

The purpose of this handbook is to provide a broad yet thorough introduction to major industries and industrial processes, with emphasis on the fire hazards that accompany them. This Handbook, therefore, is intended to complement the NFPA codes and standards, and help the user apply them intelligently. It is meant as a basic reference book, which will serve a broad audience, including fire science students as well as those directly involved in industrial fire protection.

\subsubsection{Emergency Action Guide for Selected Hazardous Materials:}

This guide was prepared to help emergency service personnel during the first 30 minutes of an accident involving a spill of a volatile, toxic, gaseous and /or flammable material that is shipped in bulk [16]. General and specific safety procedures to follow are provided in spill guides arranged alphabetically by hazardous material. Each left-hand page identifies a specific hazardous material, outlines its potential hazards and provides immediate action information for fires, spills and first aid. Each right hand page specifies recommended evacuation areas and distances for protecting the public from dangerous concentrations of toxic vapors and explosions. Where applicable, necessary water pollution controls are provided.

\subsubsection{Hazardous Materials:}

This book approaches the study of Hazardous Materials from a frame of reference, which explains why the various materials act and react as they do. This 
explanation is based on the atomic and molecular structure and the chemical reactivity of the materials. This book communicates through the use of common nomenclature, chemical symbols, and structural formulas. The reader is introduced to the laws and principles governing the behavior of hazardous materials as a background for learning to control the behavior. Frequently encountered materials, which have hazardous properties, are identified, both chemically and practically, rationale for fire fighting is based on both their chemical reactivity and their physical properties. Nationally accepted procedures for identifying hazardous chemicals and methods for crisis handling of them are summarized.

\subsubsection{1: High-Technology Approaches [19]:}

Commercially available technologies exist that could be applied to enhance the safety and security of hazmat shipments. The three high-technology approaches are:

1. Radio Frequency Identification tags (RFID)

2. Vehicle tracking and monitoring technologies

3. Enhanced information systems.

\section{RFID Tags:}

RFID tags are small inexpensive electronic devices designed to contain information that can be retrieved at a distance using a specialized reader, the most common example being the tags used for toll collection on highways. Because an RFID tag requires specialized equipment to be read, it helps to mitigate the vulnerability of a terrorist identifying a hazmat shipment by sight alone. Depending on the tag used by the shipper, however, a terrorist may be able to purchase an off-the-shelf reader and use it to 
identify the contents of a shipment. While RFID tags are relatively inexpensive per vehicle, there would be a significant infrastructure cost that would include the cost of providing portable readers to emergency responders and transport workers. RFID tags could be encoded with more information than a placard alone could provide, which should enhance emergency response.

The railroad industry has installed two RFID tags (known in the railroad industry as Automatic Equipment Identification [AEI] tags) on every freight car and locomotive in the US and Canada. Railroads use the AEI information for confirming train contents, and are beginning to use the AEI information to identify specific cars that have been flagged by wayside equipment defect detectors. AEI tags are passive and contain only vehicle initial and number and the number of wheels on the vehicle. They cost about \$125 per car set to purchase and install. Active battery powered read-write AEI tags that can accommodate commodity information are also available. AEI readers cost about $\$ 25,000$ per installation, with a large portion of that cost being for power supply, foundations, and communications links.

A number of limitations and impediments to implementing RFID tags exist. These include the high cost for implementation of a tag system capable of relaying information on hazardous materials, and the need, if implemented, to distribute millions of pieces of equipment to industry and emergency responders. RFID tags could require emergency responders to come closer to transport vehicles to read the tag, thereby placing themselves in greater danger. Additional limitations include the need to train personnel in industry and the emergency response community on how to use RFID tags, as well as the 
need to maintain the readers and other equipment associated with RFID tags. This training and maintenance would drive the total costs of using RFID tags even higher.

\section{Vehicle Tracking Systems:}

Vehicle tracking systems allow the remote monitoring of the location and condition of a vehicle from a central location. Generally in vehicle tracking systems, a tracking device located on a vehicle will use the Global Positioning System (GPS) to determine its own location and then, using a separate communications pathway, report that location back to a central monitoring facility. Communication choices fall into three basic categories:

1. Satellite

2. Terrestrial network (such as a cellular phone network)

3. Conventional radio

It does not matter which system is selected as long as the shipment is traveling within the communications coverage area. Tracking systems provide a near real-time link to the vehicle and may be used to monitor many different aspects of a shipment. Examples include monitoring for trailer break-ins using alarm sensors on a trailer, monitoring for a shipment deviating from a predetermined course (usually referred to as geo-fencing), monitoring for an antenna cable being cut (which hijackers may do as a first step to stealing a truck and its cargo), or a driver-activated single stroke emergency alert feature. 
Vehicle tracking systems may be used to respond to terrorist attacks in a variety of ways. One is to render the vehicle inoperable by turning off the engine, making hijacking significantly more difficult and risky for a terrorist. Commercial technology with this functionality is available and currently in use by industry and the U.S. Government. To function effectively, vehicle tracking devices must be augmented by staff at a monitoring site who dispatch local emergency responders, as is the case with systems operated by the U.S. Department of Energy for radioactive waste and special weapon components, and by the U.S. Department of Defense for shipments of conventional weapons and explosives. It should be noted that these systems are currently used mostly by larger carriers, at least in part because of their expense and the lack of a need by many shippers and carriers of hazmat.

Figure 2.2 is a simplified representation of the flow of data through a generic satellite-based vehicle tracking system.

- GPS is used to calculate the position of the vehicle.

- This position information is then broadcast to a satellite.

- Once received at the satellite, the information is then transmitted back down to the satellite service provider's ground station.

- The ground station in turn formats the data and delivers it to the customer's application.

The ground station can usually transmit data to more that one location, providing a redundant pathway to increase system reliability. In addition, when emergency or 
critical messages are received, the data may be routed over another network to staff at the site where the information was received who can contact emergency responders.

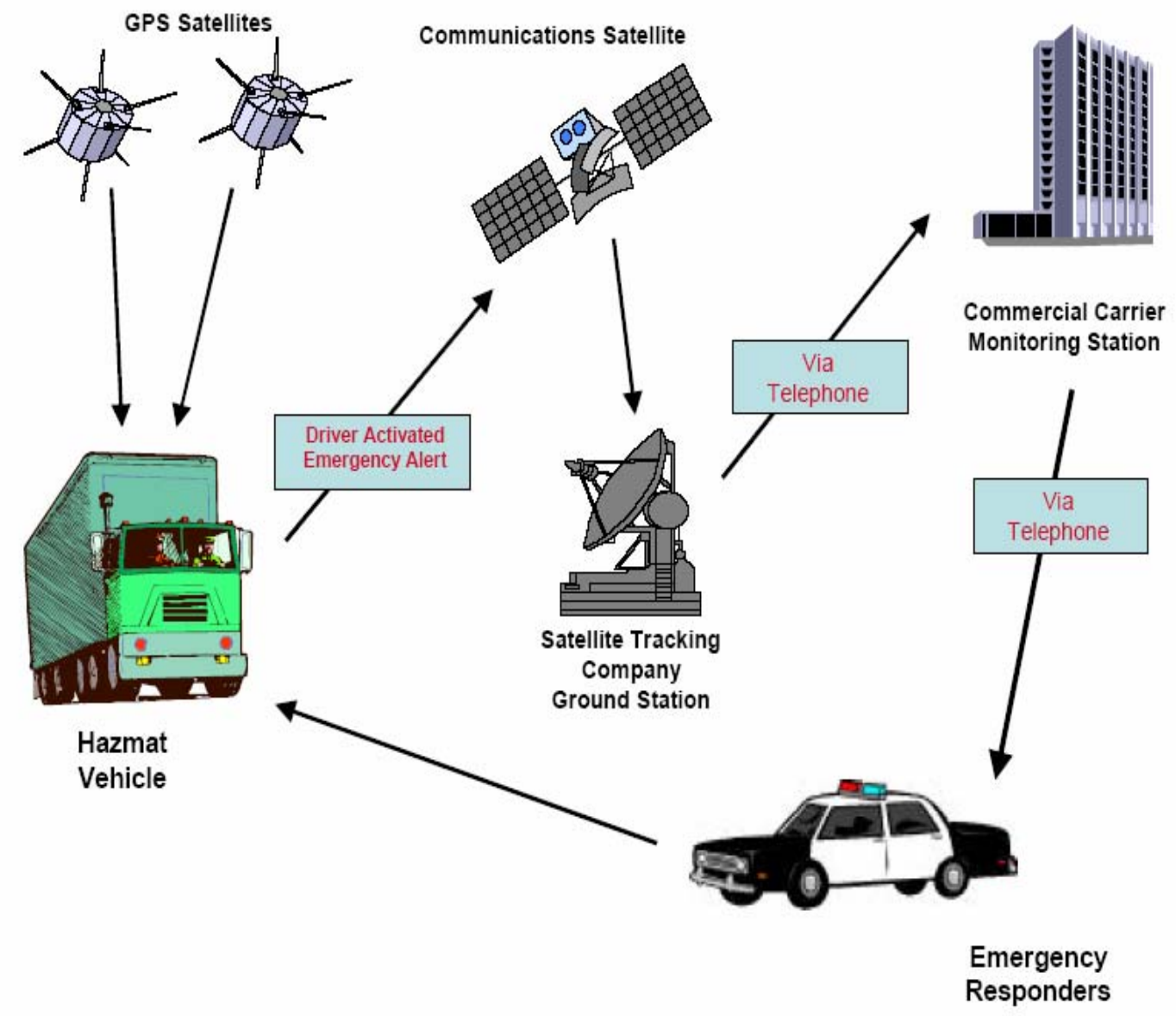

Figure 2.2: Satellite-based Vehicle Tracking

The limitations to using vehicle tracking include the high cost of the infrastructure needed for implementation and the lack of a universal standard, which would be needed 
if a universal system were to be implemented. An effective system of communicating an incident to emergency responders anywhere in the United States does not currently exist and would need to be provided for this system to be viable as a replacement to placarding. If vehicle tracking were to be used in place of placards, the information needs of transport workers and regulatory enforcement personnel would not be met.

\section{Centralized Information System:}

If all shipments were recorded in a centralized information system, then emergency responders could access the system through a call center or a web site from an incident scene and find specific information about a shipment. This system, it must be noted, does not currently exist. Currently, regulations require that shipping papers include an emergency response telephone number that emergency responders can call to find out information about a shipment if an incident occurs. Many decentralized systems providing this information currently exist. They are typically operated by the firm itself, by an independent contractor, or as a service of an industry group, such as the American Chemistry Council's CHEMTREC organization. A centralized information system, if well implemented, could provide significantly more information to the first responder. Furthermore, in a well implemented system, emergency responders could call about any incident and be confident that they would receive the information they need if the incident involved hazmat. Alternatively, if a centralized information system were combined with a vehicle tracking/monitoring system, the information about an incident could be "pushed" to responders on the way to the incident scene. 
Significant implementation barriers exist. Those barriers include costs and the lack of communications infrastructure and equipment needed to facilitate emergency responders accessing information in the system. There is also the challenge of making the system accessible to emergency responders while protecting it from unauthorized access by terrorists. All vehicles would require some marking to identify them to the centralized information system.

\subsection{Sources used to populate SAFER database:}

\subsection{1: 2004 Emergency Response Guidebook:}

This guidebook was developed jointly by Transport Canada (TC), the U.S. Department of Transportation (DOT) and the Secretariat of Transport and Communications of Mexico (SCT) for use by fire fighters, police, and other emergency services personnel who may be the first to arrive at the scene of a transportation incident involving hazardous materials.

The ERG2004 is primarily a guide to aid first responders in quickly identifying the specific or generic hazards of the material(s) involved in the incident, and protecting themselves and the general public during the initial response phase of the incident [18].

This guidebook will assist responders in making initial decisions upon arriving at the scene of a hazardous materials incident. It is primarily designed for use at a dangerous goods incident occurring on a highway or railroad. ERG2004 incorporates dangerous 
goods lists from the most recent United Nations Recommendations as well as from other international and national regulations.

Every hazardous material is assigned an ID Number and a Guide Number. The Emergency Response Index gives the ID Number and Guide Number assigned for all hazardous materials as shown in figure 2.3: 


\section{ID Guide Name of Material}

No. No.

1011115 Butane

1011115 Butane mixture

1012115 Butylene

1013120 Carbon dioxide

1013120 Carbon dioxide, compressed

1014122 Carbon dioxide and Oxygen mixture

1014122 Carbon dioxide and Oxygen mixture, compressed

1014122 Oxygen and Carbon dioxide mixture

1014122 Oxygen and Carbon dioxide mixture, compressed

1015126 Carbon dioxide and Nitrous oxide mixture

Figure 2.3: Emergency Response Index 
The Emergency Response Guide has information on:

- Potential Hazards

- Public Safety

- Emergency Response

The Potential Hazards section provides information about:

- Fire or explosion

- Health

The Public Safety section provides information about:

- Initial evacuation distance

- $\quad$ Protective clothing

- Evacuation (Spill, Fire)

The Emergency Response section provides information about response to:

- $\quad$ Fire (small fires, large fires)

- Spill (small spills, large spills)

- $\quad$ First Aid

The Emergency Response Guide page from the 2004 Emergency Response Guidebook is shown in the figure 2.4 . 


\section{POTENTIAL HAZARDS}

\section{FIRE OR EXPLOSION}

- Flammable/combustible material.

- May be ignited by heat, sparks or flames.

- DRIED OUT material may explode if exposed to heat, flame, friction or shock; Treat as an explosive (GUIDE 112).

- Keep material wet with water or treat as an explosive (GUIDE 112).

- Runoff to sewer may create fire or explosion hazard.

\section{HEALTH}

- Some are toxic and may be fatal if inhaled, swallowed or absorbed through skin.

- Contact may cause burns to skin and eyes.

- Fire may produce irritating, corrosive and/or toxic gases.

- Runoff from fire control or dilution water may cause pollution.

\section{PUBLIC SAFETY}

- CALL Emergency Response Telephone Number on Shipping Paper first. If Shipping Paper not available or no answer, refer to appropriate telephone number listed on the inside back cover.

- Isolate spill or leak area immediately for at least 100 meters (330 feet) in all directions.

- Keep unauthorized personnel away.

- Stay upwind.

- Ventilate closed spaces before entering.

\section{PROTECTIVE CLOTHING}

- Wear positive pressure self-contained breathing apparatus (SCBA).

- Structural firefighters' protective clothing will only provide limited protection.

\section{EVACUATION}

\section{Large Spill}

- Consider initial evacuation for 500 meters (1/3 mile) in all directions.

Fire

- If tank, rail car or tank truck is involved in a fire, ISOLATE for 800 meters (1/2 mile) in all directions; also, consider initial evacuation for 800 meters ( $1 / 2$ mile) in all directions.

Figure 2.4: Emergency Response Guide 


\subsubsection{The National Institute of Occupational Safety and Health, NIOSH Pocket Guide to Chemical Hazards (NPG):}

The NIOSH Pocket Guide is intended as a source of general industrial hygiene information for workers, employers, and occupational health professionals.

In 1974, NIOSH joined OSHA in developing a series of occupational health standards for substances with existing PELs. This joint effort was labeled the Standards Completion Program and involved the cooperative efforts of several contractors and personnel from various divisions within NIOSH and OSHA. The Pocket Guide was developed to make the technical information in the draft standards more conveniently available to workers, employers, and occupational health professionals. The Pocket Guide is updated periodically to reflect new data regarding the toxicity of various substances and any changes in exposure standards or recommendations.

The NPG presents key information and data in abbreviated or tabular form for 677 chemicals or substance groupings that are found in the work environment. The industrial hygiene information found in the NPG can help users recognize and control occupational chemical hazards. The data in the Pocket Guide was collected from a variety of sources, including NIOSH policy documents such as criteria documents and Current Intelligence Bulletins (CIBs), and recognized references in the fields of industrial hygiene, occupational medicine, toxicology, and analytical chemistry. 
The Pocket Guide includes the following information:

Chemical Name: The chemical name found in the OSHA General Industry Air Contaminants Standard (29 CFR 1910.1000) is listed in the top left portion of each chemical table.

Structure/Formula: The chemical structure or formula is listed under the chemical name in each chemical table.

CAS Number: The Chemical Abstracts Service (CAS) registry number is provided in the top right portion of the chemical tables. The CAS number, in the format $\mathrm{xxx}-\mathrm{xx}-\mathrm{x}$, is unique for each chemical and allows efficient searching on computerized data bases.

RTECS Number: This section lists the Registry of Toxic Effects of Chemical

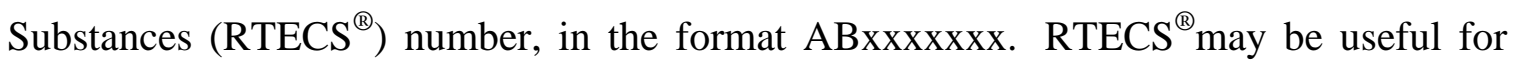
obtaining additional toxicologic information on a specific substance.

DOT ID and Guide Number: This section lists the U.S. Department of Transportation (DOT) Identification numbers and the corresponding Guide numbers. Their format is xxxx yyy. The Identification (ID) number (xxxx) indicates that the chemical is regulated by DOT. The Guide number (yyy) refers to actions to be taken to stabilize an emergency situation; this information can be found in the 2004 Emergency Response Guidebook

Synonyms and Trade Names: This section of each chemical table contains an alphabetical list of common synonyms and trade names for each chemical. 
Conversion Factors: This section lists factors for the conversion of ppm (parts of vapor or gas per million parts of contaminated air by volume) to $\mathrm{mg} / \mathrm{m}^{3}$ (milligrams of vapor or gas per cubic meter of contaminated air) at $25^{\circ} \mathrm{C}$ and 1 atmosphere for chemicals with exposure limits expressed in ppm.

Exposure Limits: The NIOSH recommended exposure limits (RELs) are listed first in this section.

IDLH - Immediately Dangerous to Life and Health: This section lists the immediately dangerous to life or health concentrations (IDLHs). The purpose for establishing an IDLH value in the Standards Completion Program was to determine the airborne concentration from which a worker could escape without injury or irreversible health effects from an IDLH exposure in the event of the failure of respiratory protection equipment.

Physical Description: This entry provides a brief description of the appearance and odor of each substance.

Chemical and Physical Properties: Table 2.1 shows the abbreviations used for the chemical and physical properties for each substance. "NA" indicates that a property is not applicable, and a question mark (?) indicates that it is unknown. 


\section{Table 2.1: Physical and Chemical Properties of Substances}

\begin{tabular}{|c|c|}
\hline MW & Molecular weight \\
\hline $\mathrm{BP}$ & Boiling point at 1 atmosphere, ${ }^{\circ} \mathrm{F}$ \\
\hline Sol & $\begin{array}{l}\text { Solubility in water at } 68^{\circ} \mathrm{F} \text { (unless a different temperature is noted), \% by } \\
\text { weight (i.e., g/100 ml) }\end{array}$ \\
\hline Fl.P & $\begin{array}{l}\text { Flash point (i.e., the temperature at which the liquid phase gives off enough } \\
\text { vapor to flash when exposed to an external ignition source), closed cup (unless } \\
\text { annotated "(oc)" for open cup), }{ }^{\circ} \mathrm{F}\end{array}$ \\
\hline IP & $\begin{array}{l}\text { Ionization potential, eV (electron volts) [Ionization potentials are given as a } \\
\text { guideline for the selection of photoionization detector lamps used in some } \\
\text { direct-reading instruments.] }\end{array}$ \\
\hline VP & $\begin{array}{l}\text { Vapor pressure at } 68^{\circ} \mathrm{F} \text { (unless a different temperature is noted), mm Hg; } \\
\text { "approx" indicates approximately }\end{array}$ \\
\hline MLT & Melting point for solids, ${ }^{\circ} \mathrm{F}$ \\
\hline FRZ & Freezing point for liquids and gases, ${ }^{\circ} \mathrm{F}$ \\
\hline UEL & $\begin{array}{l}\text { Upper explosive (flammable) limit in air, \% by volume (at room temperature } \\
\text { unless otherwise noted) }\end{array}$ \\
\hline LEL & $\begin{array}{l}\text { Lower explosive (flammable) limit in air, \% by volume (at room temperature } \\
\text { unless otherwise noted) }\end{array}$ \\
\hline $\mathrm{MEC}$ & Minimum explosive concentration, g/m³ (when available) \\
\hline Sp.Gr & $\begin{array}{l}\text { Specific gravity at } 68^{\circ} \mathrm{F} \text { (unless a different temperature is noted) referenced to } \\
\text { water at } 39.2^{\circ} \mathrm{F}\left(4^{\circ} \mathrm{C}\right)\end{array}$ \\
\hline RGasD & $\begin{array}{l}\text { Relative density of gases referenced to air }=1 \text { (indicates how many times a gas } \\
\text { is heavier than air at the same temperature) }\end{array}$ \\
\hline
\end{tabular}


Incompatibilities and Reactivities: This entry lists important hazardous incompatibilities or reactivities for each substance.

Personal Protection and Sanitation: This section presents a summary of recommended practices for each substance. These recommendations supplement general work practices (e.g., no eating, drinking, or smoking where chemicals are used) and should be followed if additional controls are needed after using all feasible process, equipment, and task controls. Table 2.2 describes each category.

\section{Table 2.2: Recommended Practices}

\begin{tabular}{|l|l|}
\hline SKIN: & Recommends the need for personal protective clothing. \\
\hline EYES: & Recommends the need for eye protection. \\
\hline WASH & Recommends when workers should wash the spilled chemical from the \\
\hline REMOVE: & Advises workers when to remove clothing that has accidentally become \\
\hline CHANGE: & Recommends whether the routine changing of clothing is needed. \\
\hline PROVIDE: & Recommends the need for eyewash fountains and/or quick drench \\
\hline & facilities. \\
\hline
\end{tabular}


First Aid: This entry lists emergency procedures for eye and skin contact, inhalation, and ingestion of the toxic substance.

Exposure Route: This section lists the toxicologically important routes of entry for each substance and whether contact with the skin or eyes is potentially hazardous.

Symptoms: This entry lists the potential symptoms of exposure and whether NIOSH considers the substance a potential occupational carcinogen.

Target Organs: This entry lists the organs that are affected by exposure to each substance. For carcinogens, the type(s) of cancer are listed in brackets. Information in this section reflects human data unless otherwise noted. 


\section{CHAPTER 3}

\section{SOFTWARE DESIGN AND IMPLEMENTATION}

\subsection{Overview of ASP.NET 2005}

The software tool, SAFER (2.0) was implemented in ASP.NET version: 2.0.50727 and SQL Server 2005 as the database. There are some new features and functionality in Visual Studio 2005 IDE (Interactive Development Environment). The creation of a new project is separated as Web Site for Web-based application and Project for non Web-based application. Figures 3.1, 3.2, 3.3 show the screen shots of the new project creation wizard. Comparing to the previous Visual Studio.NET 2002/2003, which the project creation wizard mixes up web-based and non web-based application projects together, this feature provides a clear interface for the developer to create their own specific type project more easily. 


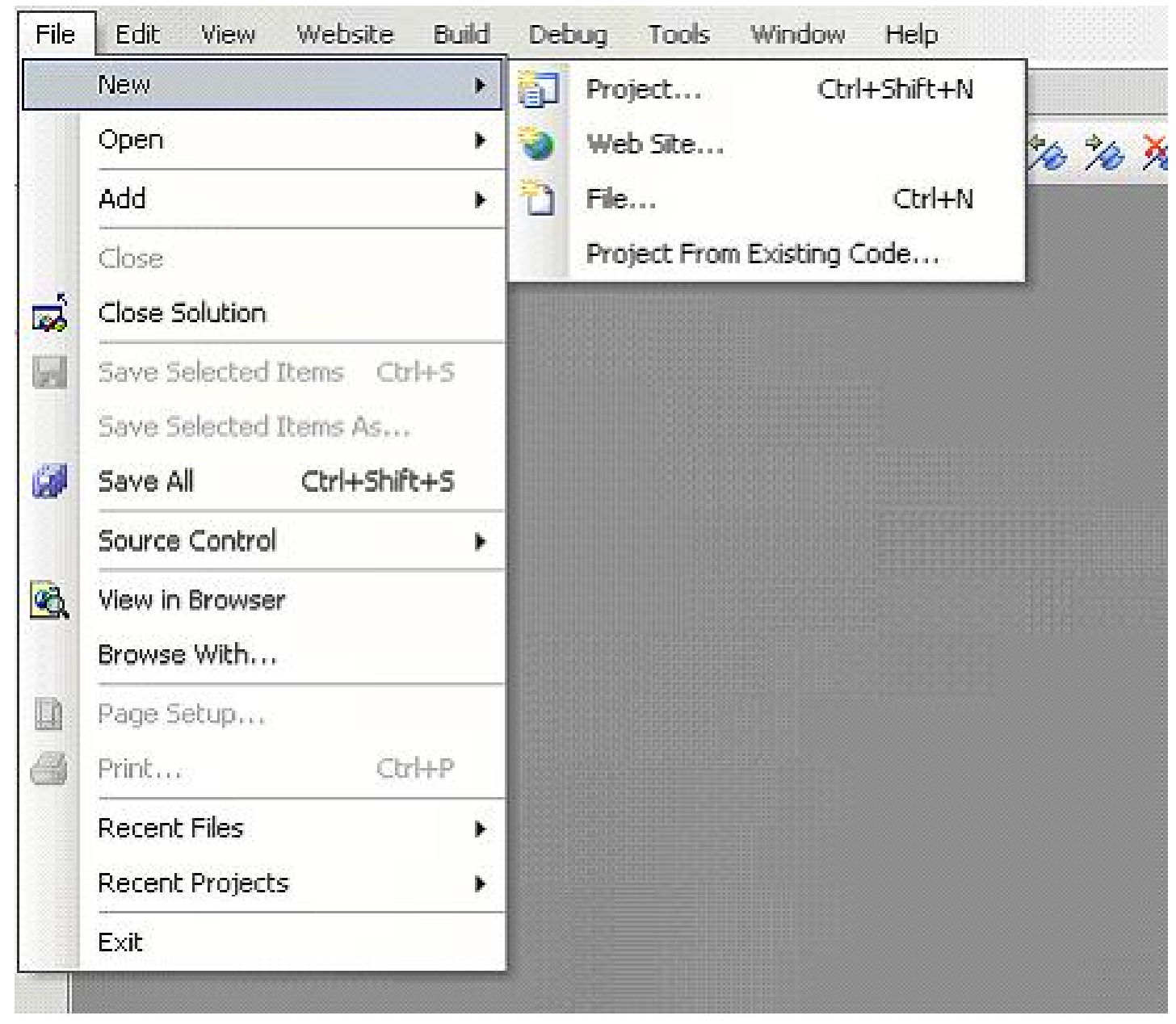

Figure 3.1: Screen shot of creating a new project in VS.NET 2005 IDE 


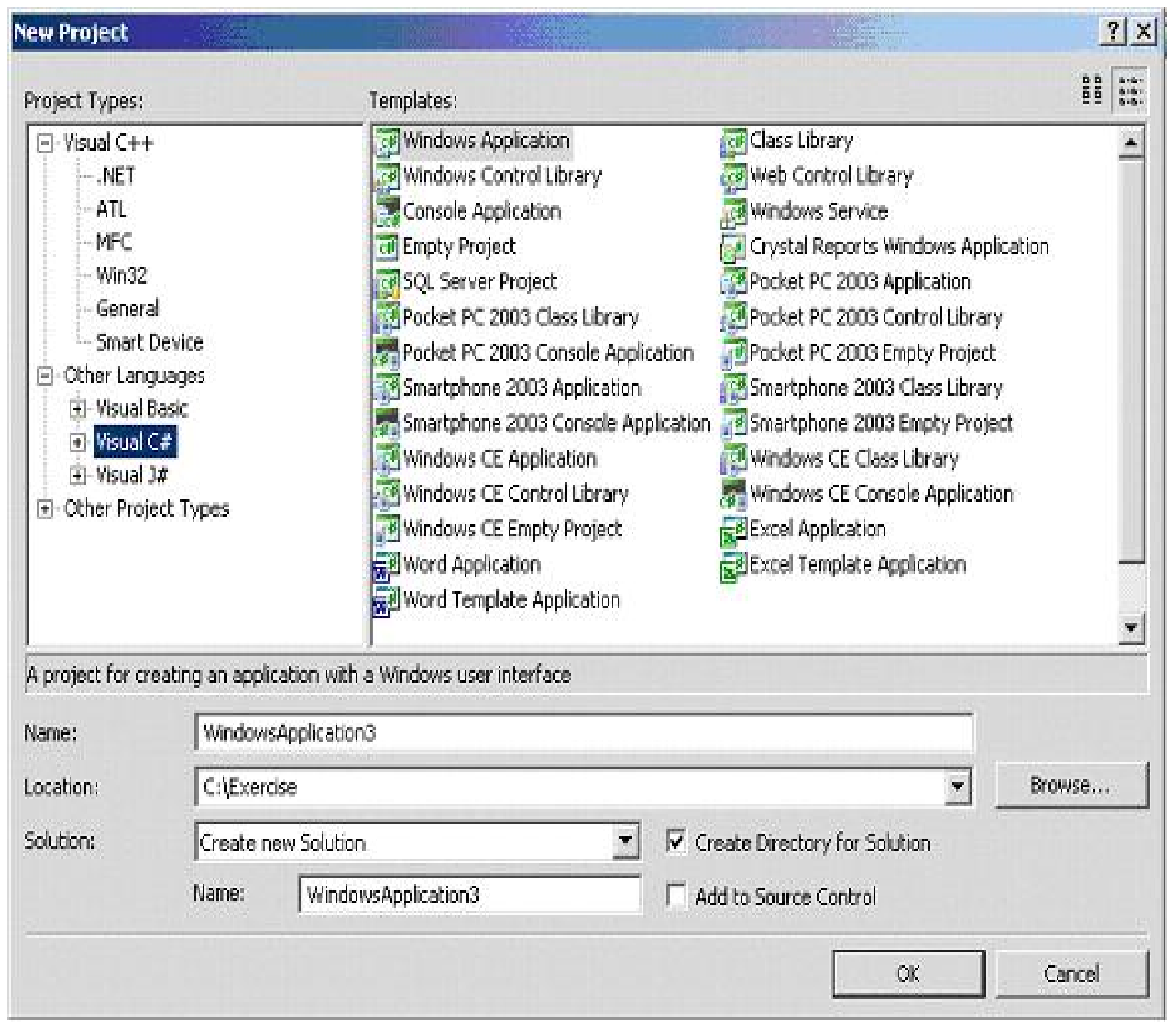

Figure 3.2: Screen shot of creating a new non web-based project in VS.NET 2005 


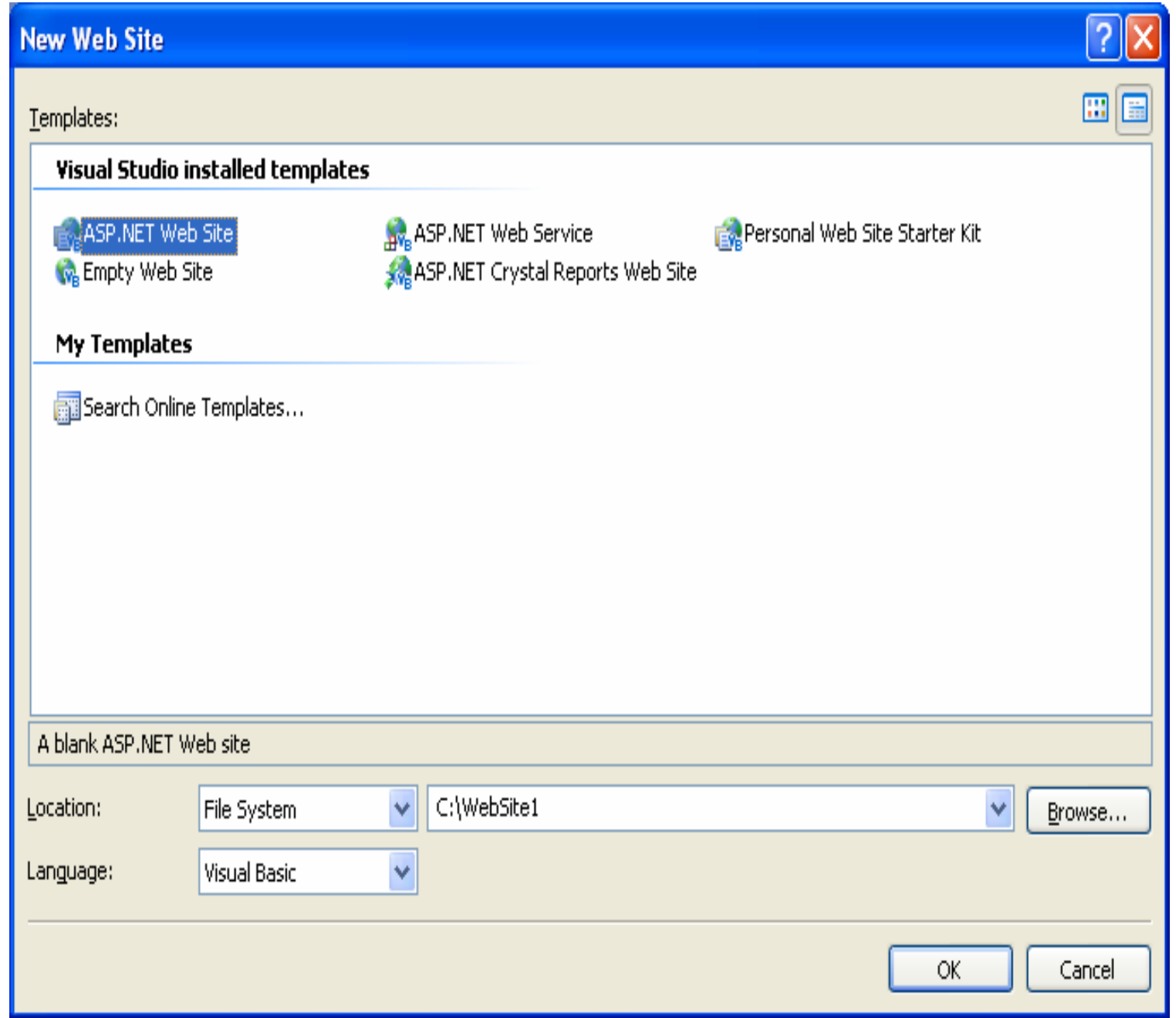

Figure 3.3: Screen shot of creating a new web-based project in VS.NET 2005 
ASP.NET is Microsoft's latest technology for building web-based applications and services. It brings a whole new functionality, power, and ease of rapid development for web programmers. ASP.NET provides an efficient approach to developing web-based applications because of:

- The ability to create applications directly implemented on the World Wide Web (WWW).

- The ability to design a user-friendly interface while being able to write underlying programs within this design.

- The ability to write programs designed specifically for PDA's.

- The simplistic, effective approach in creating database structures.

Accessing database from a web application is an often used technique for displaying data to website visitors. ASP.NET 2005 makes it easier than ever to access database for this purpose. ASP.NET provides a simple model that enables developers to write logic that runs at the application level. ASP.NET provides easy-to-use application and sessionstate-facilities that are familiar to ASP developers and readily compatible with all other .NET framework [15]. ASP.NET takes advantage of performance enhancements found in the .NET framework and common language runtime. The .NET framework and ASP.NET provide default authorization and authentication schemes for web application. 


\subsection{Software Design}

\subsubsection{SAFER Architecture [21]:}

SAFER has been developed as 3.Tier architecture. A 3-tier application is a program which is organized into three major disjunctive tiers. These tiers are

- Presentation Tier (Front end)

- Logical Tier (Middleware)

- Data Tier (Backend)

Each layer can be deployed in geographically separated computers in a network. Some architects divide Logic Tier in to two sub tiers: Business and Data Access Tiers, in order to increase scalability and transparency. The tiers can be deployed on physically separated machines. The characteristic of the tier communication is that the tiers will communicate only to their adjacent neighbors. For an example, The Presentation Tier will interact directly with the Business Tier and not directly with Data Access or Data Tiers. Figure 3.4 represents a 3. Tier Architecture scenario. 


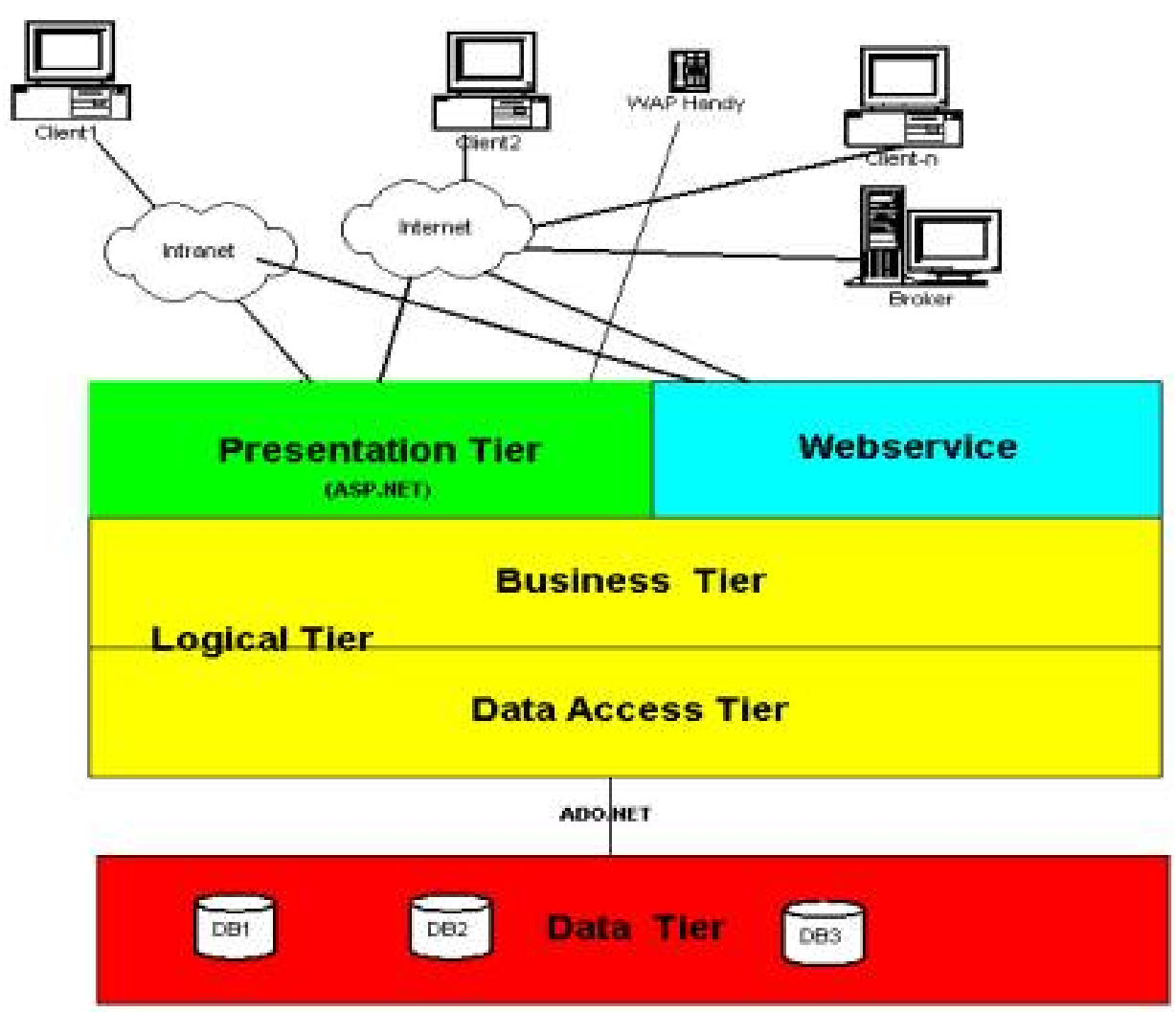

A Typical 3.Tier Archtecture

Figure 3.4: 3.Tier Architecture

\section{Data Tier}

This Tier is responsible for retrieving, storing and updating from Information, therefore this tier can be ideally represented through a commercial database. We consider stored procedures as a part of the Data Tier. Usage of stored procedures increases the performance and code transparency of an application.

\section{Logical Tier}

This is the brain of the 3.Tier Application. Some architects do not make any distinction between Business Tier and Data Access Tier. There are more advantages, if 
we separate Logical Tier in to Business Tier and Data Access Tier. Some of these advantages are

- Increases code transparency

- Supports changes in Data Layer. You can change or alter database with out touching the Business Layer and this would be a very minimum touch up.

\section{Business Tier}

This tier does not know about any GUI controls and how to access databases. The classes of Data Access Tier will supply the needy information from the databases to this sub tier.

\section{Data Access Tier:}

This tier acts as an interface to Data Tier. This tier knows, how to (from which database) retrieve and store information.

\section{Presentation Tier:}

This Tier is responsible for communication with the users and web service consumers and it will use objects from Business Layer to response GUI raised events.

For example, if the SAFER application is being used, the user's computer and the web browser would be considered a Client, and the computer, database, and application that make up SAFER will be considered the Server. When the user's web browser (Presentation Tier) requests a particular page from SAFER (Logical Tier), the SAFER server finds all of the information required to display the page in the SAFER database 
(Data Tier), assembles it into a web page, and sends it back to the user's web browser. The overall architecture of SAFER is shown in Figures 3.5(a) and 3..5(b) and the flowchart is shown in Figure 3.6.

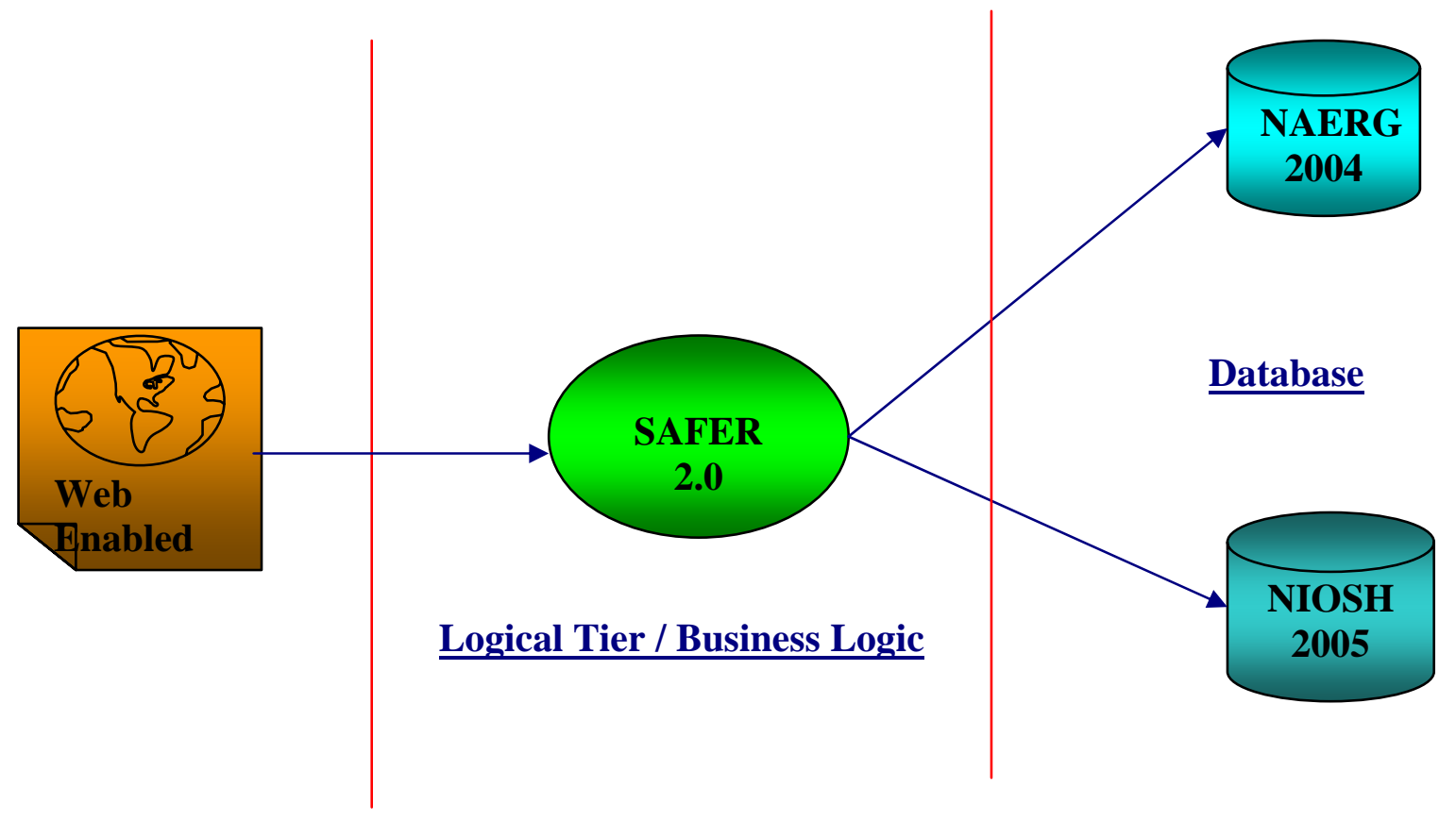

Figure 3.5(a): SAFER Architecture Overview 


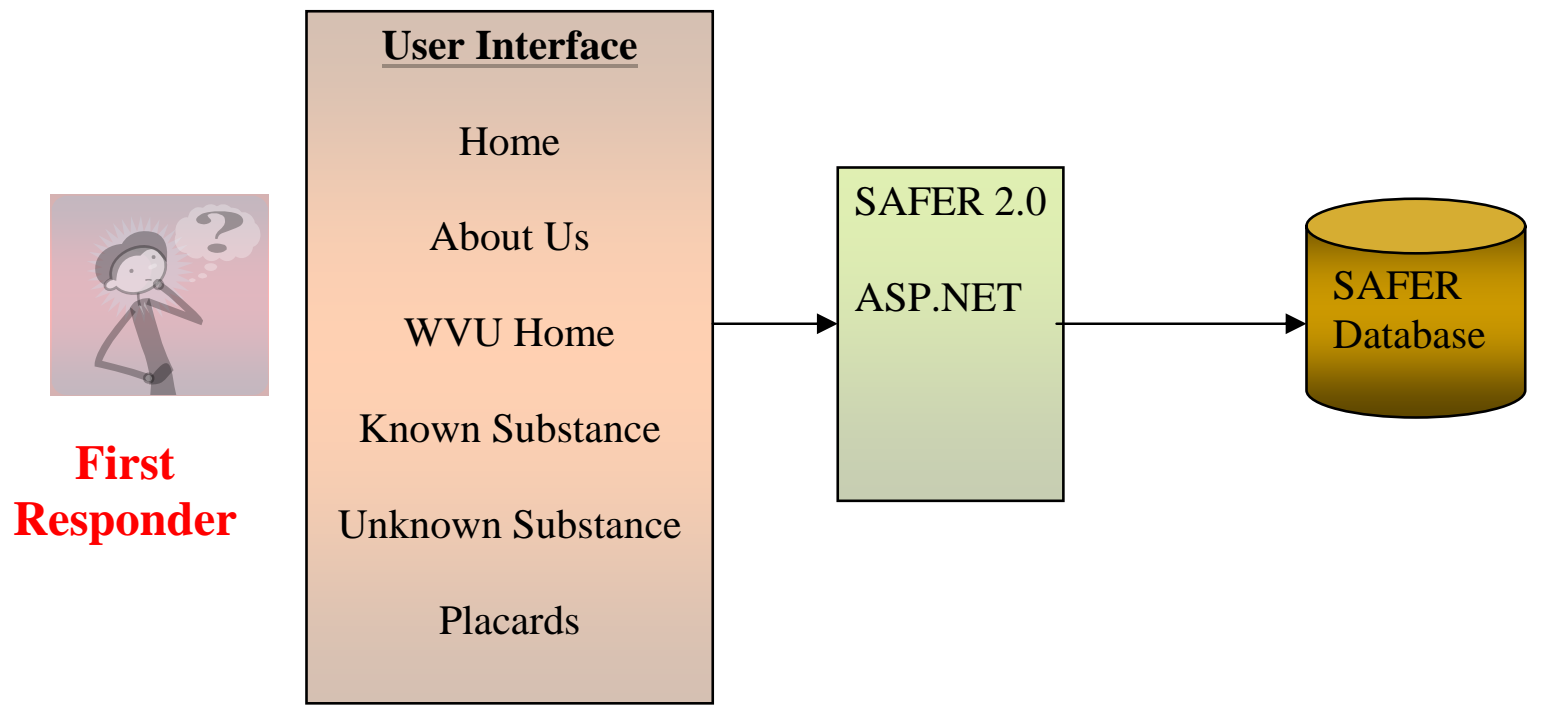

Figure 3.5(b): SAFER Architecture Details 


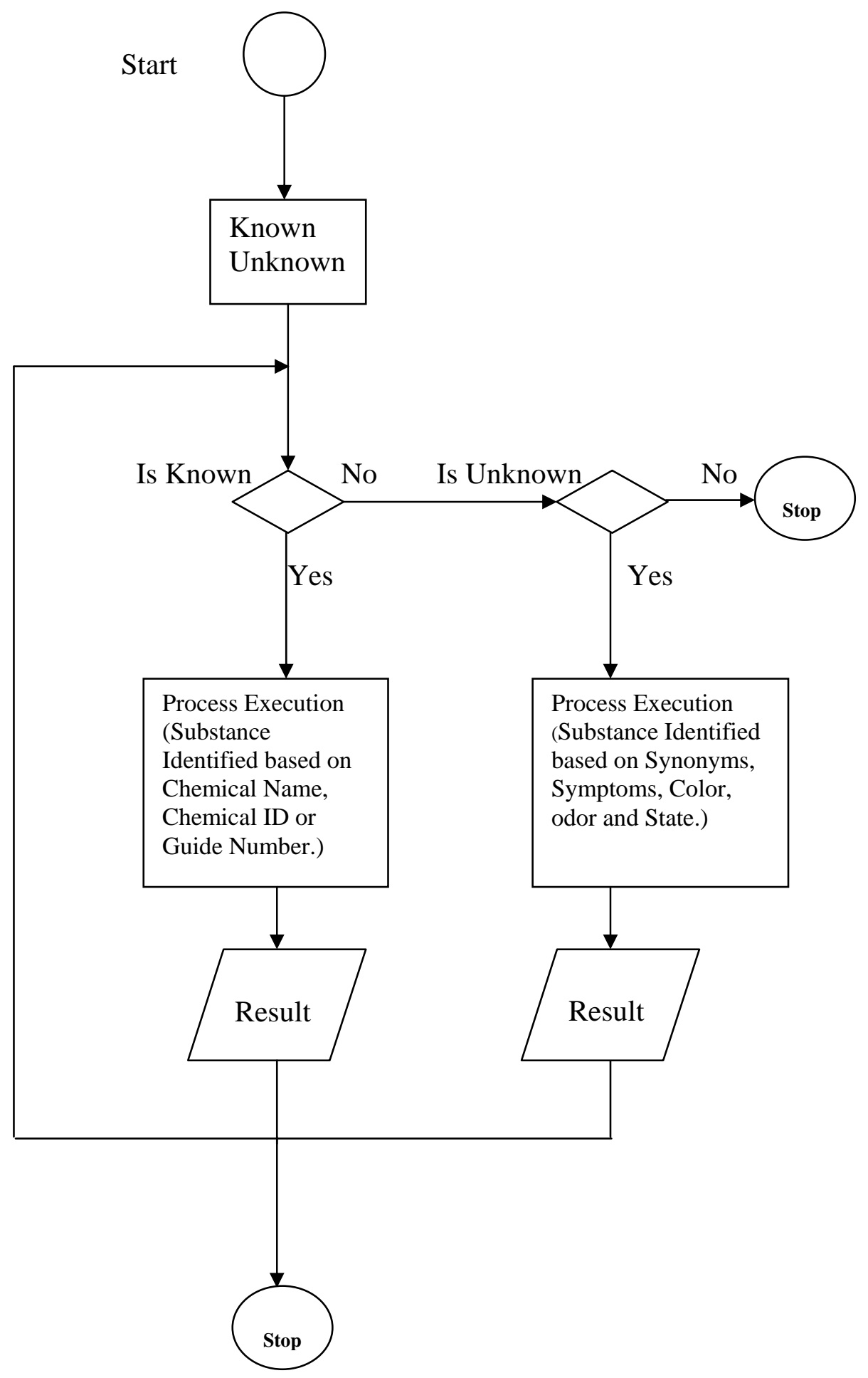

Figure 3.6: SAFER Flowchart 


\subsubsection{SAFER Class Diagram}

In the Unified Modeling Language (UML), a class diagram is a type of static structure diagram that describes the structure of a system by showing the system's classes and the relationships between them. There are three classes in the SAFER class diagram and figure 3.7 shows the class diagram for SAFER:

- UserInterface

- KnownSubstance

- UnknownSubstance 


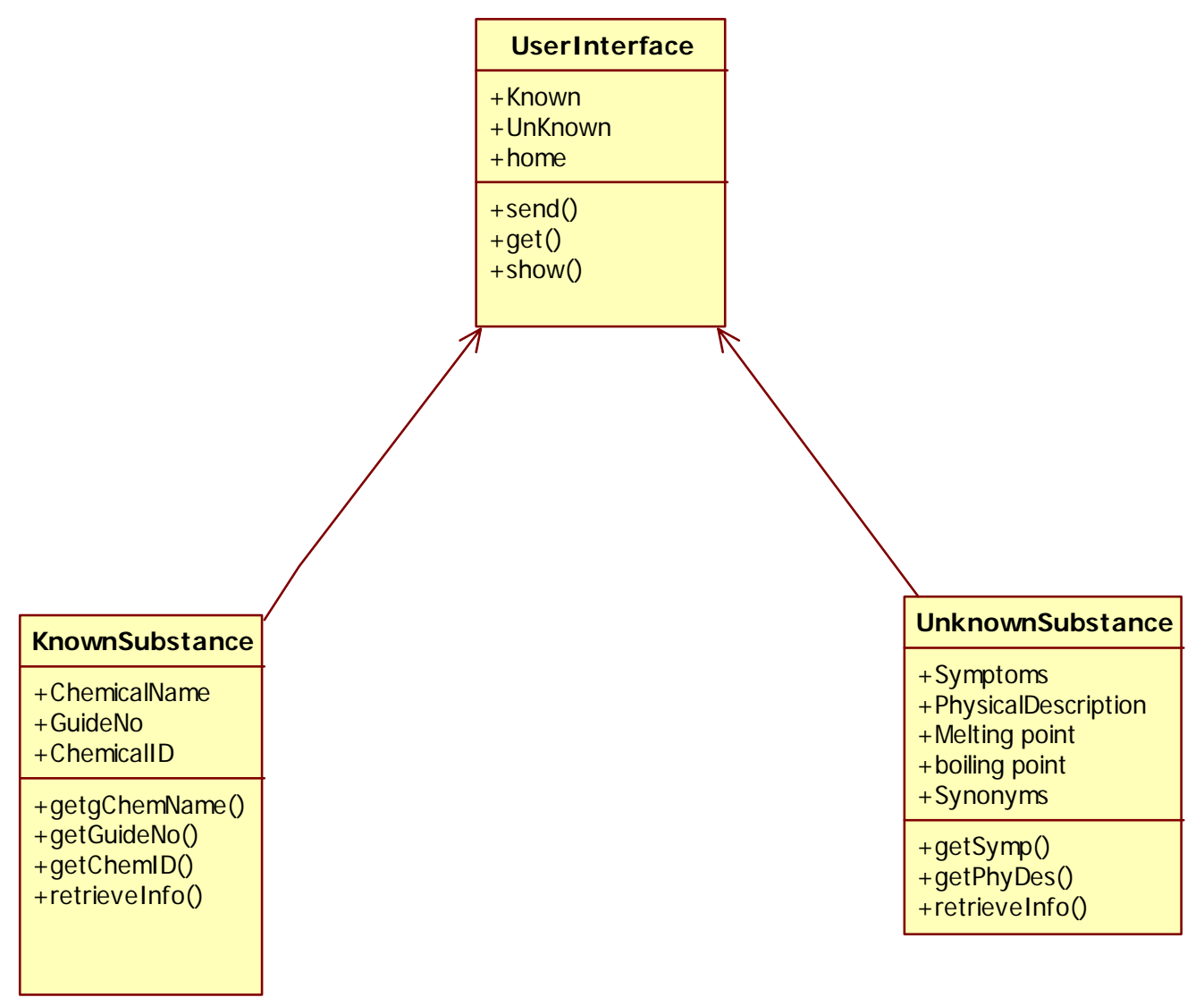

Figure 3.7: Class Diagram of SAFER 
The Attributes and Operations in each of these classes are:

UserInterface:

\section{Attributes:}

Known

Unknown

Home

KnownSubstance:

Attributes:

ChemicalName

GuideNo

ChemicalID

\section{UnknownSubstance:}

Attributes:

Symptoms

PhysicalDescription

MeltingPoint

BoilingPoint

Synonyms

\section{Operations:}

send( )

get( )

show( )

\section{Operations:}

getChemName( )

getGuideNo( )

getChemID ( )

retrieveInfo( )

\section{Operations:}

$$
\begin{aligned}
& \text { getSymp( ) } \\
& \text { getPhyDesc( ) } \\
& \text { getMP( ) } \\
& \text { getBP( ) } \\
& \text { retrieveInfo( ) }
\end{aligned}
$$




\subsubsection{Sequence Diagram for SAFER}

The SAFER database is 3.Tier architecture. The properties of a server are:

- $\quad$ Passive (Slave)

- Waiting for requests

- $\quad$ On requests serves them and send a reply

The properties of a client are:

- $\quad$ Active (Master)

- $\quad$ Sending requests

- Waits until reply arrives

The interaction between a client and server is often described using sequence diagrams.

Figure 3.8 describes the sequence diagram for the SAFER. 


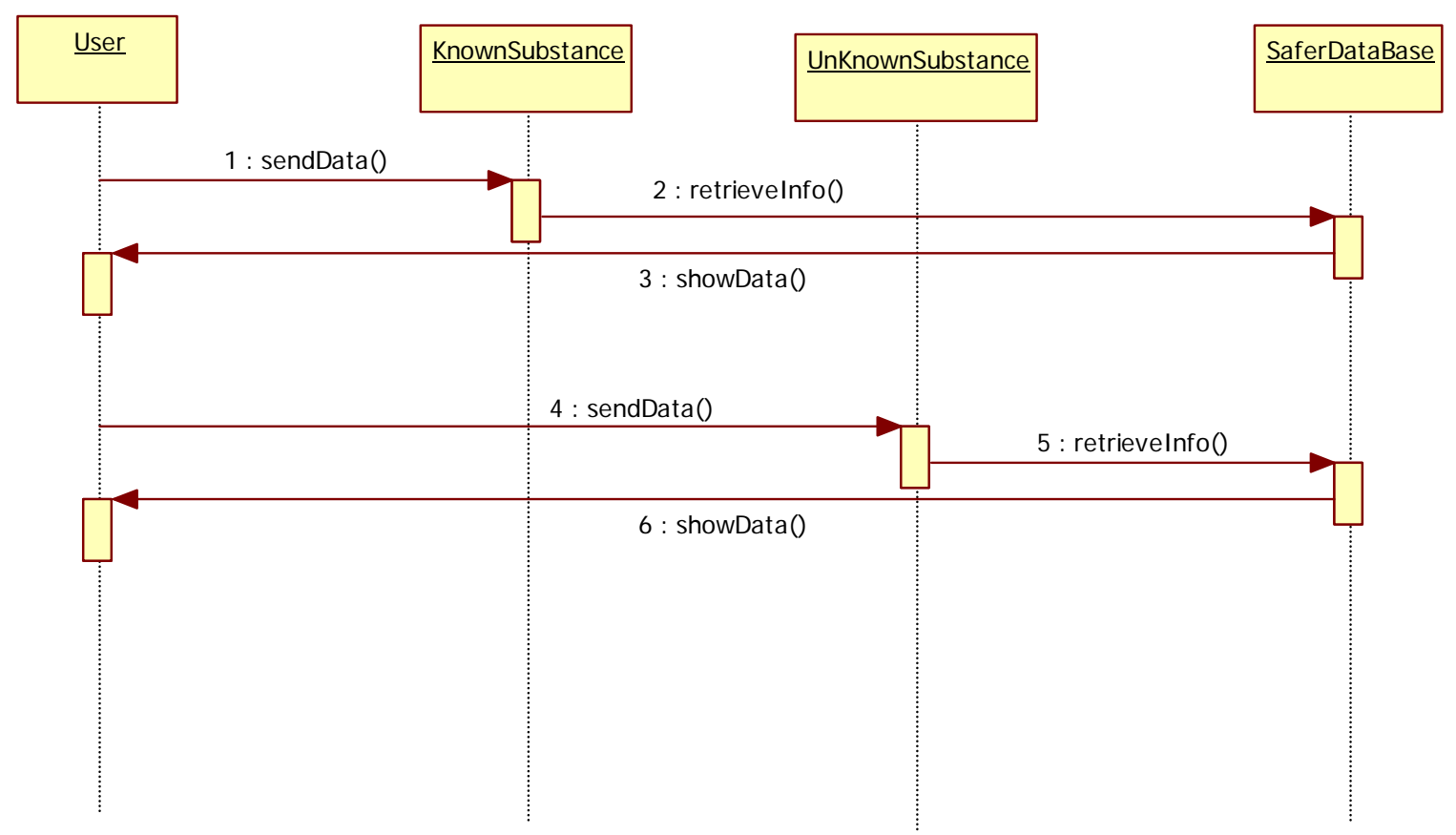

Figure 3.8: Sequence Diagram of SAFER 
A Sequence Diagram is a Unified Modeling Language (UML) diagram that shows the processes that execute in sequence. The sequence diagram shows the sequence of messages, which are exchanged among roles that implement the behavior of the system, arranged in time. It shows the flow of control across many objects that collaborate in the context of a scenario. The sequence diagram in figure 4.6 above describes the sequences of messages of the application SAFER 2.0. This diagram represents:

- First Responder (User) identifying the substance by selecting from the options of known substance/unknown substance

- Accessing the information required to deal with the emergency.

- The dotted lines extending downwards indicate the timeline, time flows from top to bottom. The arrows represent messages (stimuli) from an actor or object to other objects.

- First Responder (User) sends message 'showData( )' to the Safer database.

\subsection{Software Implementation:}

The SAFER application can be accessed via the Internet through any web browser at the URL (Uniform Resource Locator): http://dev.rsa.wvu.edu/safer2.

The navigation bar has the following links:

- Home

- About Us

- WVU Home

- Known Substance 
- Unknown Substance

- Placards

Home: The homepage describes the SAFER application.

About Us: This page provides the contact information.

Known Substance: This page helps the user in identifying the substance involved in the hazardous material incident based on:

- Chemical ID

- Guide Number

- Chemical Name

Unknown Substance: This link helps the user identify the substance involved in the hazardous material incident based on the CAS number, Melting Point, Boiling Point, physical description, symptoms and other properties.

Placards: This link helps identify the substance based on the placard symbol. 


\section{CHAPTER 4}

\section{DATABASE DESIGN AND IMPLEMENTATION}

\subsection{Database}

In today's connected world, data and the systems that manage that data must always be secure yet available to the users. With SQL Server 2005, users and information technology (IT) professionals will benefit from:

- Reduced application downtime

- Increased scalability and performance

- Tight yet flexible security controls

- Many new and improved capabilities to help increase the productivity

SQL Server 2005 includes many new technologies that bring significant increases in developer productivity. From .NET Framework support to tight integration with Visual Studio, these features provide developers with the ability to more easily create secure, robust database applications at a lower cost. SQL Server 2005 enables developers to take advantage of existing skills across a variety of development languages while providing an end-to-end development environment for the database.

\subsection{Database Design}

\subsubsection{Database Schema:}

It is defined as the representation of database tables and their relationships. Figure 4.1 represents the database schema for the SAFER application. 


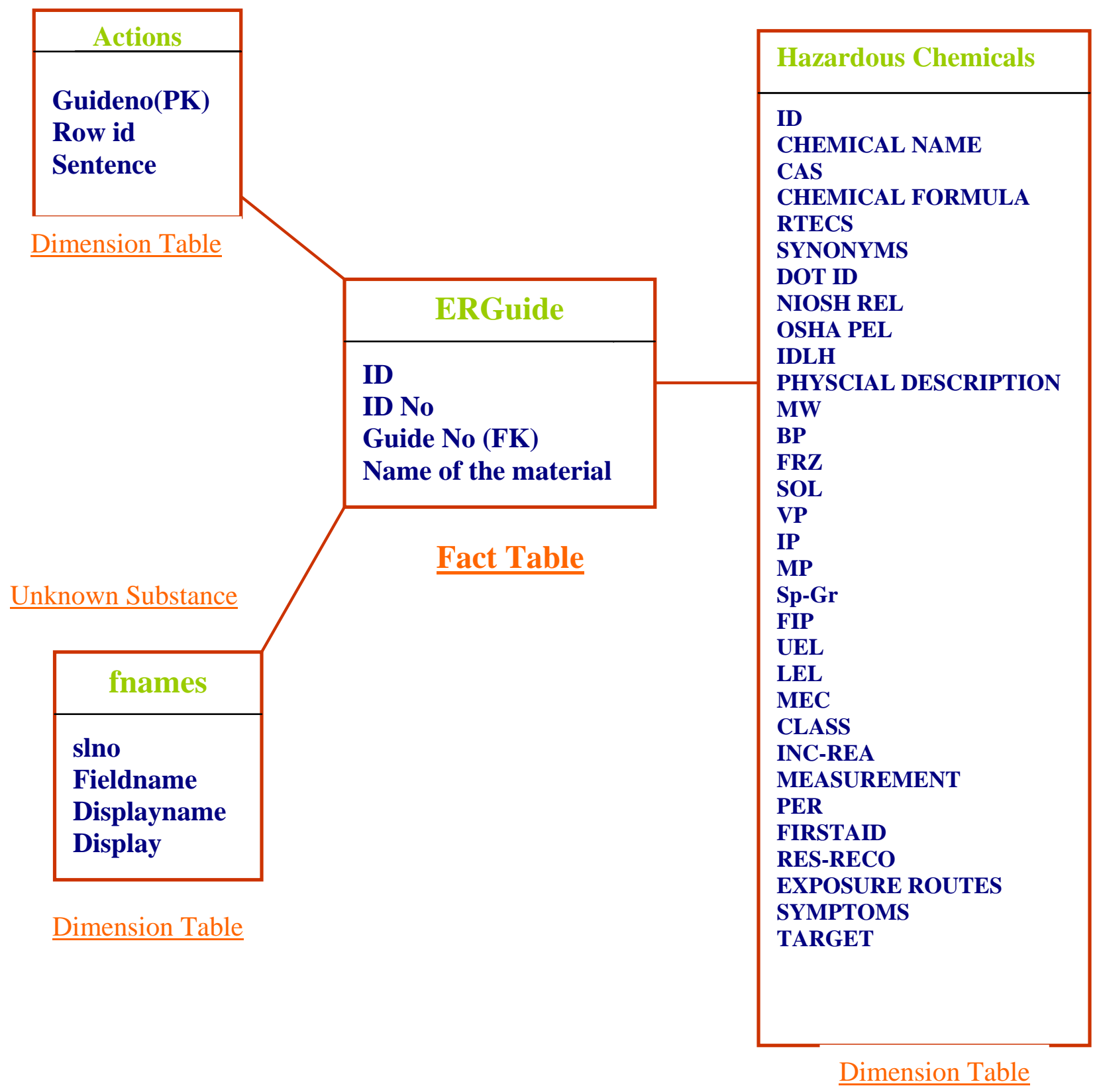

Figure 4.1: Database Schema 


\subsection{Database Implementation}

The tables in the SAFER database are:

- 2004 Emergency Response Index (ERGuide)

- 2004 Emergency Response Guide (Actions)

- $\quad$ NIOSH Pocket Guide key information (fnames)

- Hazardous Chemicals description (HazardousChemicals)

2004 Emergency Response Index:

Every hazardous material is assigned an ID Number and a Guide Number. The Emergency Response Index gives the ID Number and Guide Number assigned for all hazardous materials. The various fields of the Emergency Response Index table are shown in table 4.1 and the table is shown in figure 4.2. The table contains the Chemical Name, Chemical ID and the Guide Number.

\section{Table 4.1: Emergency Response Index fields (ERGuide)}

\begin{tabular}{|l|l|l|}
\hline \multicolumn{1}{|l|}{$\begin{array}{l}\text { ERGuide } \\
\text { Column Name }\end{array}$} & \multicolumn{1}{c|}{ Data Type } & Allow Nulls \\
\hline ID & int & \\
\hline [ID No] & float & \\
\hline [Guide No] & nvarchar(255) & \\
\hline [Name of Material] & nvarchar(255) & \\
\hline & & \\
\hline
\end{tabular}




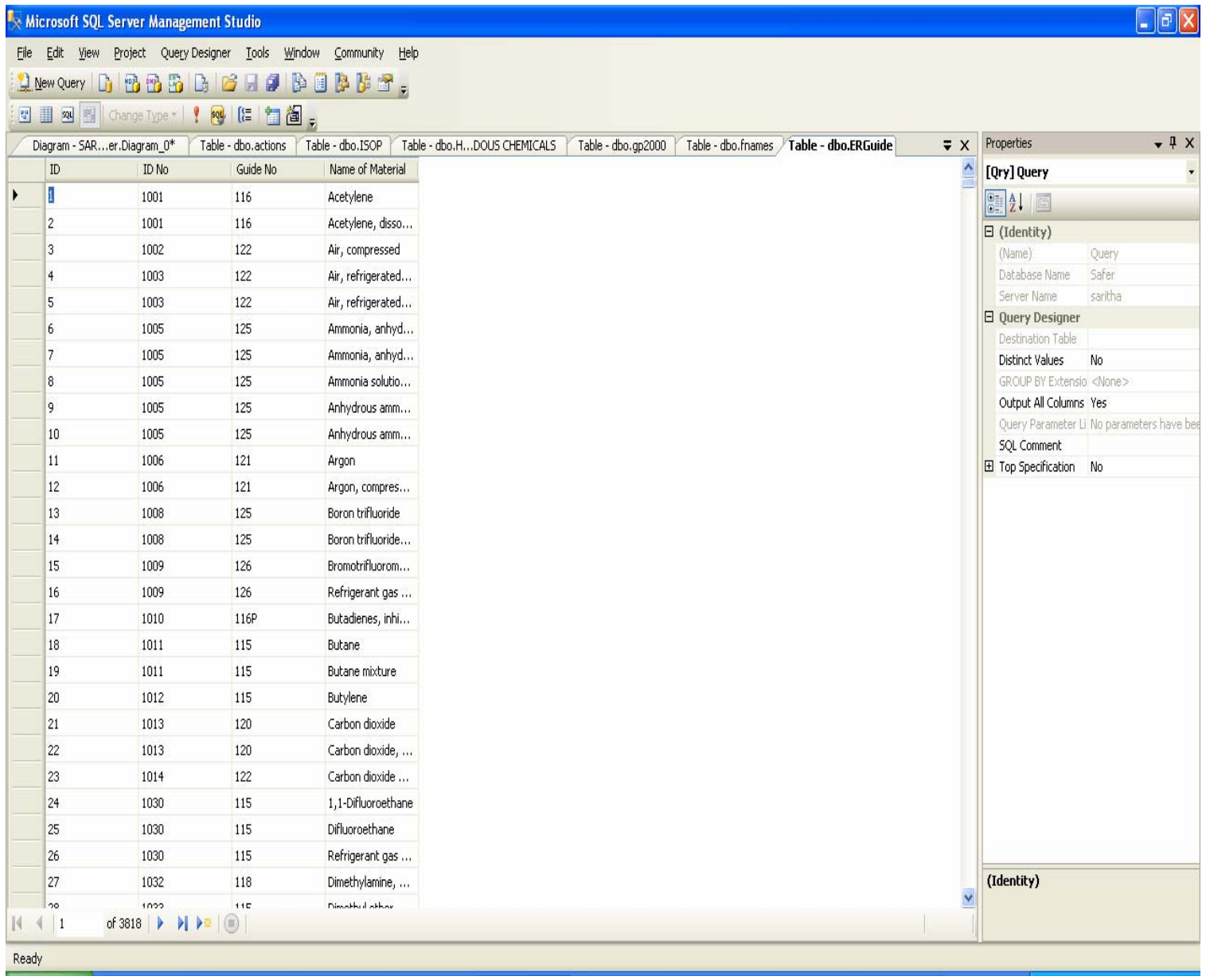

Figure 4.2: Emergency Response Index table view (ERGuide) 
2004 Emergency Response Guide:

The Emergency Response Guide table has information on Potential Hazards, Public Safety and Emergency Response. The Potential Hazards section provides information about Fire or explosion and Health. The Public Safety section provides information about Initial evacuation distance, Protective clothing, Evacuation (Spill, Fire). The Emergency Response section provides information about response to Fire (small fires, large fires), Spill (small spills, large spills) and First Aid. The various fields of the Emergency Response Guide table are shown in table 4.2 and the table is shown in figure 4.3.

Table 4.2: Emergency Response Guide fields (Actions)

\begin{tabular}{|c|c|c|}
\hline \multicolumn{3}{|l|}{ actions } \\
\hline Column Name & Data Type & Allow Nulls \\
\hline guide_no & nvarchar(50) & $\square$ \\
\hline Rowid & int & $\square$ \\
\hline sentence & nvarchar(80) & $\square$ \\
\hline & & $\square$ \\
\hline
\end{tabular}




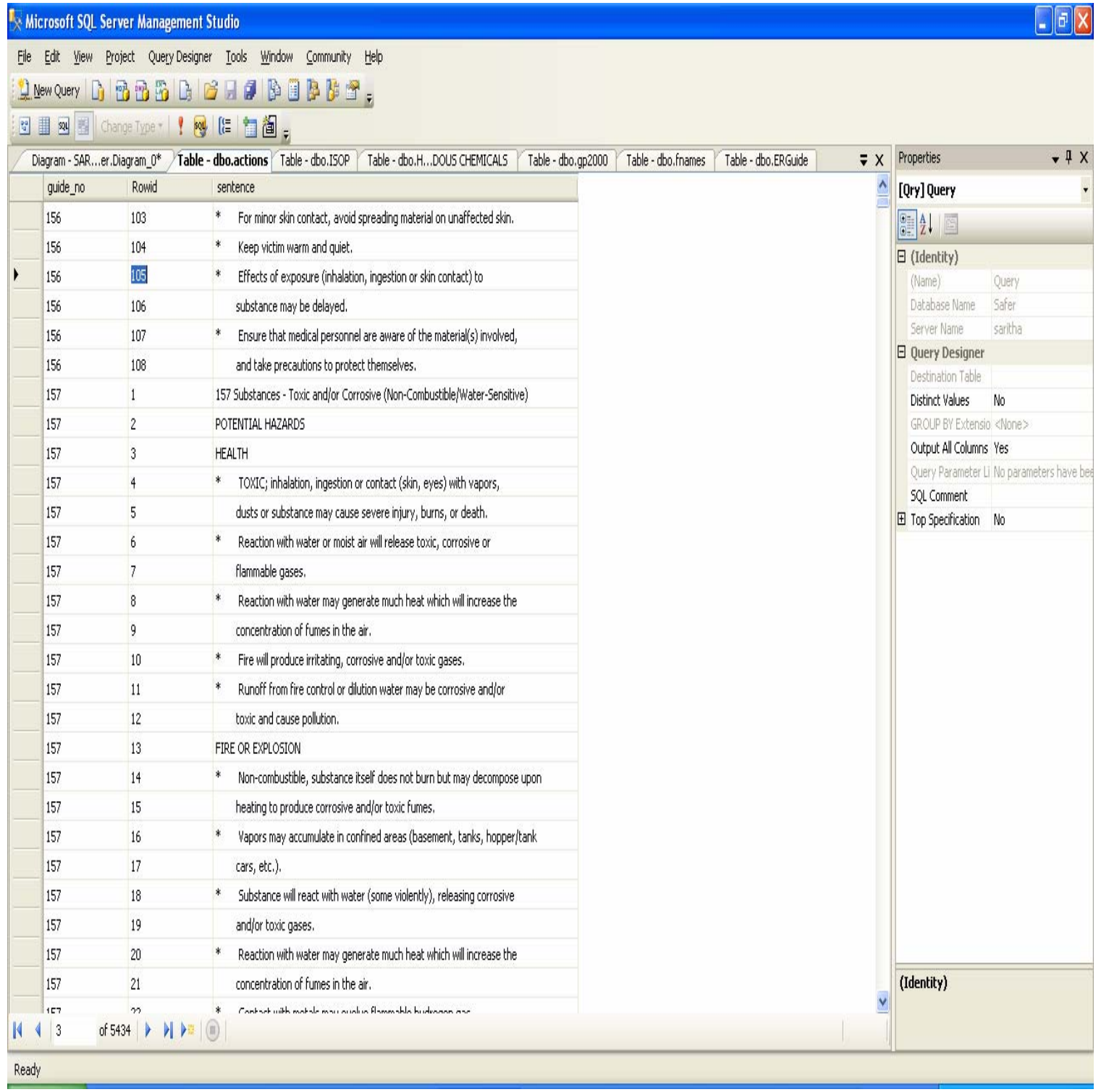

Figure 4.3: Emergency Response Guide table view (Actions) 


\subsubsection{NIOSH Pocket Guide key information}

The NIOSH Pocket Guide table has information about the different physical and chemical properties of the substances. The various fields of the NIOSH Pocket Guide table are shown in table 4.3 and the table is shown in figure 4.4.

Table 4.3: NIOSH Pocket Guide Fields (fnames)

\begin{tabular}{|c|c|c|}
\hline \multicolumn{3}{|l|}{ fnames } \\
\hline Column Name & Data Type & Allow Nulls \\
\hline slno & int & $\square$ \\
\hline Fieldname & nvarchar(50) & $\square$ \\
\hline Display Name & nvarchar(50) & $\square$ \\
\hline display & bit & $\square$ \\
\hline & & $\square$ \\
\hline
\end{tabular}




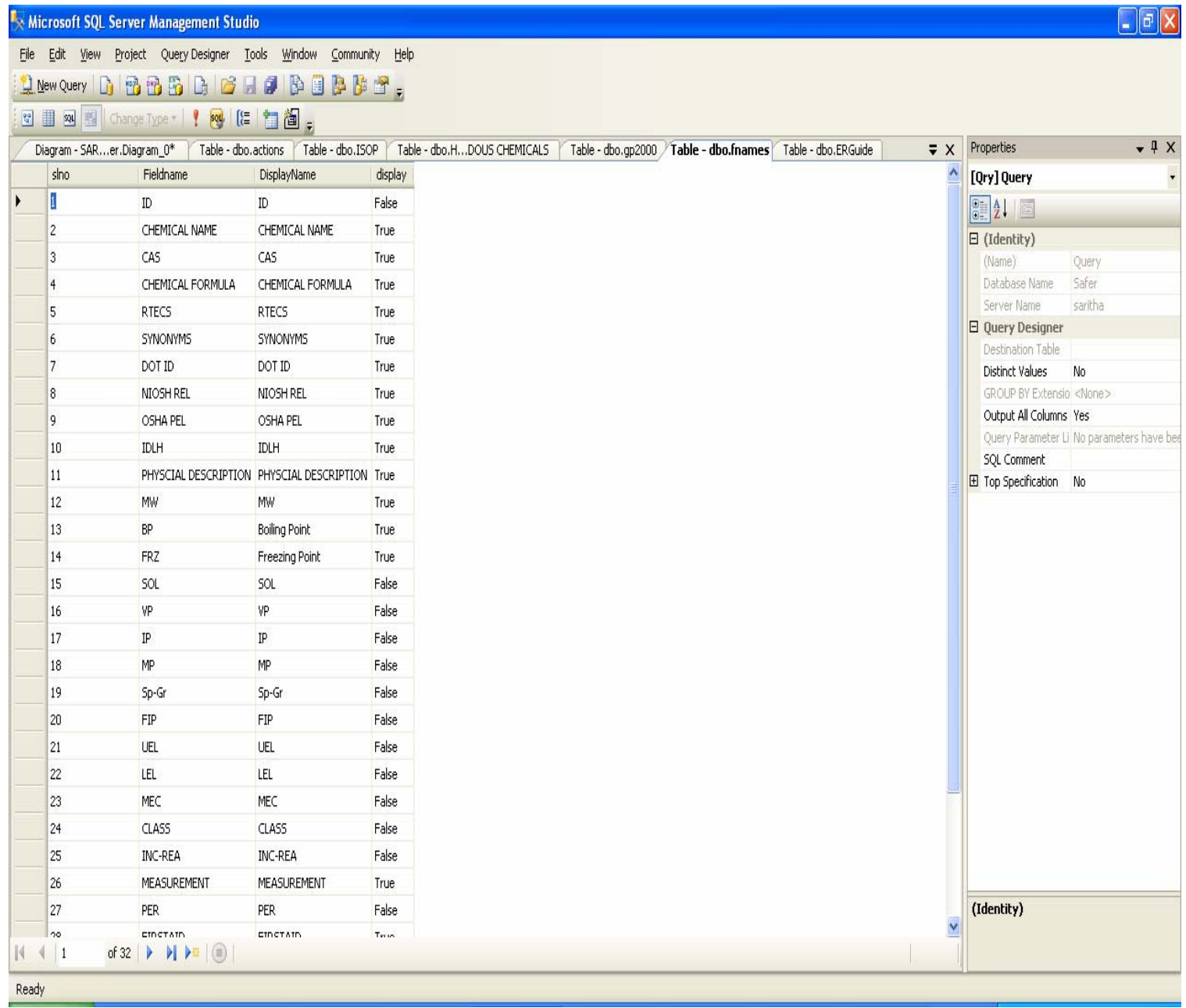

Figure 4.4: NIOSH Pocket Guide table view (fnames) 


\subsubsection{Hazardous Chemicals Description}

The Hazardous Chemicals Description table provides information about more than 30 physical and chemical properties associated with each chemical. The various fields of the Hazardous Chemicals table are shown in table 4.4 and the table is shown in figure 4.5 . 
Table 4.4: Hazardous Chemicals fields (Hazardous Chemicals)

\begin{tabular}{|c|c|c|}
\hline \multicolumn{3}{|c|}{ HAZARDOUS CHEMI CALS } \\
\hline | Column Name & Data Type & Allow Nulls \\
\hline ID & int & $\square$ \\
\hline [CHEMICAL NAME] & nvarchar(255) & $\square$ \\
\hline CAS & nvarchar(255) & $\square$ \\
\hline [CHEMICAL FORMULA] & nvarchar(255) & $\square$ \\
\hline RTECS & nvarchar(255) & $\square$ \\
\hline SYNONYMS & nvarchar(255) & $\square$ \\
\hline [DOTID] & nvarchar(255) & $\square$ \\
\hline [NIOSH REL] & nvarchar(255) & $\square$ \\
\hline [OSHA PEL] & nvarchar(255) & $\square$ \\
\hline IDLH & nvarchar(255) & $\square$ \\
\hline [PHYSCIAL DESCRIPTI... & nvarchar(255) & $\square$ \\
\hline MW & nvarchar(255) & $\square$ \\
\hline $\mathrm{BP}$ & nvarchar(255) & $\square$ \\
\hline FRZ & nvarchar(255) & $\square$ \\
\hline SOL & nvarchar(255) & $\square$ \\
\hline VP & nvarchar(255) & $\square$ \\
\hline IP & nvarchar(255) & $\square$ \\
\hline MP & nvarchar(255) & $\square$ \\
\hline$[\mathrm{Sp}-\mathrm{Gr}]$ & nvarchar(255) & $\square$ \\
\hline FIP & nvarchar(255) & $\square$ \\
\hline UEL & nvarchar(255) & $\square$ \\
\hline LEL & nvarchar(255) & $\square$ \\
\hline MEC & nvarchar(255) & $\square$ \\
\hline CLASS & nvarchar(255) & $\square$ \\
\hline [INC-REA] & ntext & $\square$ \\
\hline MEASUREMENT & nvarchar(255) & $\square$ \\
\hline PER & ntext & $\square$ \\
\hline FIRSTAID & nvarchar(255) & $\square$ \\
\hline [RES-RECO] & ntext & $\square$ \\
\hline [EXPOSURE ROUTES] & nvarchar(255) & $\square$ \\
\hline SYMPTOMS & ntext & $\square$ \\
\hline TARGET & nvarchar(255) & $\square$ \\
\hline & & $\square$ \\
\hline
\end{tabular}




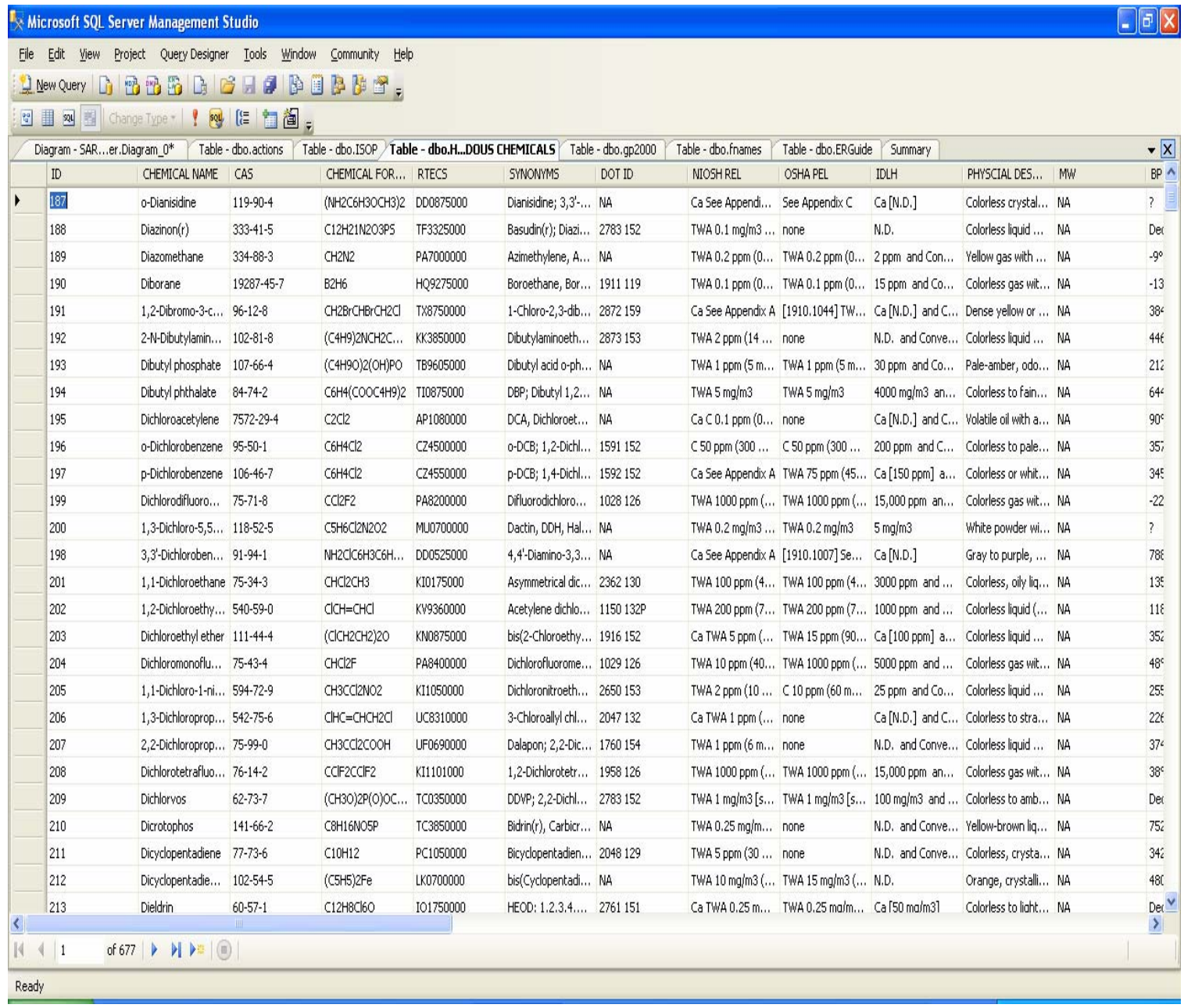

\section{Figure 4.5: Hazardous Chemicals table view}




\section{CHAPTER 5}

\section{APPLICATION}

One of the first duties of the response personnel to a hazardous material incident is the identification of the substance involved in the hazard. The material needs to be identified before any action can be taken, in the interest of the safety of the first responders and the public. The safety precautions to be followed by a first responder are listed in appendix 1.

First responders at the scene of a hazardous material incident should seek

additional specific information about any material in question as soon as possible. The information can be received by:

- The emergency response number on the shipping document

- Contacting the appropriate emergency response agency

- Consulting the information on or accompanying the shipping document

\subsection{Shipping document}

The shipping document provides vital information when responding to a hazardous materials incident. The shipping document contains information needed to identify the materials involved in the hazardous incident. The shipping document contains the proper shipping name, the hazard class or division of the material(s), ID number, and, where appropriate, the Packing Group. Shipping documents are required for most dangerous goods in transportation. Shipping documents are usually kept in:

- The cab of the motor vehicle 
- The possession of the train crew member

- A holder on the bridge of a vessel

\subsubsection{Identifying the material}

Finding one of the following can help identify the material:

- The 4-digit ID number on a placard or orange panel: The 4-digit ID Number may be shown on the diamond-shaped placard or on an adjacent orange panel displayed on the ends and sides of a cargo tank, vehicle or rail car. Figure 5.1 shows a Placard and Panel with ID number.

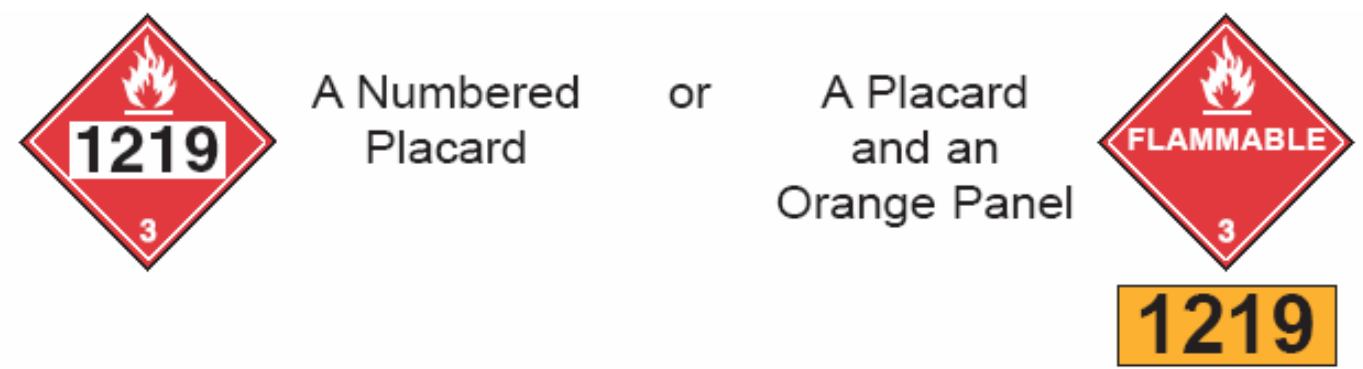

Figure 5.1: Placard and Panel with ID number

- The 4-digit ID number on a shipping document

- The name of the material on a shipping document or placard

Using the ID number or the name of the material, the information on the corresponding guide can be obtained. This guide provides information on health, fire or explosion, public safety, protective clothing, evacuation, spill or leak and first aid. 


\subsection{Emergence Response Telephone Number}

Locate and call the telephone number listed on the shipping document. The person answering the phone at the listed emergency response number must be knowledgeable of the materials and mitigation actions to be taken, or must have immediate access to a person who has the required knowledge.

\subsection{Emergency Response Agency}

If the emergency response telephone number is not available, contact the appropriate emergency response agency. Upon receipt of a call describing the nature of the incident, the agency will provide immediate advice on handling the early stages of the incident. The agency will also contact the shipper or manufacturer of the material for more detailed information and request on-scene assistance when necessary.

\subsection{Scenarios to use SAFER}

In this section, two scenarios are being described for using SAFER 2.0. In the first scenario, the substance is known, in the second scenario, the substance is not unknown substance. During the initial phase of a hazardous materials incident, the First Responder can use SAFER 2.0 in both of these scenarios in responding to the incident. 


\subsubsection{Known Substance}

This is the first scenario. In this scenario, the First Responder is at the scene of the hazardous materials incident. There is an overturned cargo tank with 'Hypochlorite solution' on the side; the shipping document provides vital information when responding to a hazardous materials incident. The shipping document contains information needed to identify the materials involved. Using this information, it has been identified that the material involved in the incident is Hypochlorite Solution. There is a small fire caused by the engine on the cargo tank. The driver of the truck has been splashed with the Hypochlorite solution and may have ingested some of it.

The immediate tasks are to clear out an appropriate area around the tanker truck, treat the driver, correctly respond to the small fire and call for assistance from qualified personnel. The qualified personnel will access the SAFER website by accessing the URL: http://dev.rsa.wvu.edu/safer2. Figure 5.2 shows the home page of the SAFER website. 


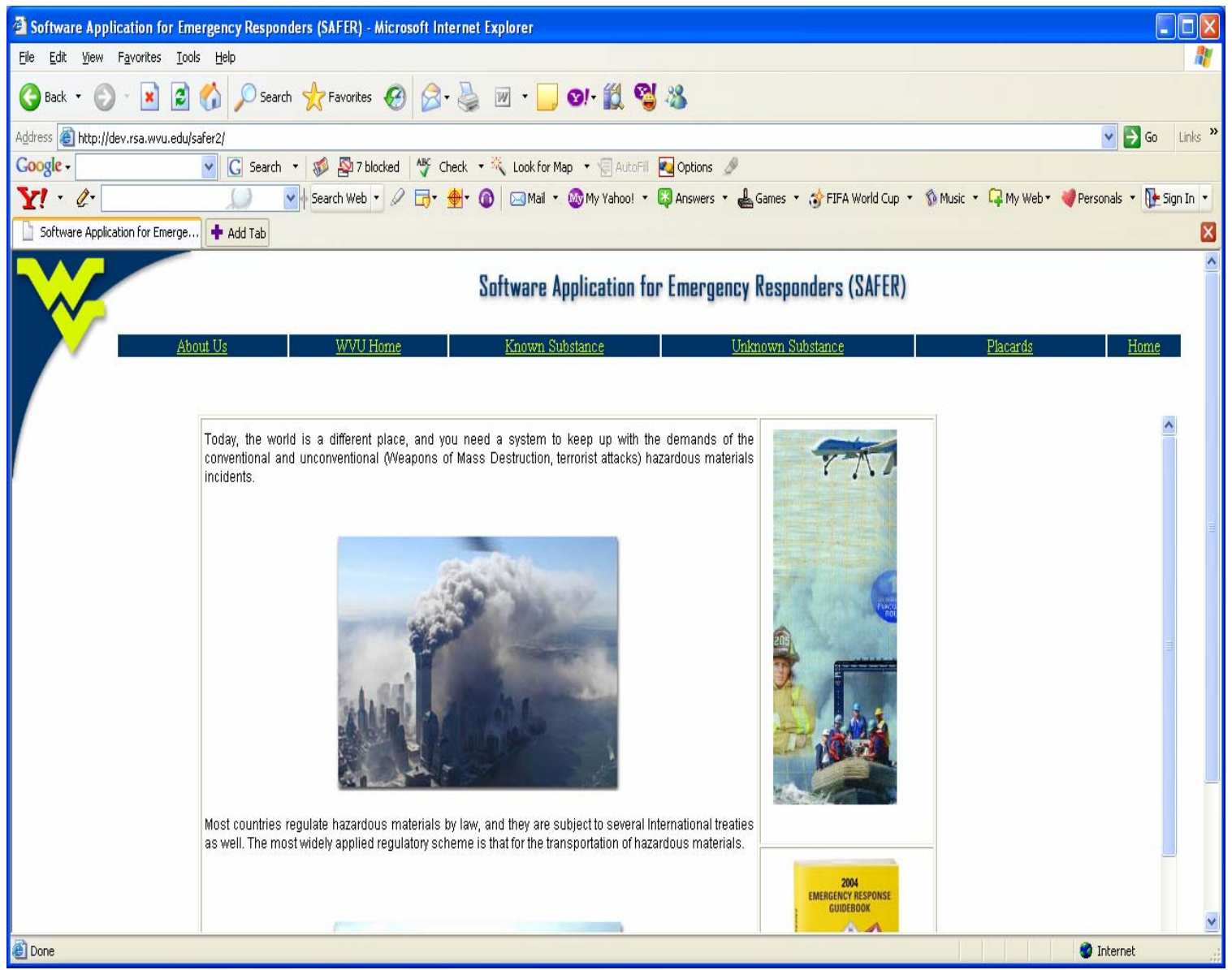

Figure 5.2: Home page of SAFER website 
Based on the information provided by the first responder, the 'Known Substance' link is selected. Figure 5.3 shows the known substance page.

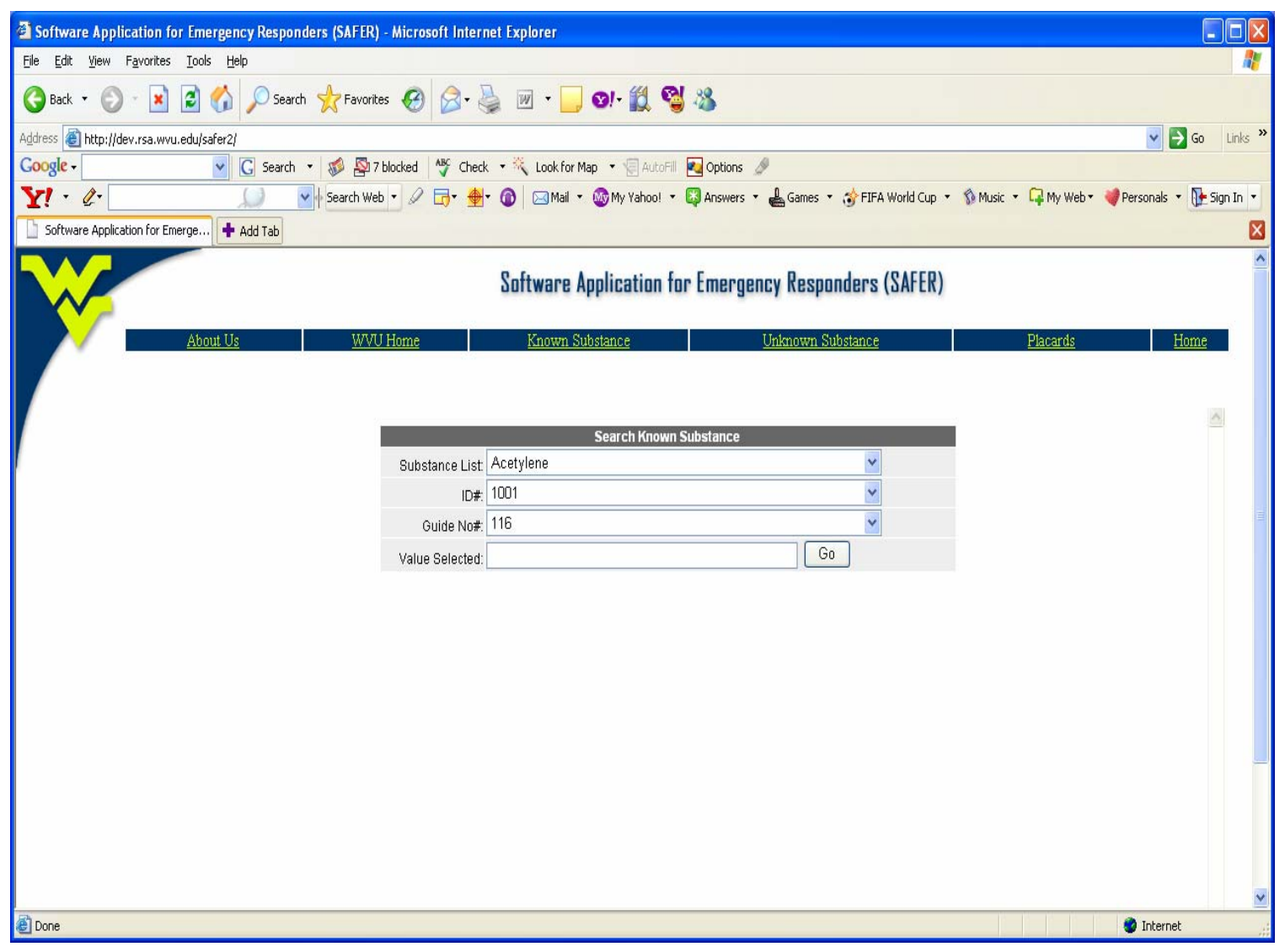

Figure 5.3: Known substance page 
The Known Substance page provides the option to identify the substance based

on:

- Chemical Name

- Chemical ID

- Guide Number 
As the material involved in the incident has been identified to be hypochlorite solution, click on the arrow of the dropdown box besides the substance list option. Figure 5.4 shows this option.

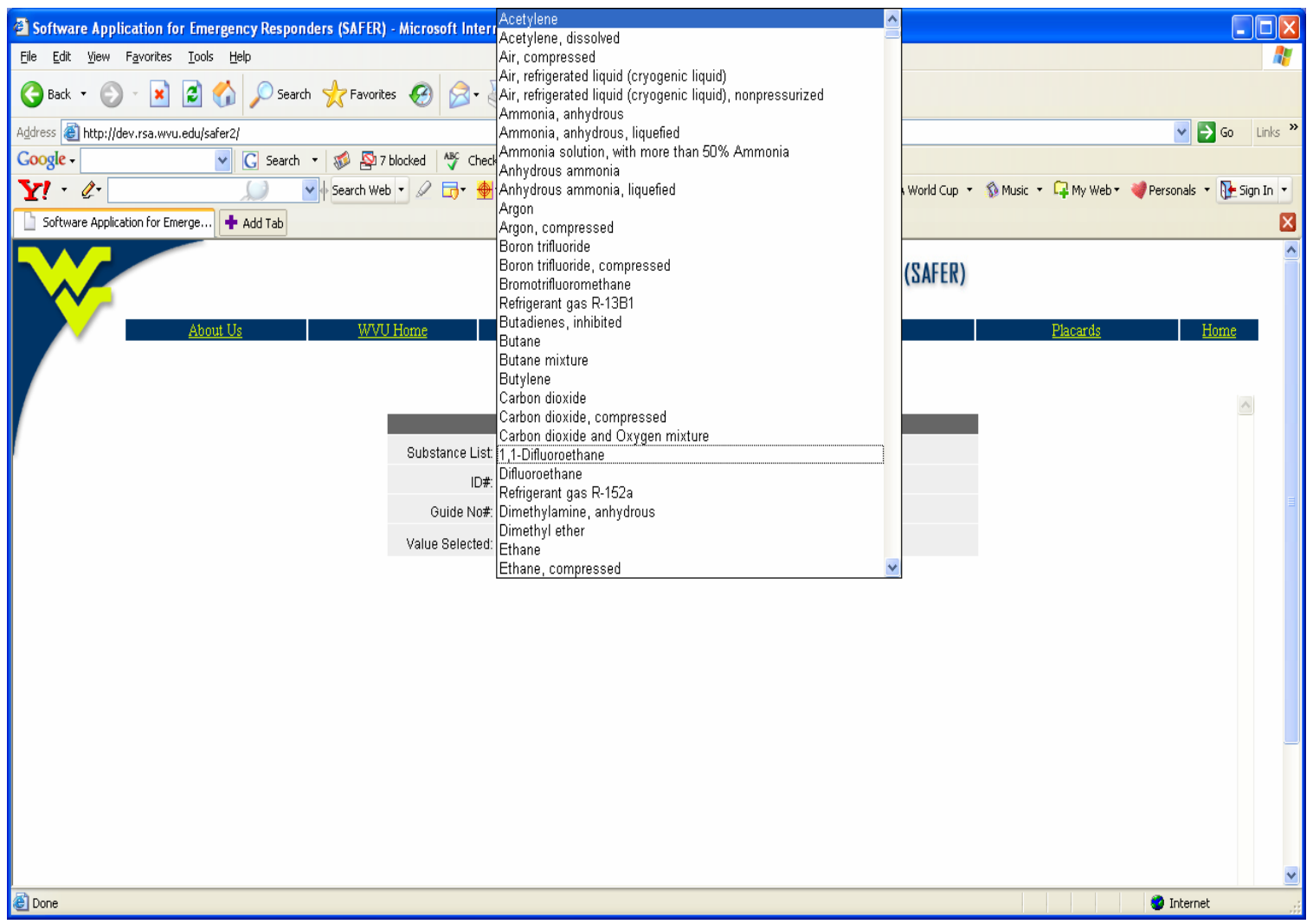

Figure 5.4: Dropdown menu for substance list 
Click on letter ' $h$ ' on the keyboard, the list of substances will scroll down to substances beginning with letter ' $h$ '. Figure 5.5 shows the option ' $h$ '.

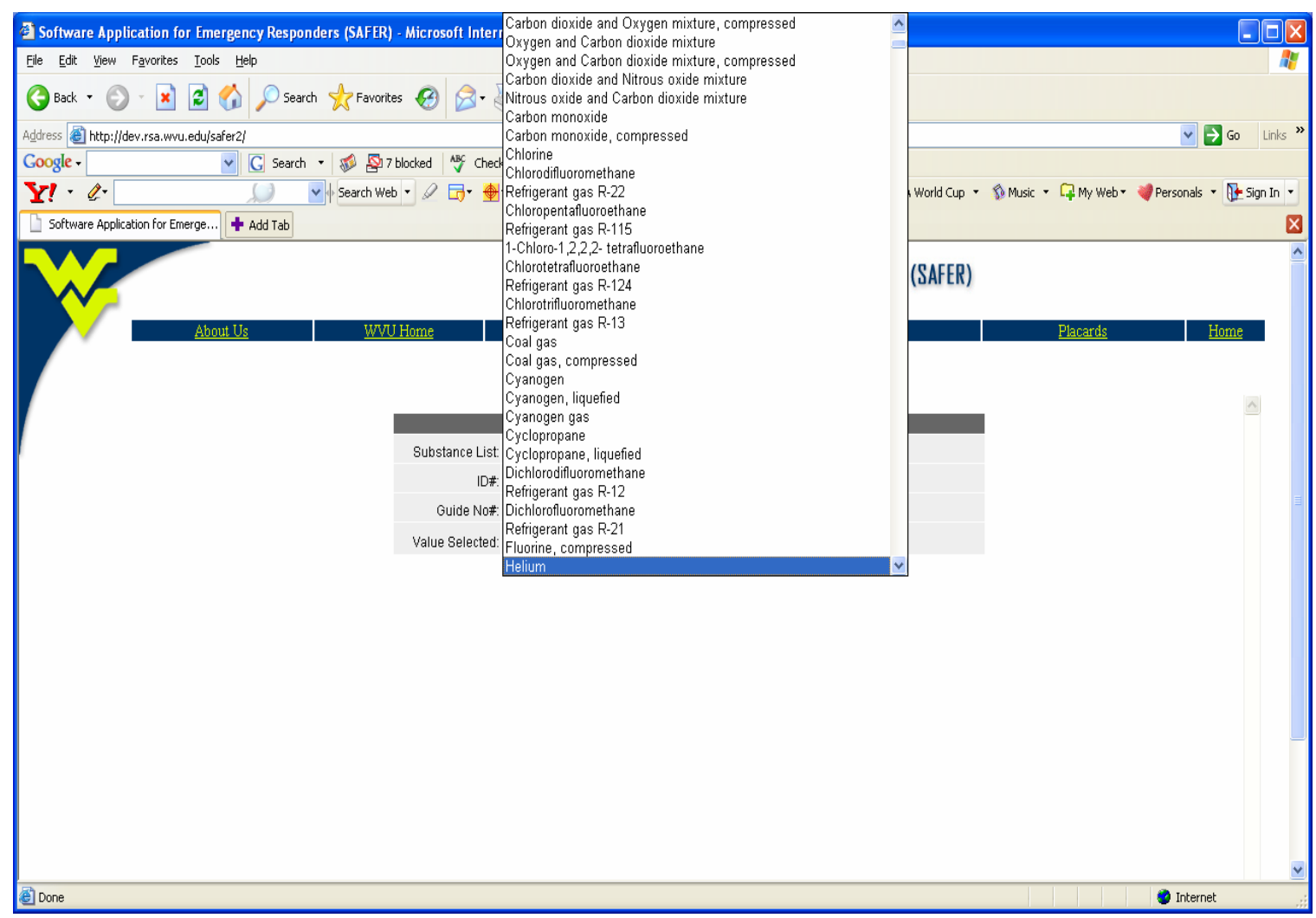

Figure 5.5: Option 'h' highlighted 
Continue scrolling down until Hypochlorite solution is visible in the list. Figure 5.6 shows the hypochlorite solution highlighted.

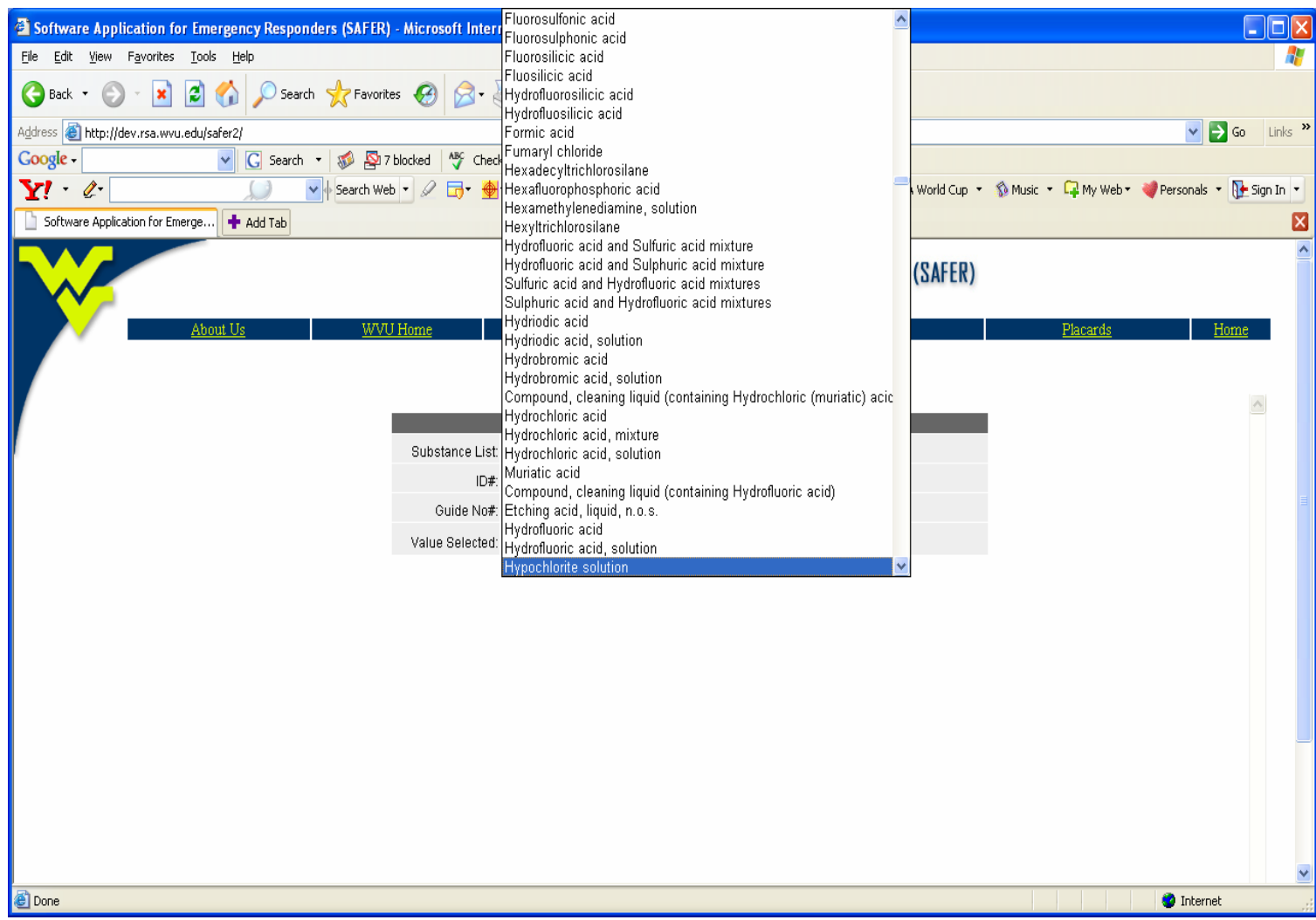

Figure 5.6: Hypochlorite solution highlighted 
Select hypochlorite solution and click on 'Go'. This will automatically populate the Chemical ID and Guide Number fields with the values corresponding to the Hypochlorite Solution selected in the Substance List. Figure 5.7 shows the fields with the corresponding values.

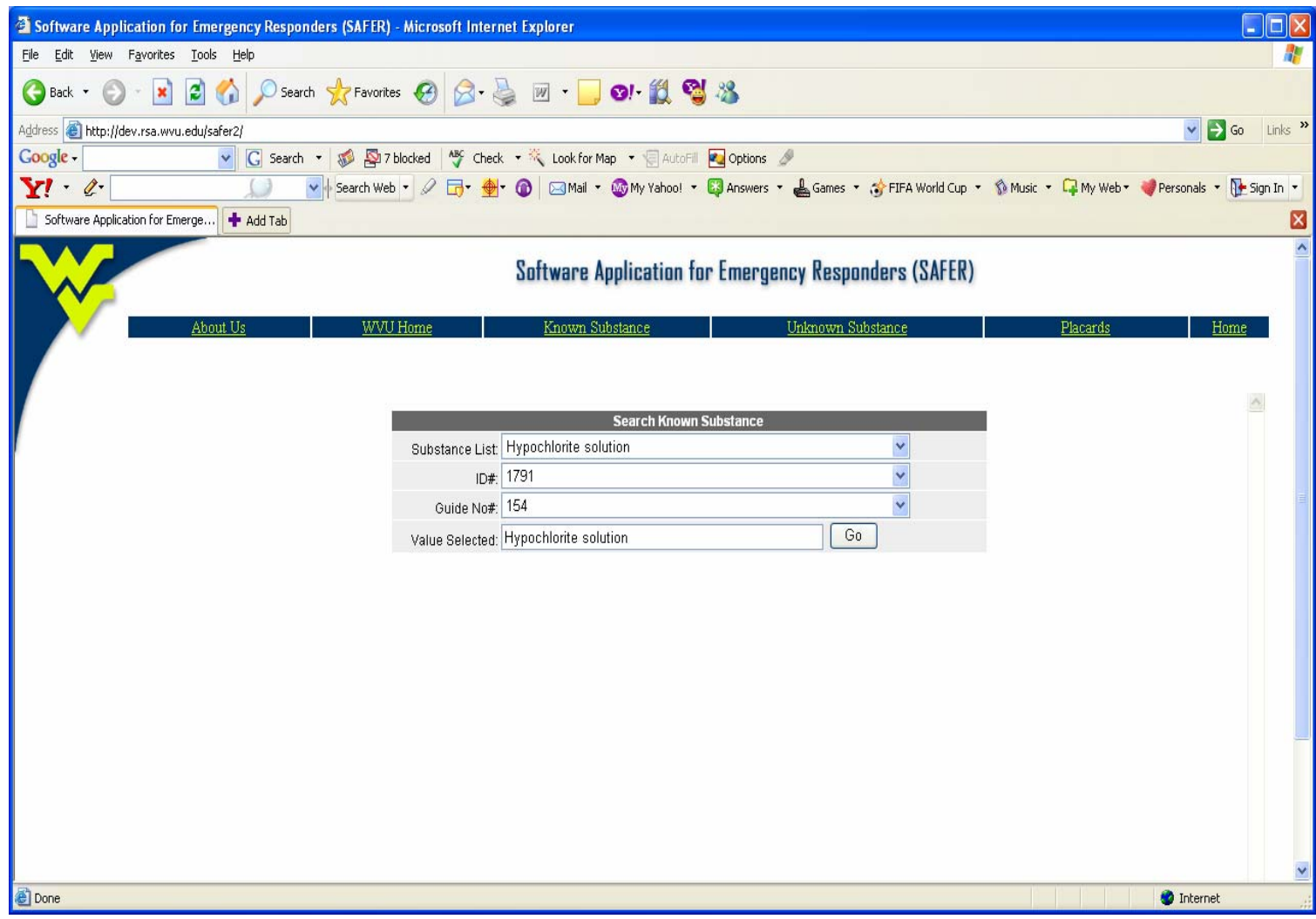

Figure 5.7: Chemical ID and Guide No. associated with Hypochlorite Solution 
Click on 'Go' button and it takes the user to the data page of hypochlorite solution, showing the options to choose from. Figure 5.8 shows the data page for the hypochlorite solution.

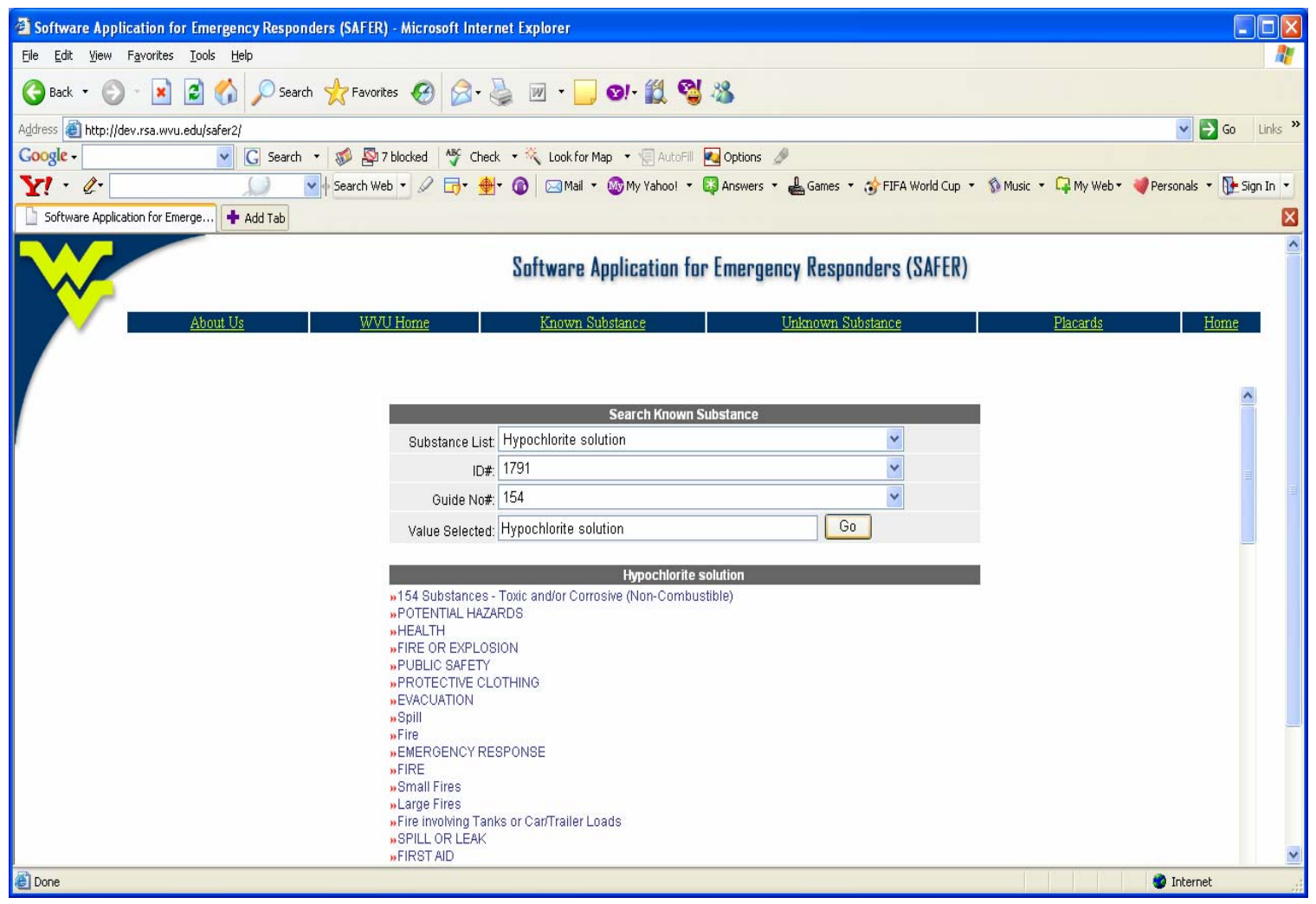

Figure 5.8: Hypochlorite data page 
The first option on the data page describes the guide number for hypochlorite solution. The user has the option to choose from the different links and get the required information to deal with the hazardous material incident.

To determine the potential hazards associated with hypochlorite solution, click on the 'Potential Hazards' link on the data page. The Potential Hazards section will display the information about health and fire or explosion. Figure 5.9 shows the potential hazards page for the hypochlorite solution.

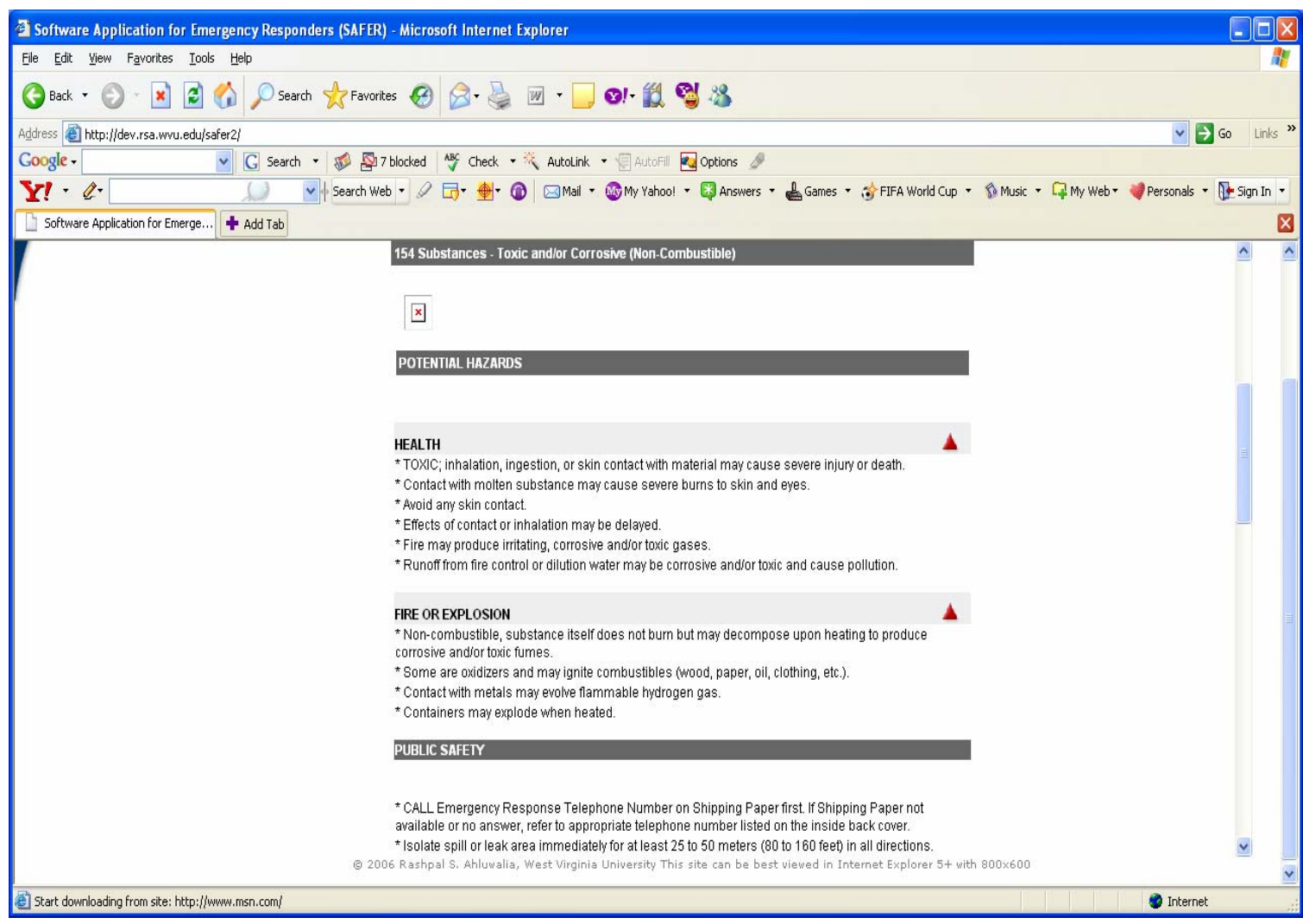

Figure 5.9: Potential Hazards 
To select another option, click on the red arrow as shown in figure 5.9. To determine the actions to be taken for public safety, click on the 'Public Safety' link on the data page. The Public Safety section will display the information about the distance to be immediately isolated, protective clothing required for the first responders and specific instruction on how to deal with in case of a spill or fire. Figure 5.10 shows the public safety pages for the hypochlorite solution.

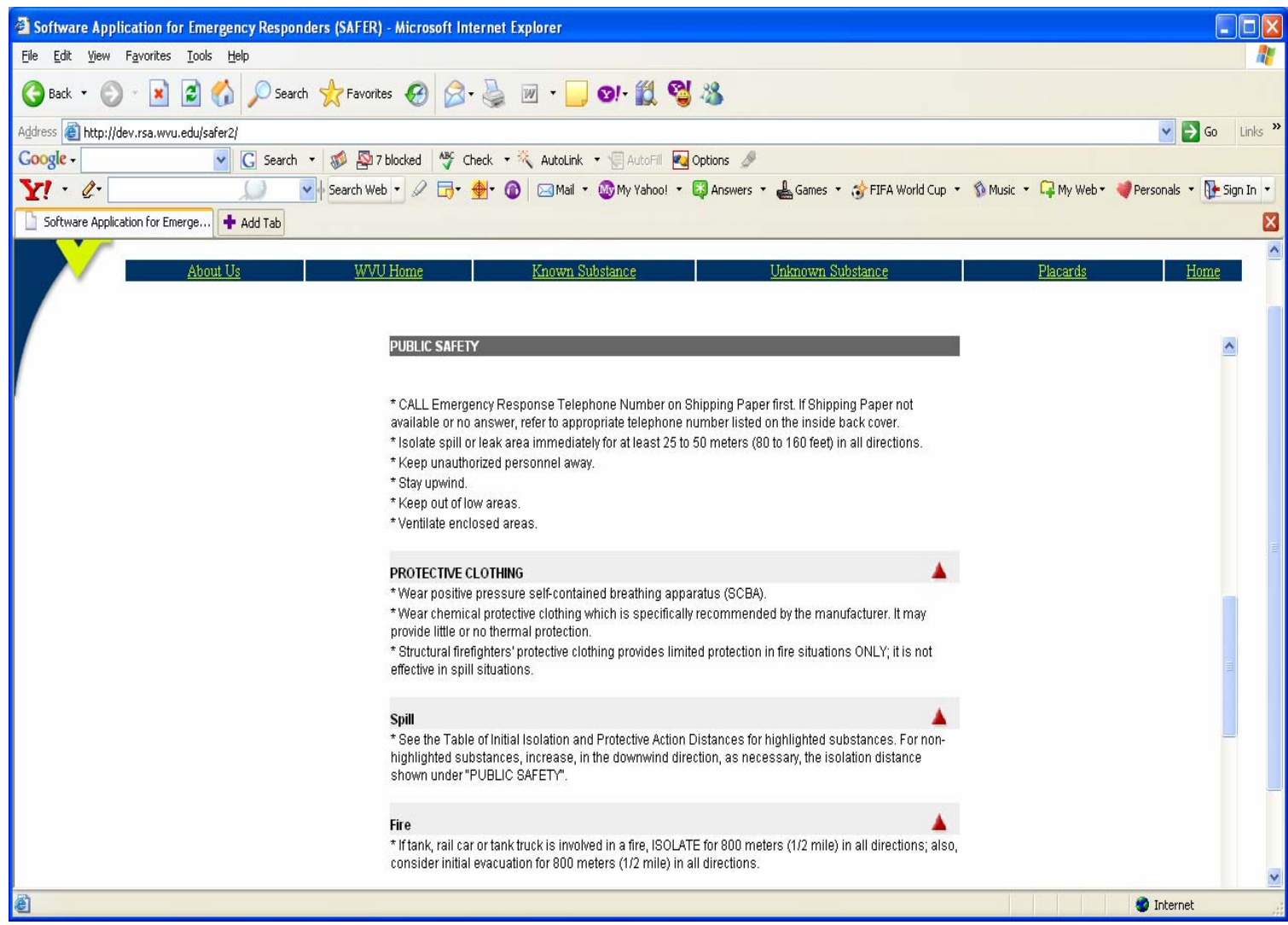

Figure 5.10: Public Safety 
To determine the emergency response for the hypochlorite solution, click on the 'Emergency Response' link on the data page. The Emergency Response section will provide the information on how to deal with the chemical involved in the hazard (hypochlorite solution) in case of fire or spill. This page gives detailed information on how to deal with in case of small fires, large fires and fire involving tanks. Figure 5.11 shows the Emergency Response pages for the hypochlorite solution.

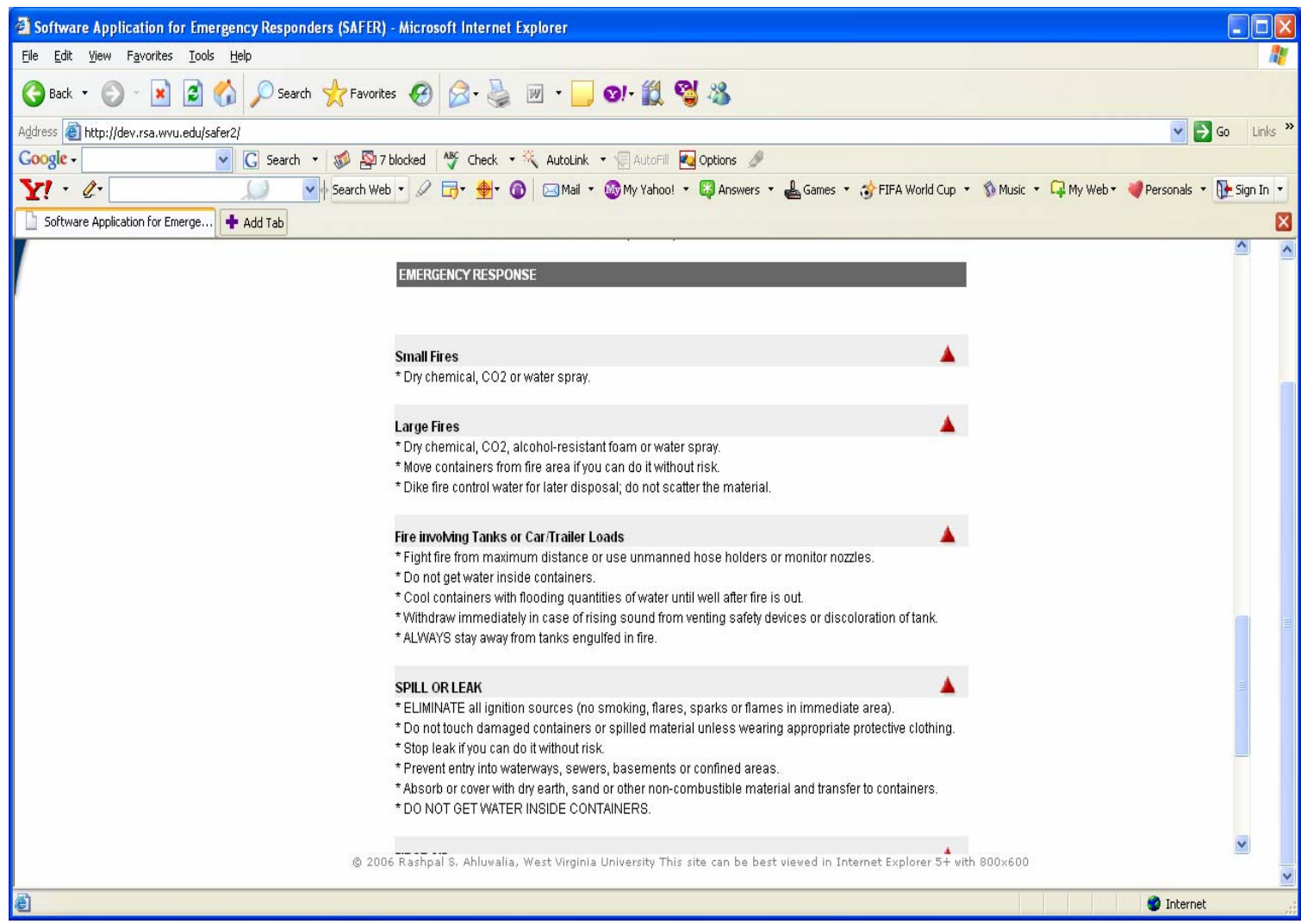

Figure 5.11: Emergency Response page (Fire, Spill or Leak) 
Finally, treatment of the driver can be determined by selecting the First

aid link from the data page, as shown in figure 5.12:

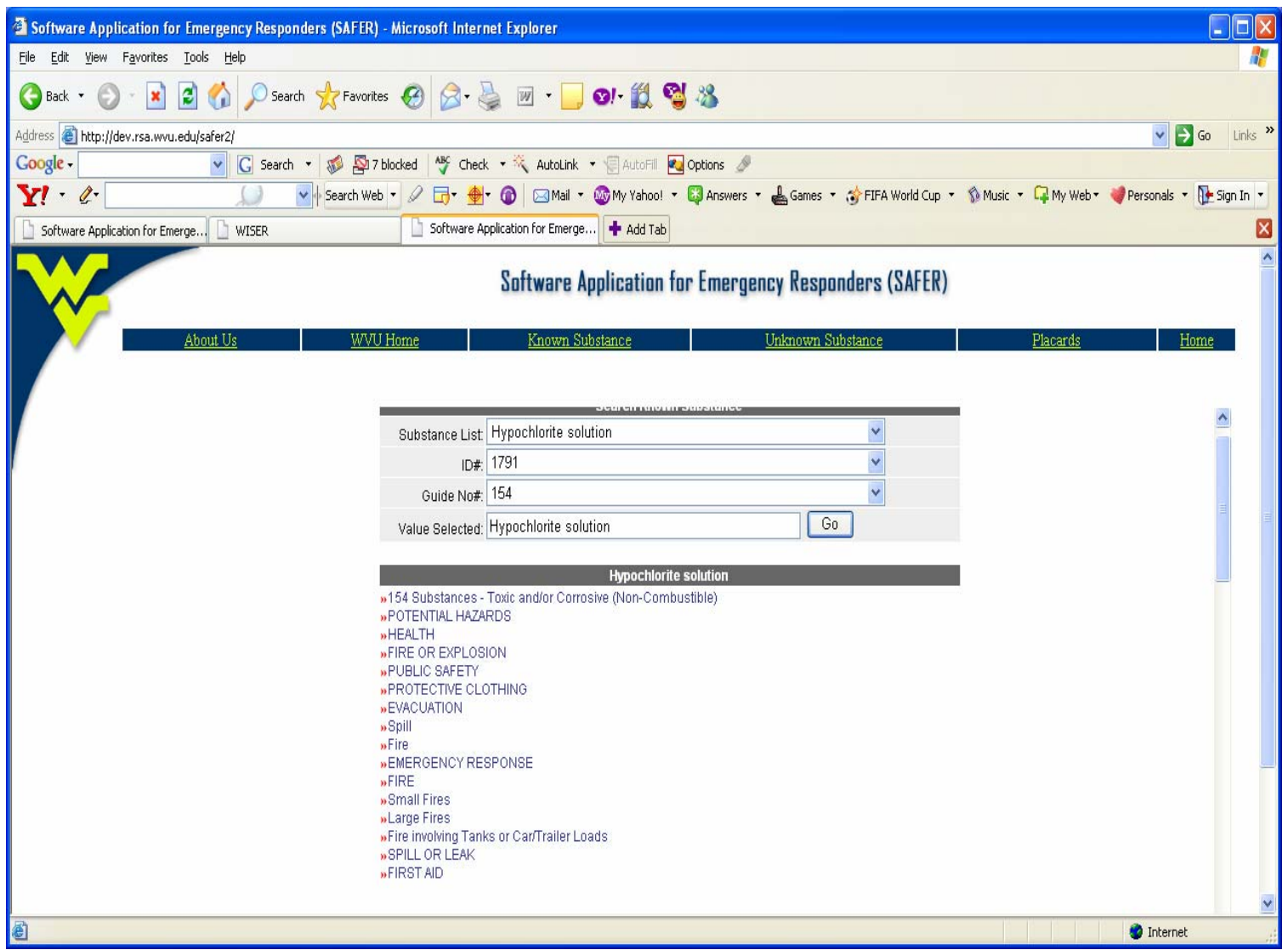

Figure 5.12: First aid option on the data page 
This will bring up the information for First Aid to treat the driver of the truck, as shown in figure 5.13.

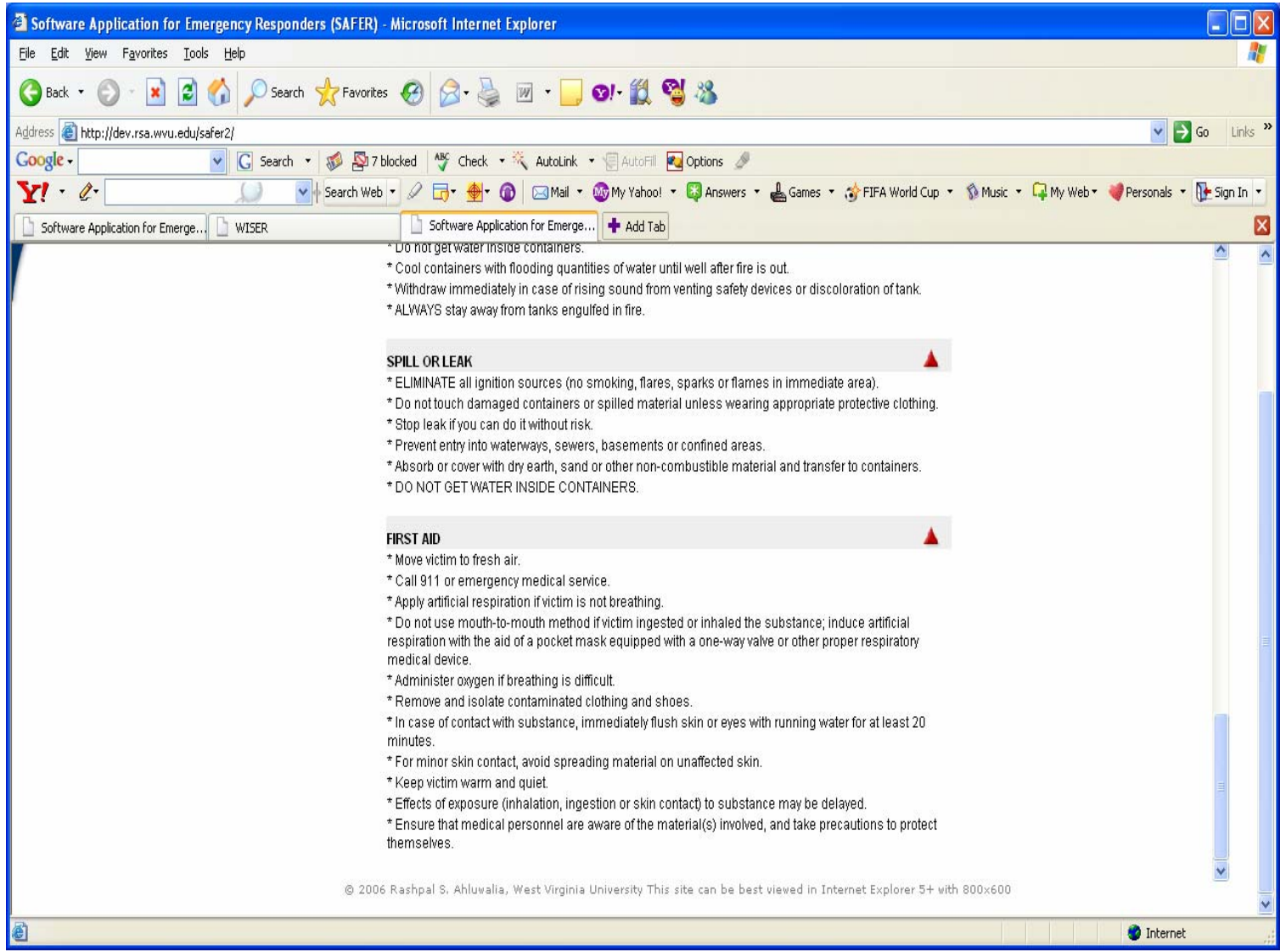

Figure 5.13: First aid 


\subsubsection{Unknown Substance}

In this scenario, you are the Hazardous Materials Specialist responding to an incident at a chemical plant. The place has been cleared and the situation has been stabilized. Your primary task is to identify the substance and provide information and recommendations to the Incident Commander.

The substance in question has been leaking from an unmarked barrel. It has been described as a colorless liquid with an ether like odor. 
The 'Unknown Substance' link is selected from the SAFER homepage. Figure 5.14 shows the unknown substance page.

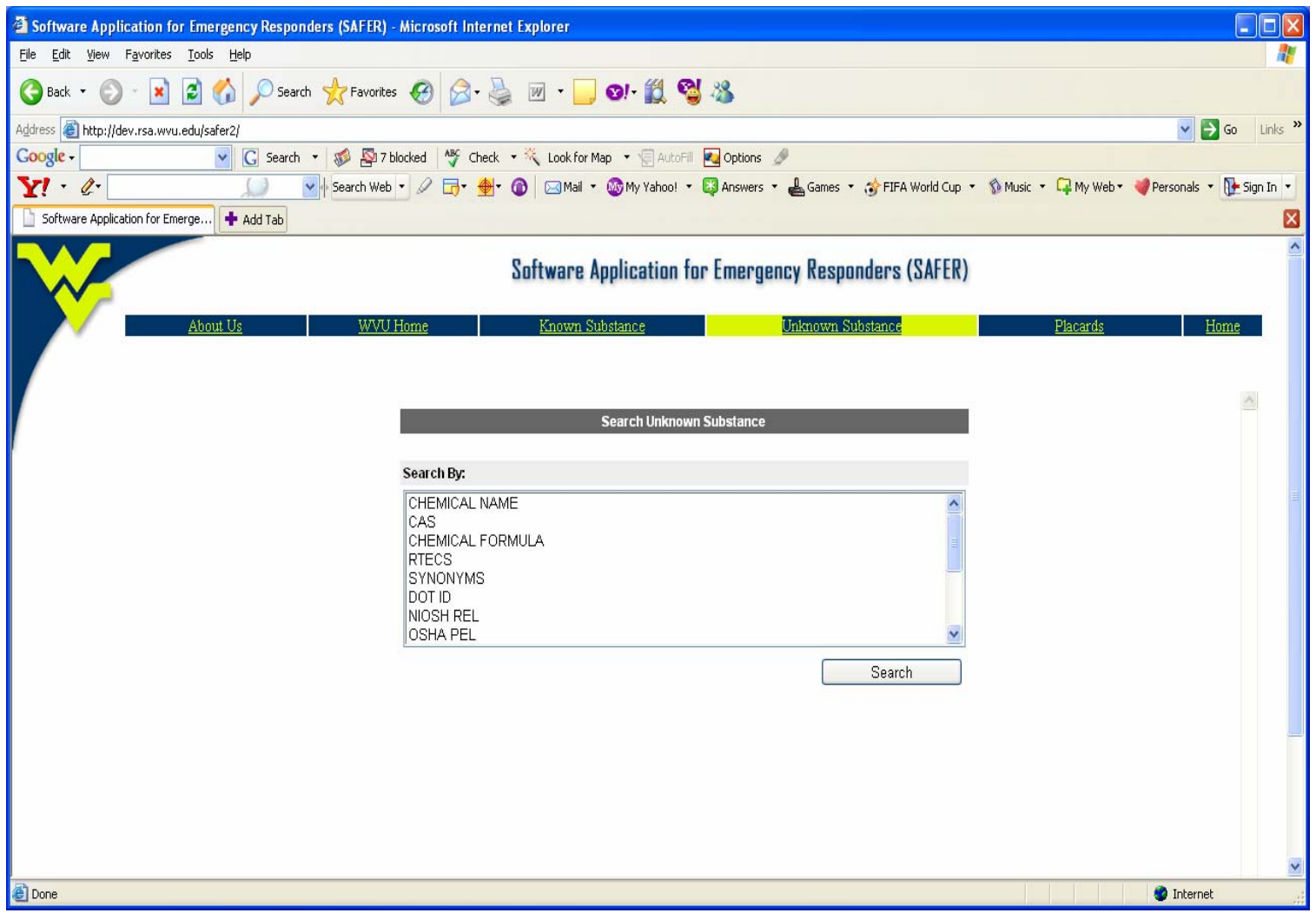

Figure 5.14: Unknown substance page 
The material involved in the incident has to be identified before any action can be taken. The unknown substance page helps the personnel identify the material involved in the hazard based on any information available at the chemical plant. The following options are available to help identify the substance:

- Chemical Structure

- Synonyms and Trade Names

- Conversion Factors

- Exposure Limits

- Immediately Dangerous to Life or Health (IDLH)

- Physical Description

- Chemical and Physical Properties

- Incompatibilities and Reactivities

- Measurement Methods

- Symptoms 
The substance in question has been described as a colorless liquid with ether-like odor. Use SAFER to identify the unknown substance based on its physical description. Select the 'Physical Description' option from the first list box on the unknown substance and then click on 'Search'. Figure 5.15 shows this option.

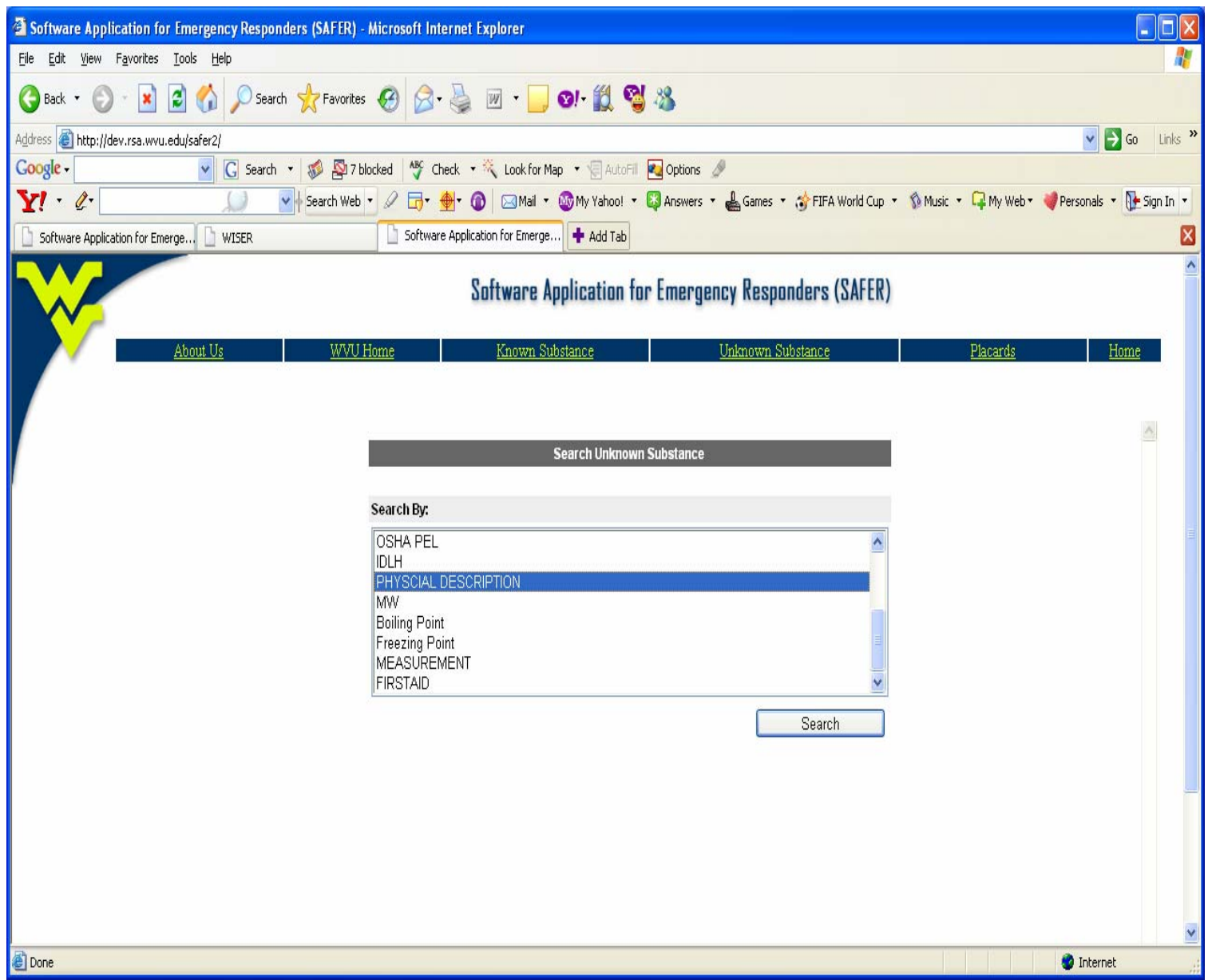

Figure 5.15: Physical description highlighted 
When the 'Search' button is clicked on, it provides the user with a link to sort by color, odor and state as shown in figure 5.16.

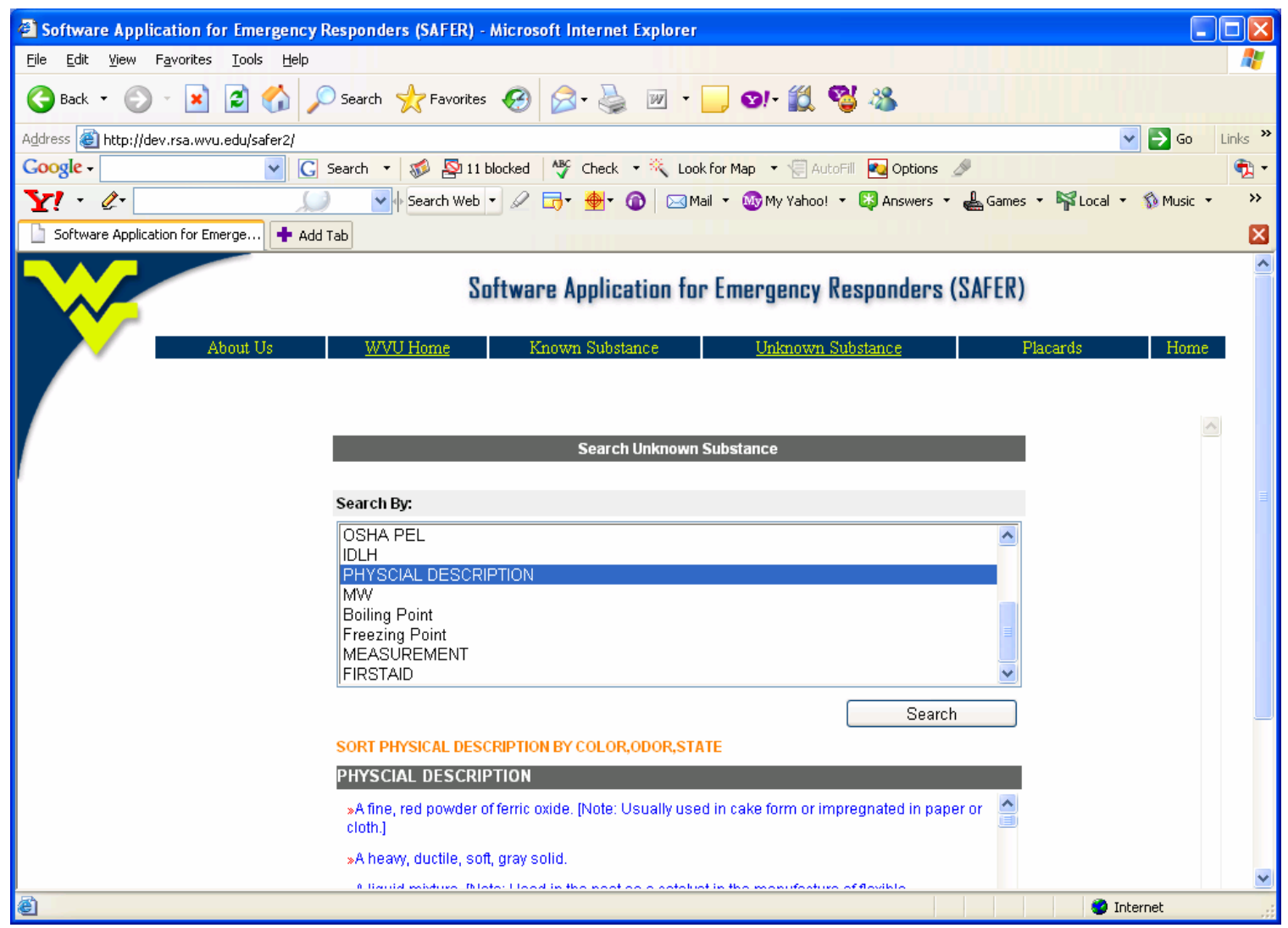

Figure 5.16: To sort physical description by color, odor and state 
Click on the link and it will take the user to the page where in the substance can be identified based on the color, odor and state, as shown in figure 5.17.

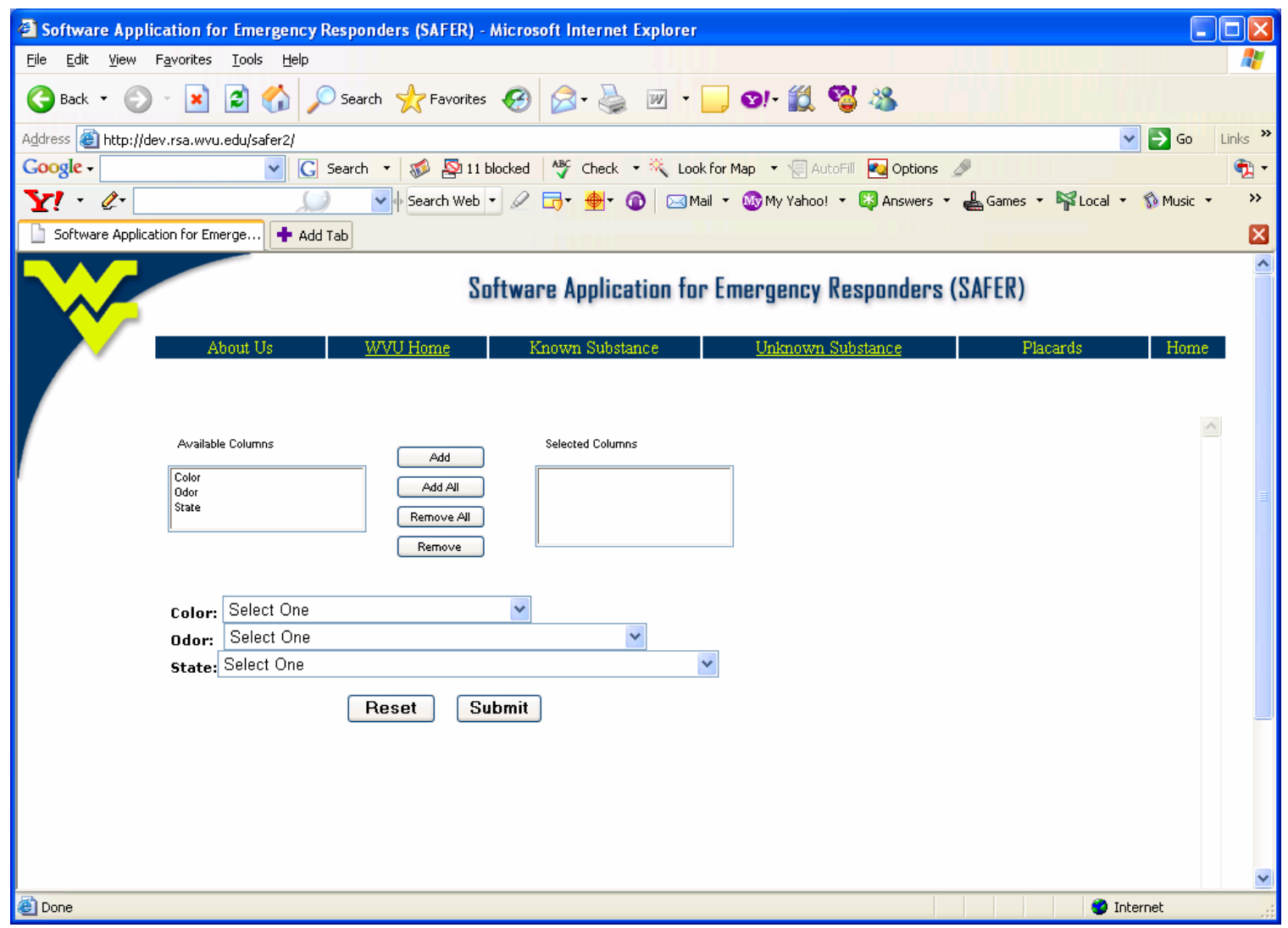

Figure 5.17: Options to identify substance based on color, odor and state 
The substance at the chemical plant has the properties of colorless liquid with ether-

like odor. Select color and odor from the available columns list and add to selected columns list as shown in figure 5.18.

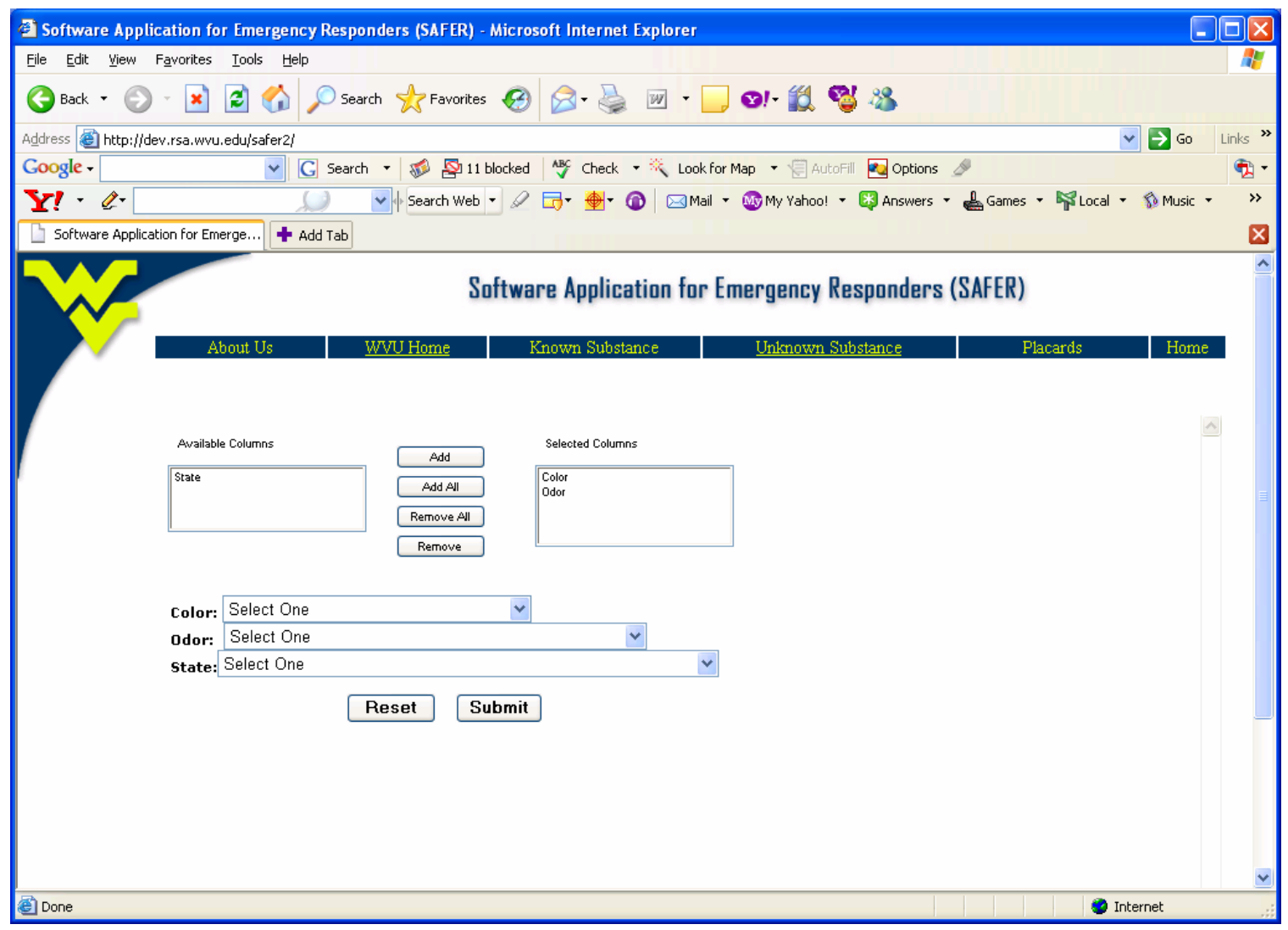

Figure 5.18: color and odor fields selected 
From the dropdown box adjacent to color, select the color to be colorless and from the dropdown box adjacent to odor, select the odor to be ether-like odor, as shown in figure 5.19 .

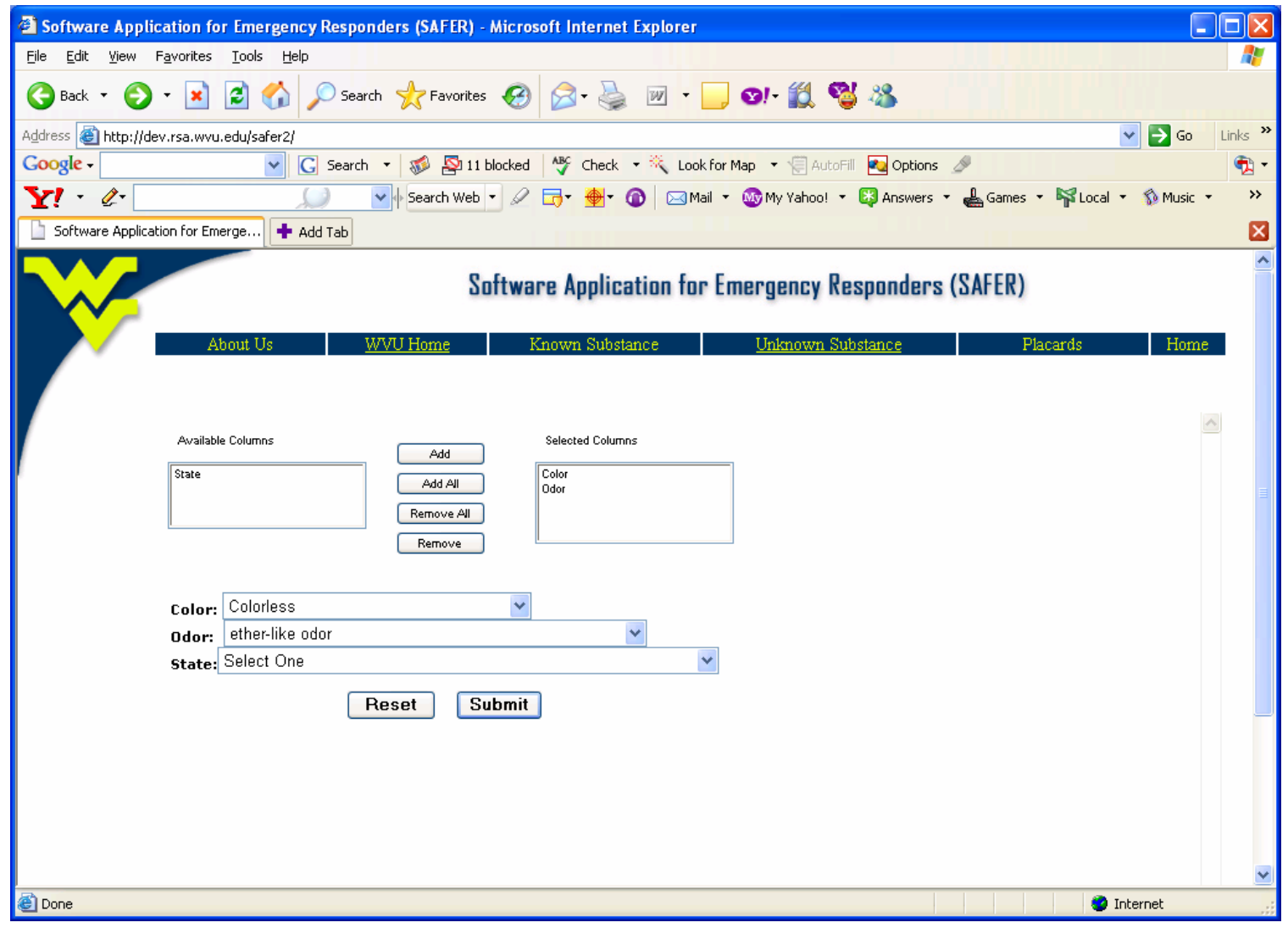

Figure 5.19: Color and odor selected 
Then click on submit and it has identified the chemical to be Tetrahydrofuran, as shown in figure 5.20 .

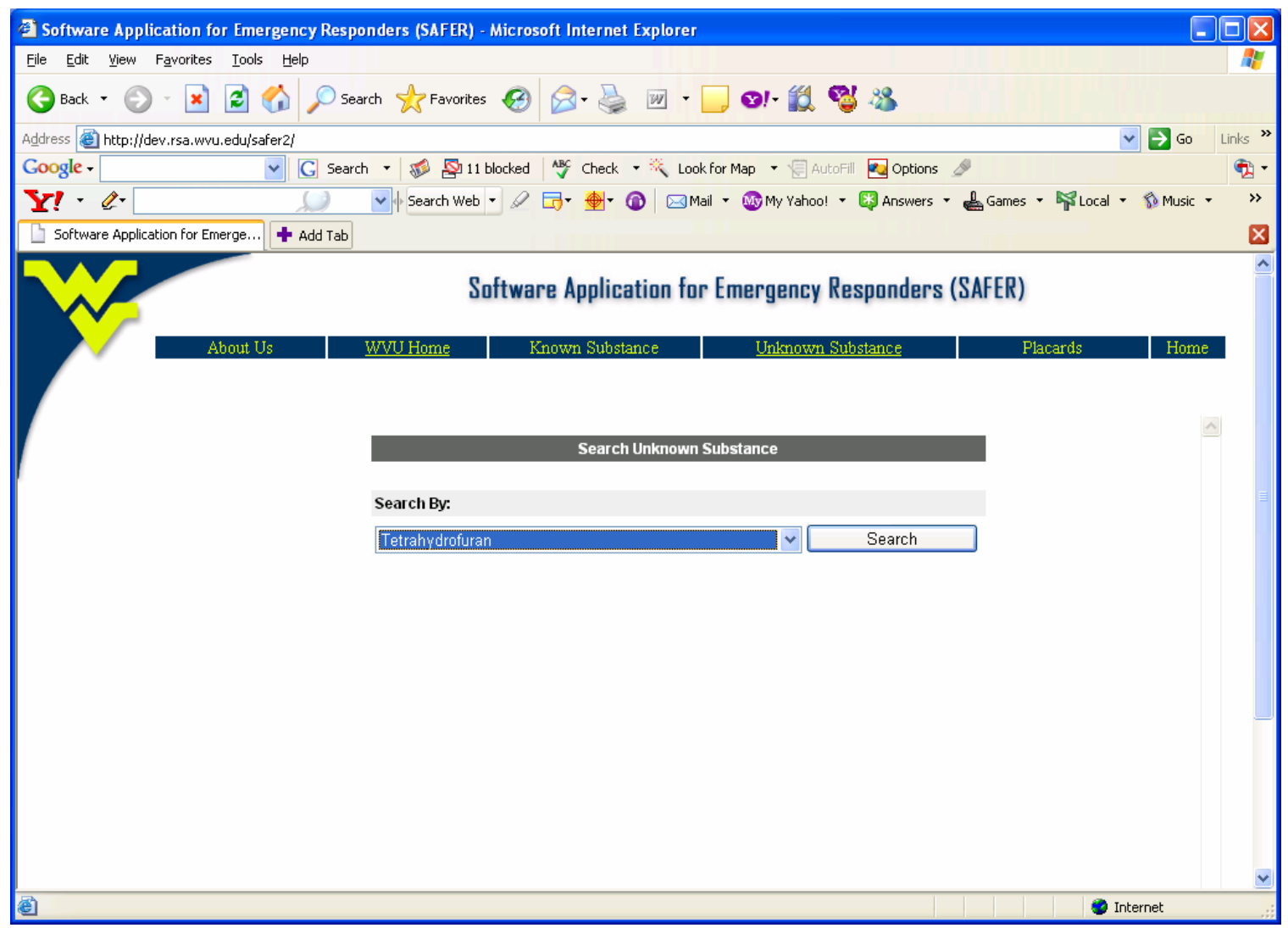

Figure 5.20: Chemical identified to be Tetrahydrofuran 
Click on the 'Search' button, and it will take the user to the properties page of the identified chemical 'Tetrahydrofuran', as shown in figure 5.21.

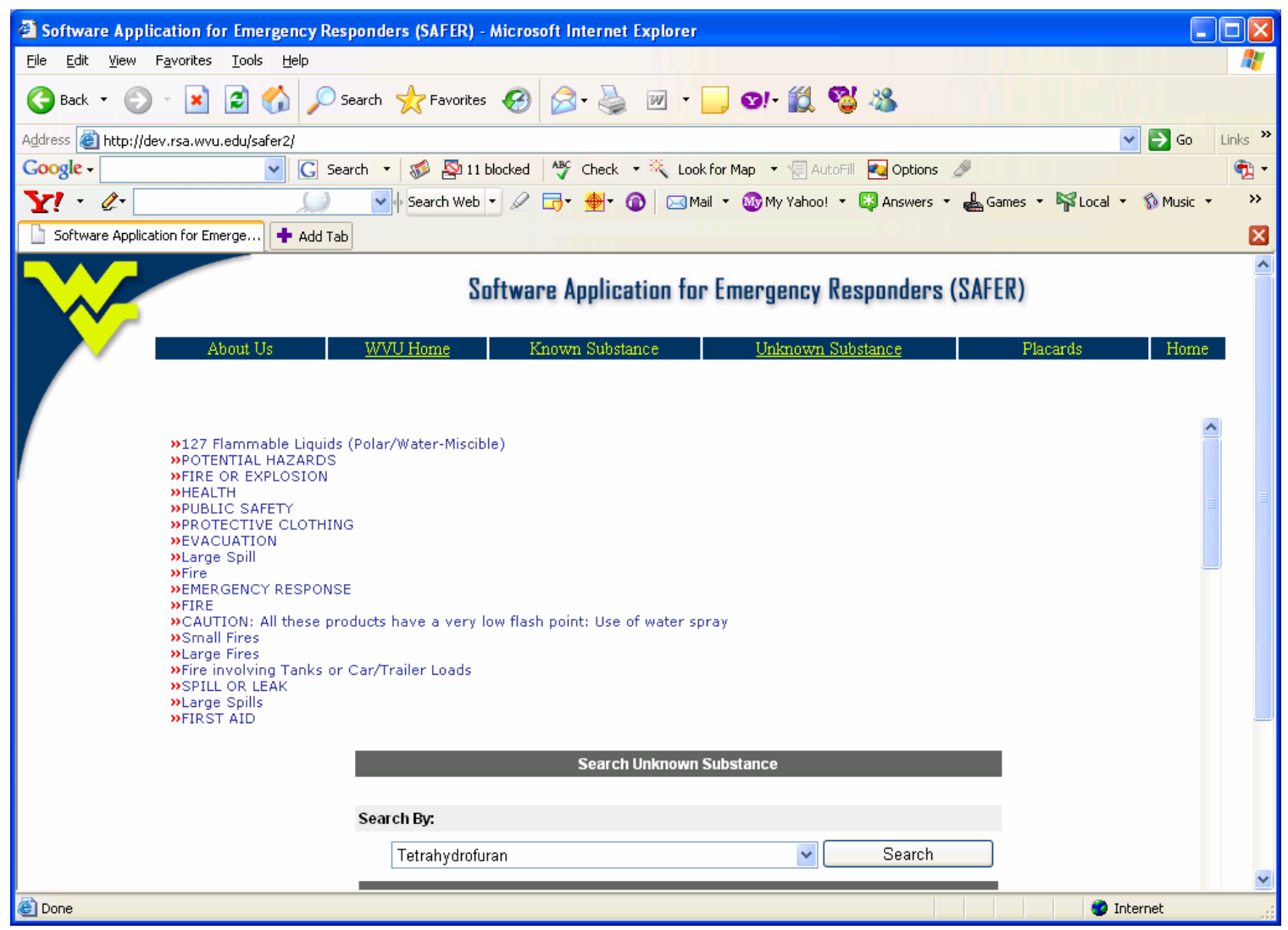

Figure 5.21: Properties page of identified chemical 'Tetrahydrofuran' 
The first option on the data page describes the guide number associated with ‘Tetrahydrofuran’, as shown in Figure 5.22.

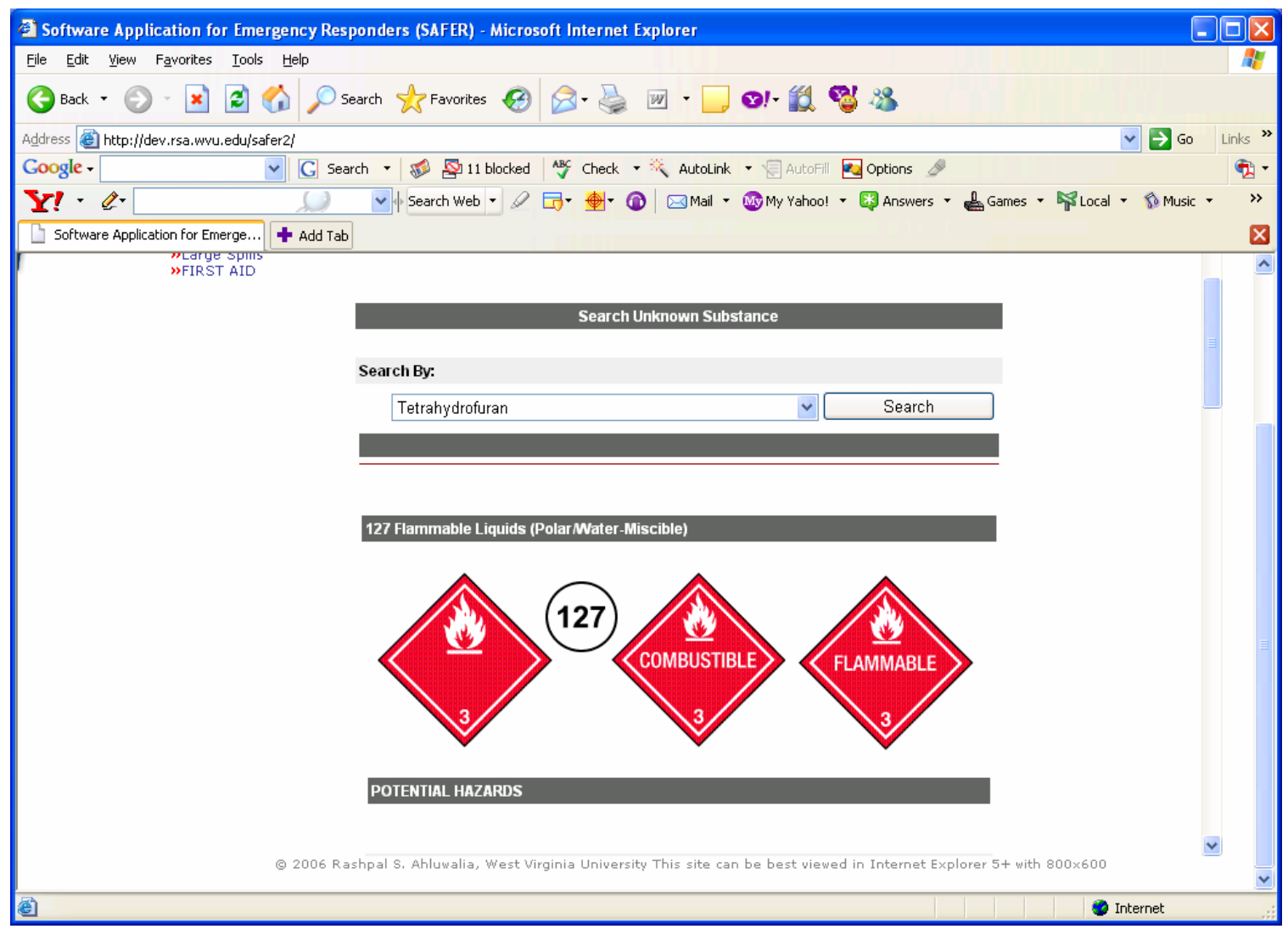

Figure 5.22: 127 Flammable Liquids 
The user has the option to choose from the different links and get the required information to deal with the hazardous material incident.

If the workers at the chemical plant are showing the following symptoms: Irritation eyes, nose, cough, wheezing, and bronchitis. To help identify the unknown substance based on the symptoms, choose the symptoms option from the first list box on the unknown substance page and then click on the 'Search' button. Figure 5.23 shows this option.

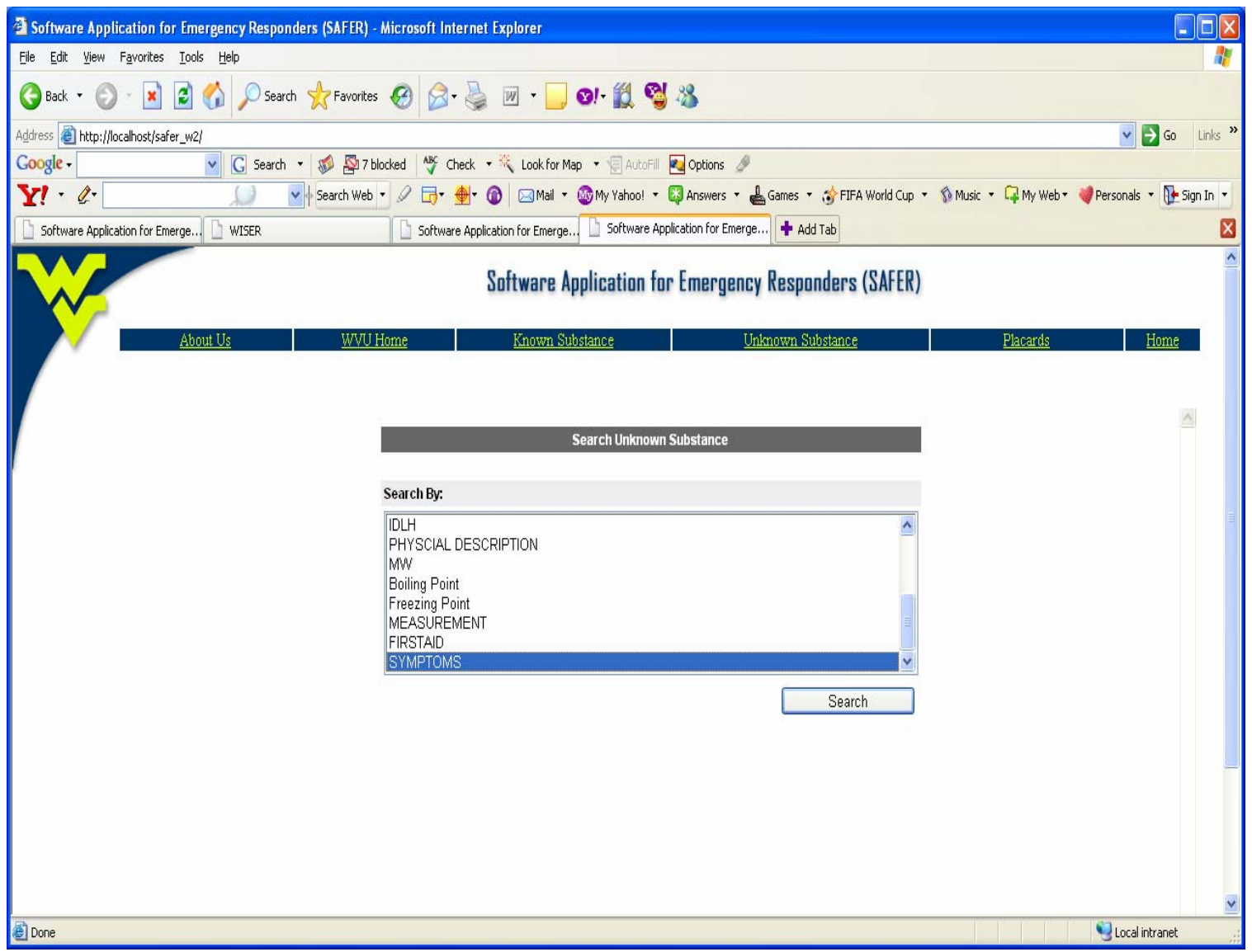

Figure 5.23: Symptoms 
Select the link displaying Irritation eyes, nose, cough, wheezing, bronchitis from the second list box and click on it. Figure 5.24 displays this option.

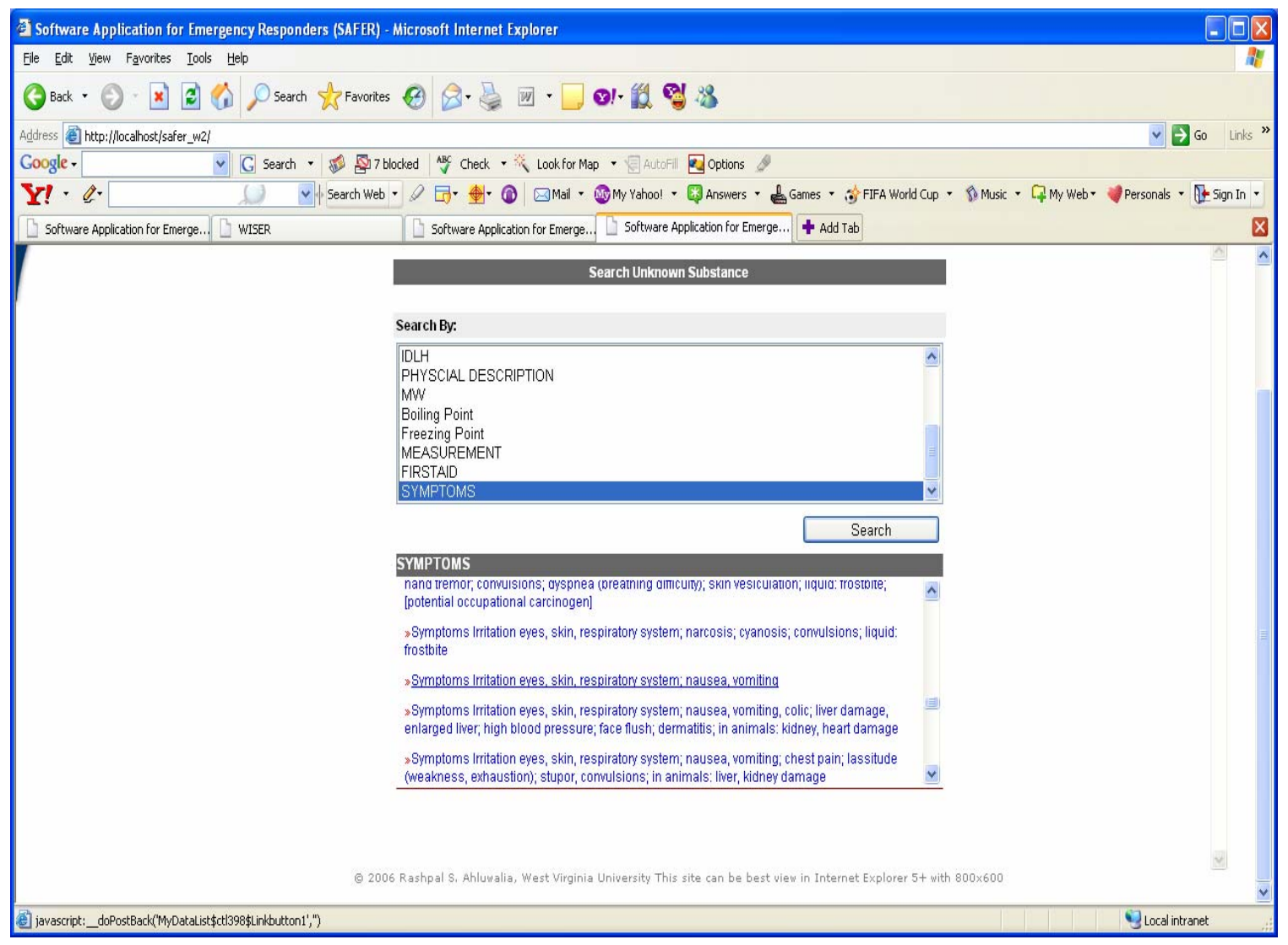

Figure 5.24: Selecting the appropriate symptoms 
This will display the chemical name and the data associated with the symptoms we have selected. The chemical has been identified to be Oxygen, Compressed. Figure 5.25 shows the data page for Oxygen, Compressed.

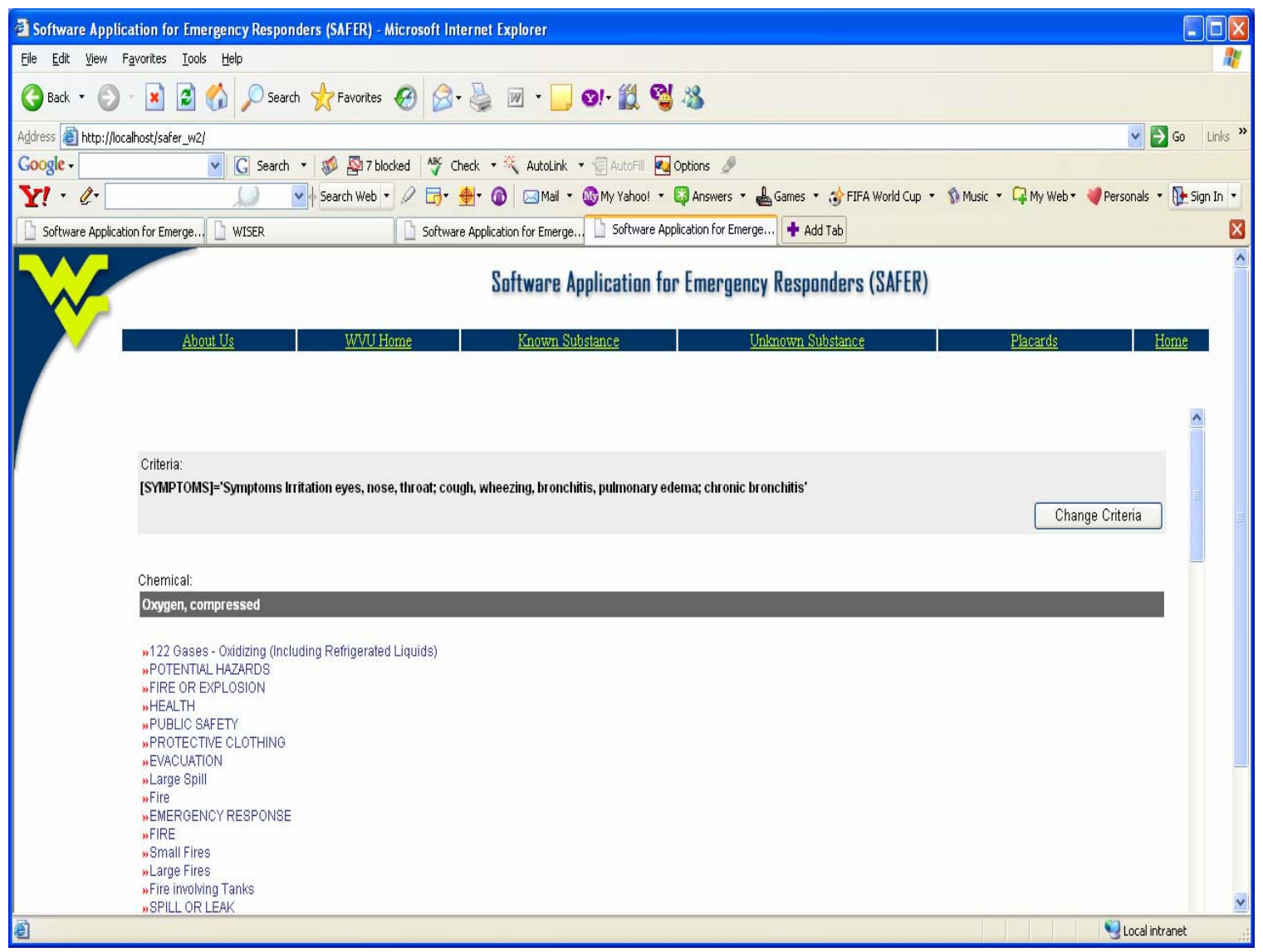

Figure 5.25: Oxygen, Compressed data page 
Based on the symptoms, the unknown substance has been identified to be Oxygen, Compressed. Figure 5.26 shows the guide number associated with Oxygen, Compressed.

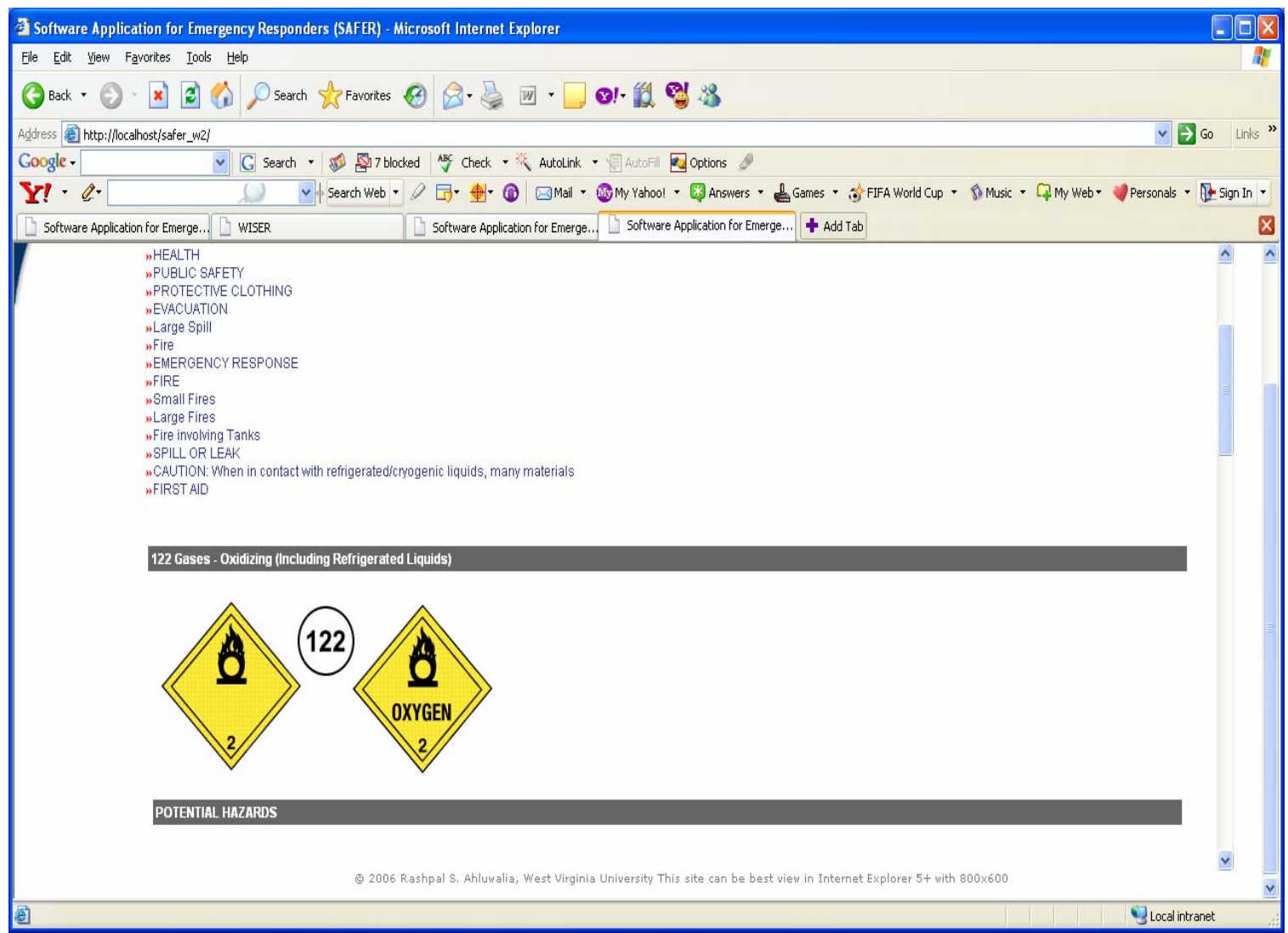

Figure 5.26: 122 Gases-Oxidizing (Including refrigerated liquids) 
For information on spill or leak for this chemical, click on the spill or link option on the data page as shown in Figure 5.27.

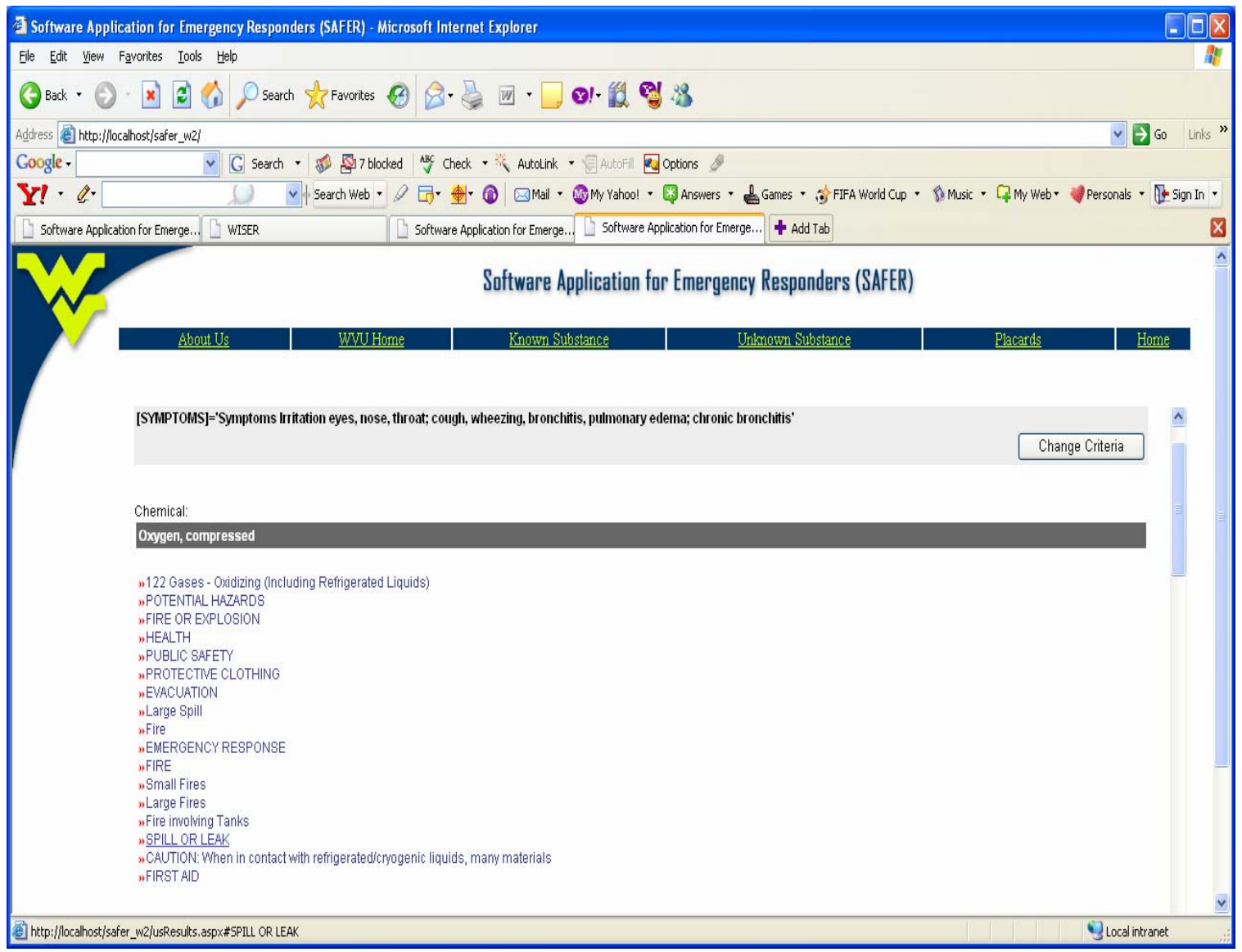

Figure 5.27: Data on Spill or Leak 
Figure 5.28 displays information on Spill or Leak for Oxygen, compressed.

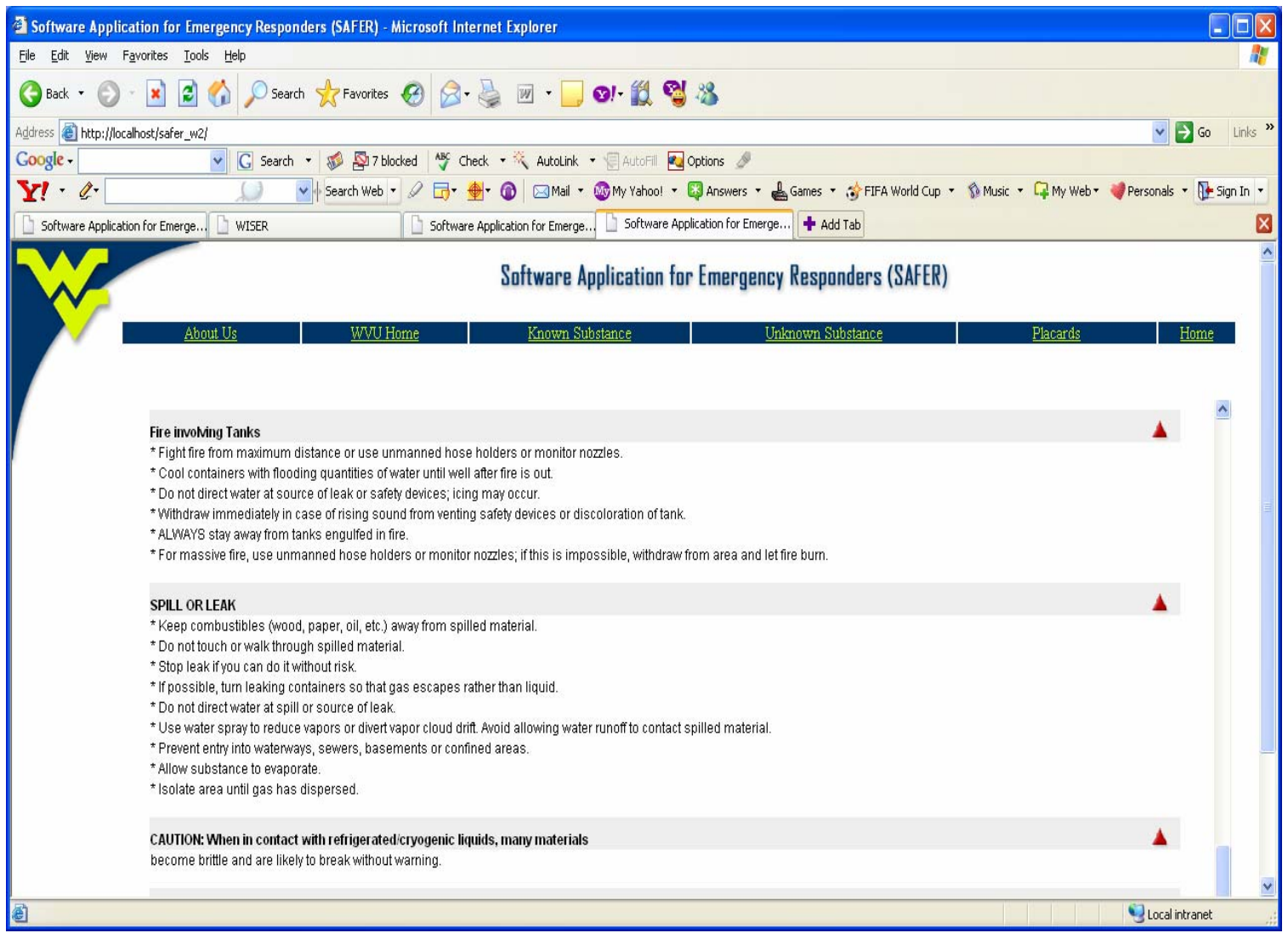

Figure 5.28: Data for Spill or Leak 
The user can go to the top of the page by clicking on the red arrow $\boldsymbol{\Delta}$, to choose a different data option.

To change the criteria of search for the unknown chemical, click on the 'change criteria' button as shown in figure 5.29.

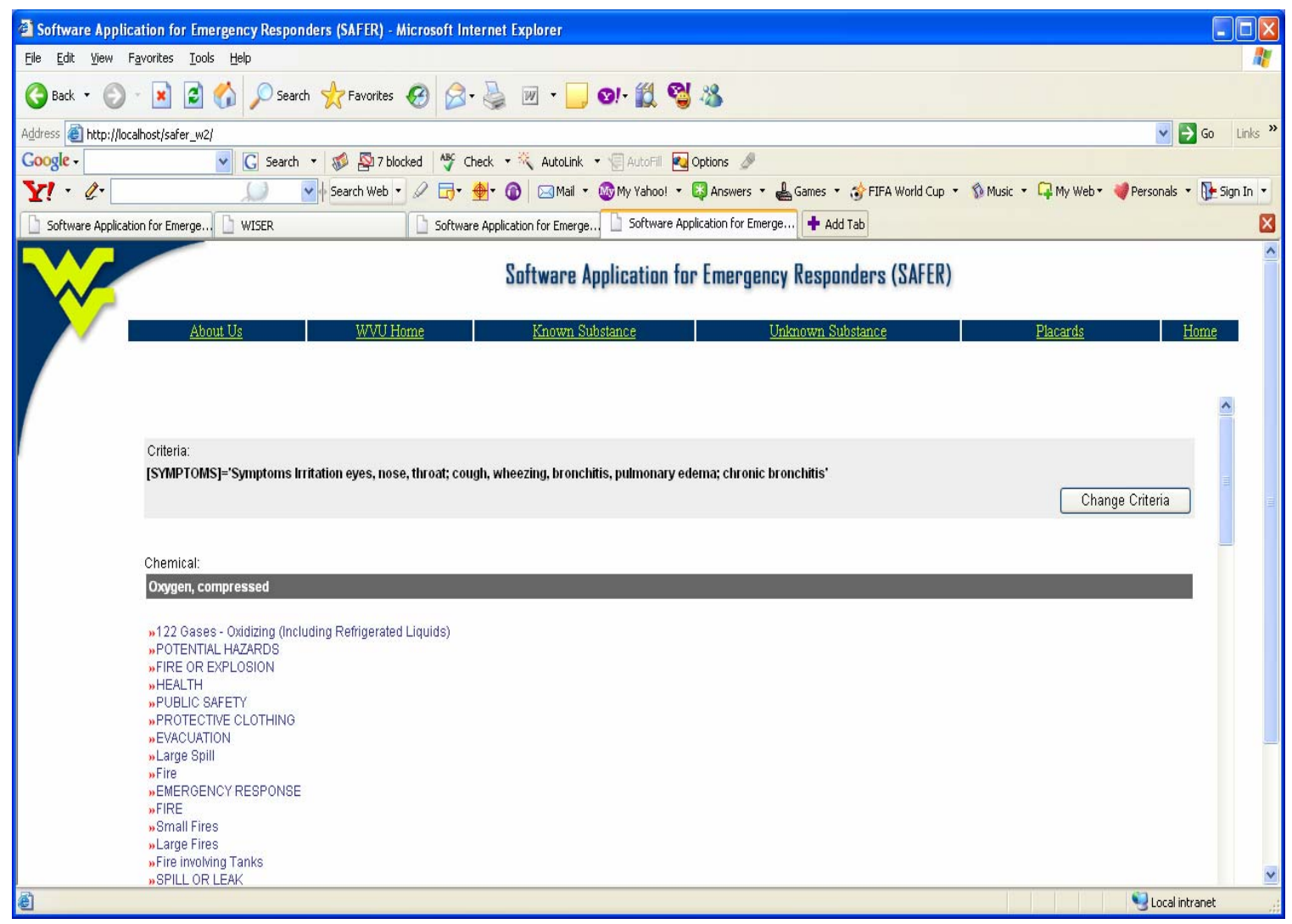

Figure 5.29: Change Criteria option 
It takes the user back to the unknown substance page as shown in figure 5.30.

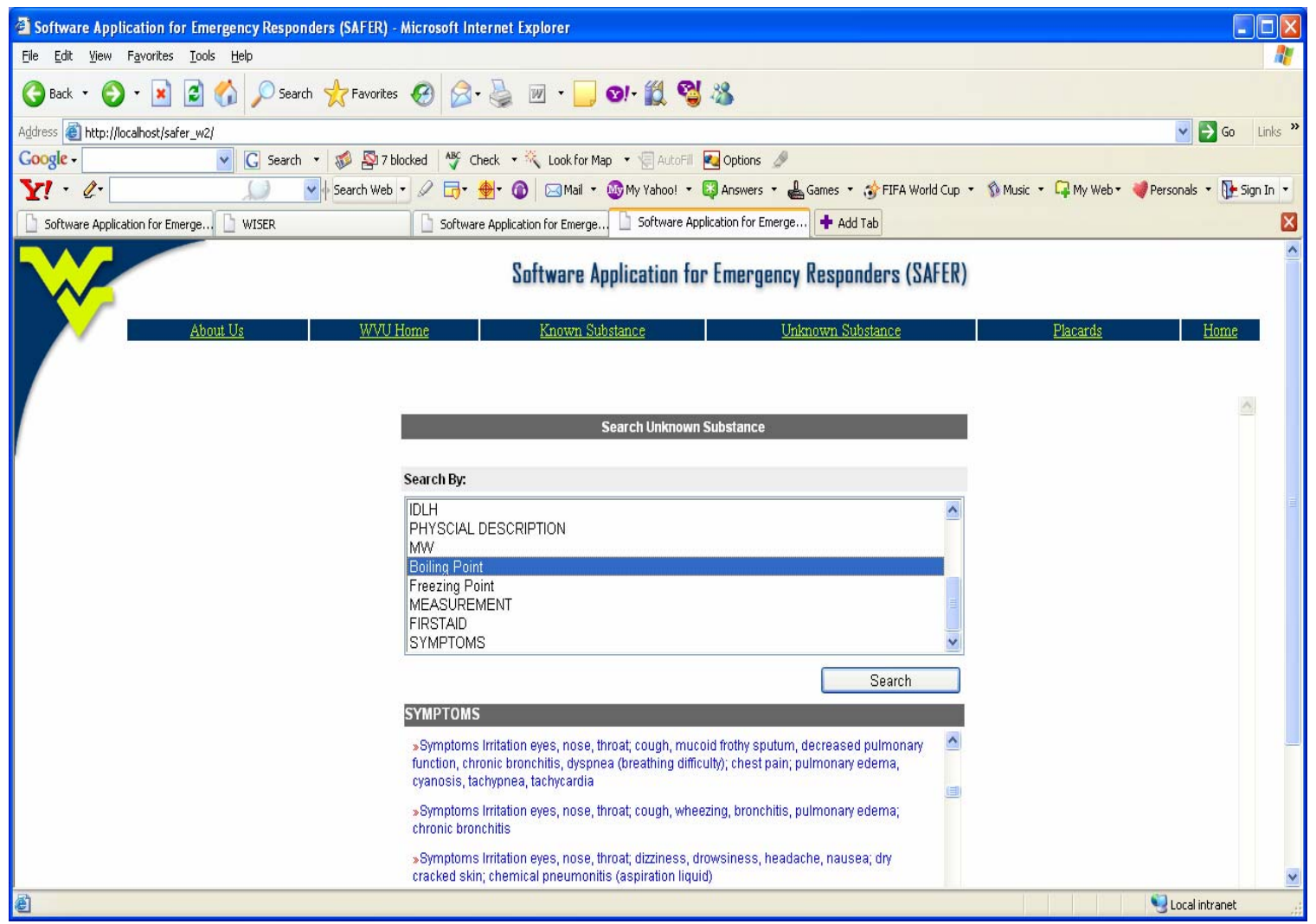

Figure 5.30: Unknown substance start page 
If there is no other option to identify the chemical, the user can use the 'Placards' option in the SAFER application to identify the substance involved in the chemical hazard.

Figure 5.31 shows this option.

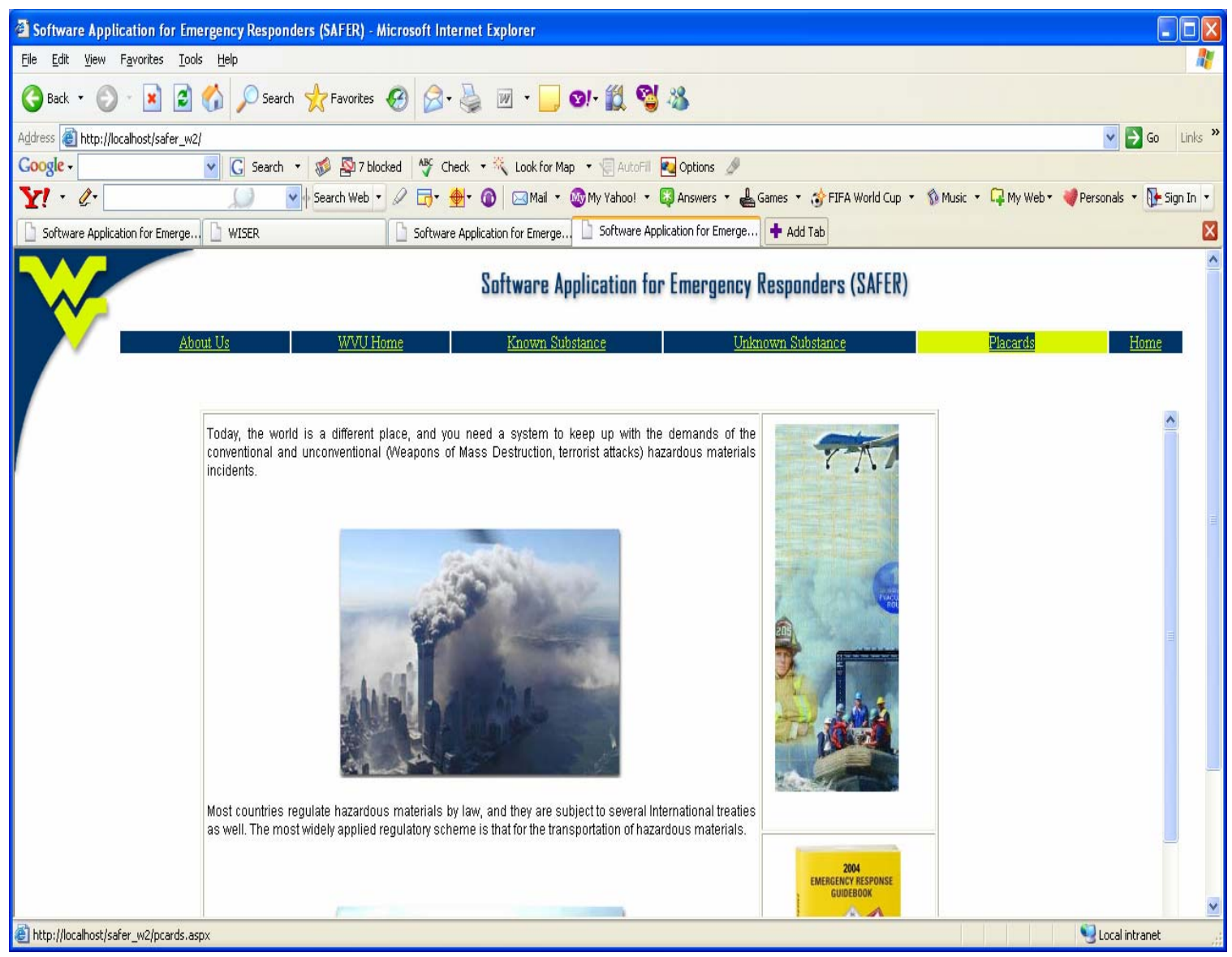

Figure 5.31: Placards option highlighted 
Click on the 'Placards' link on the navigation bar, the page shown in figure 5.32 is displayed.

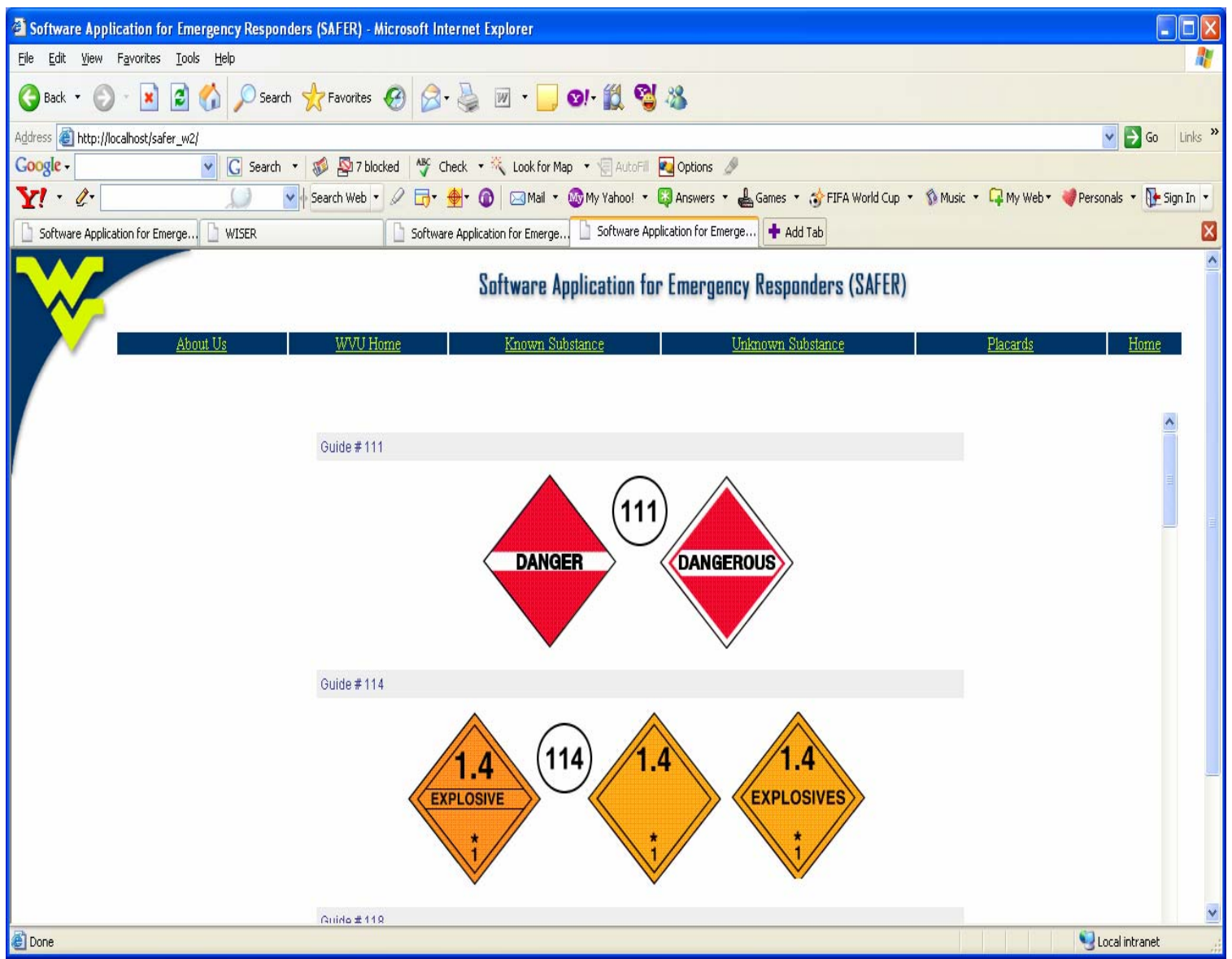

Figure 5.32: Placards page 
This page has the placards listed along with the associated Guide Numbers. Click on the Image and it will provide the user with the data associated with that guide number, as shown in Figure 5.33.

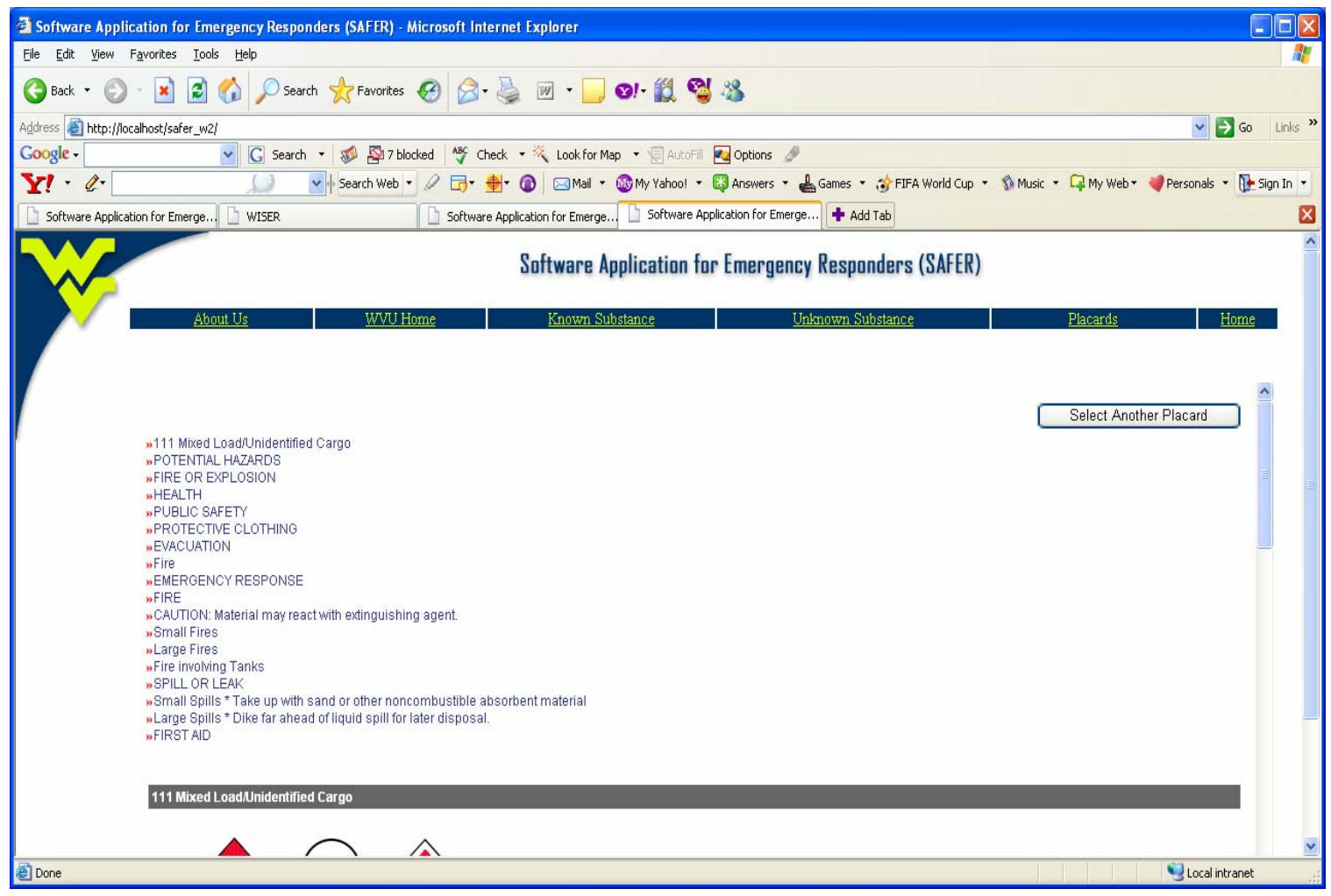

Figure 5.33: Data page based on Placard search 
The user has the option to click on the guide number link provided at the top of each placard, which will open up the data page. The guide number link is shown in figure 5.34.

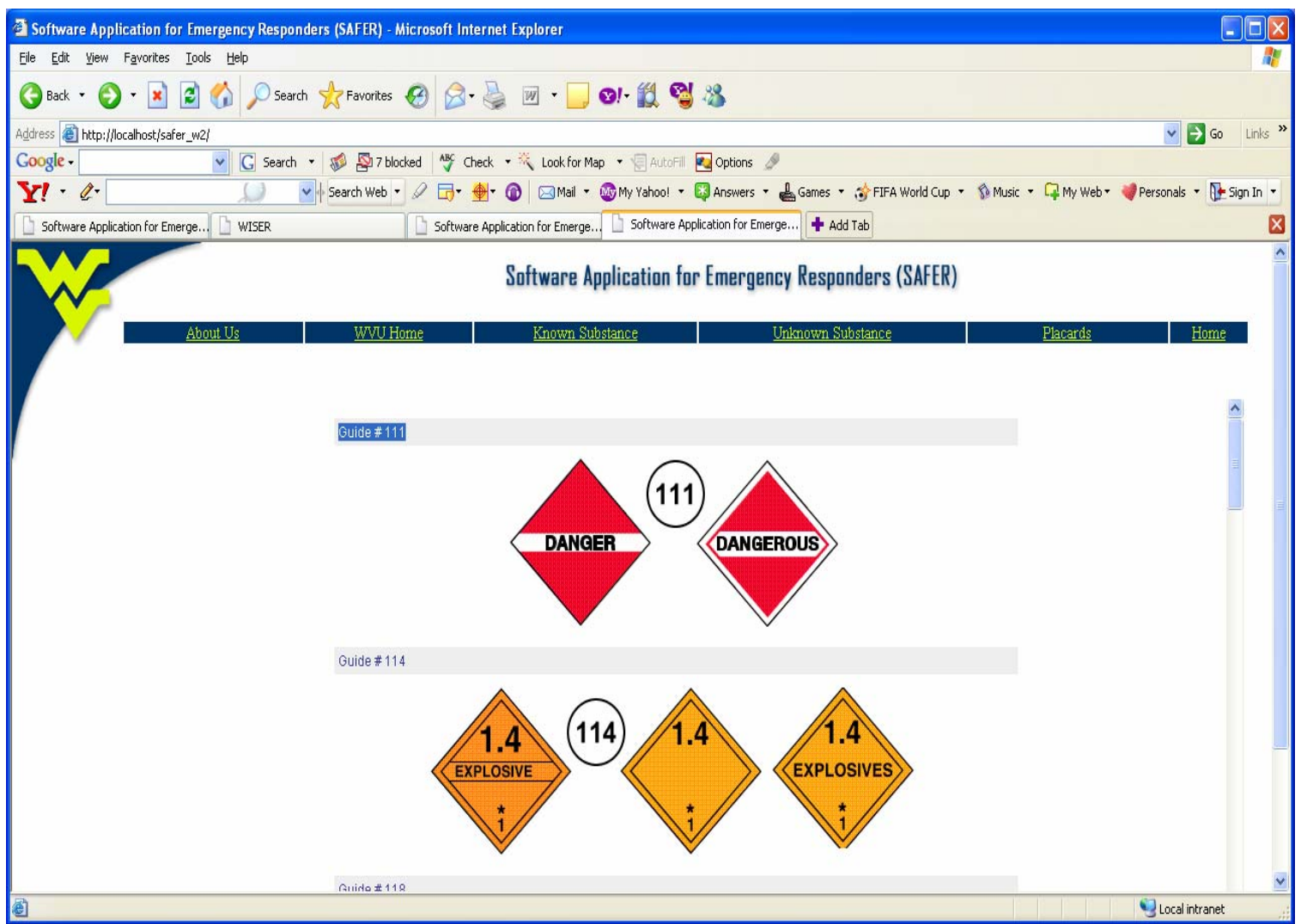

Figure 5.34: Guide number link highlighted 
If the user wants to select another placard, just click on the 'Select Another Placard' button on the data page as shown in figure 5.35 .

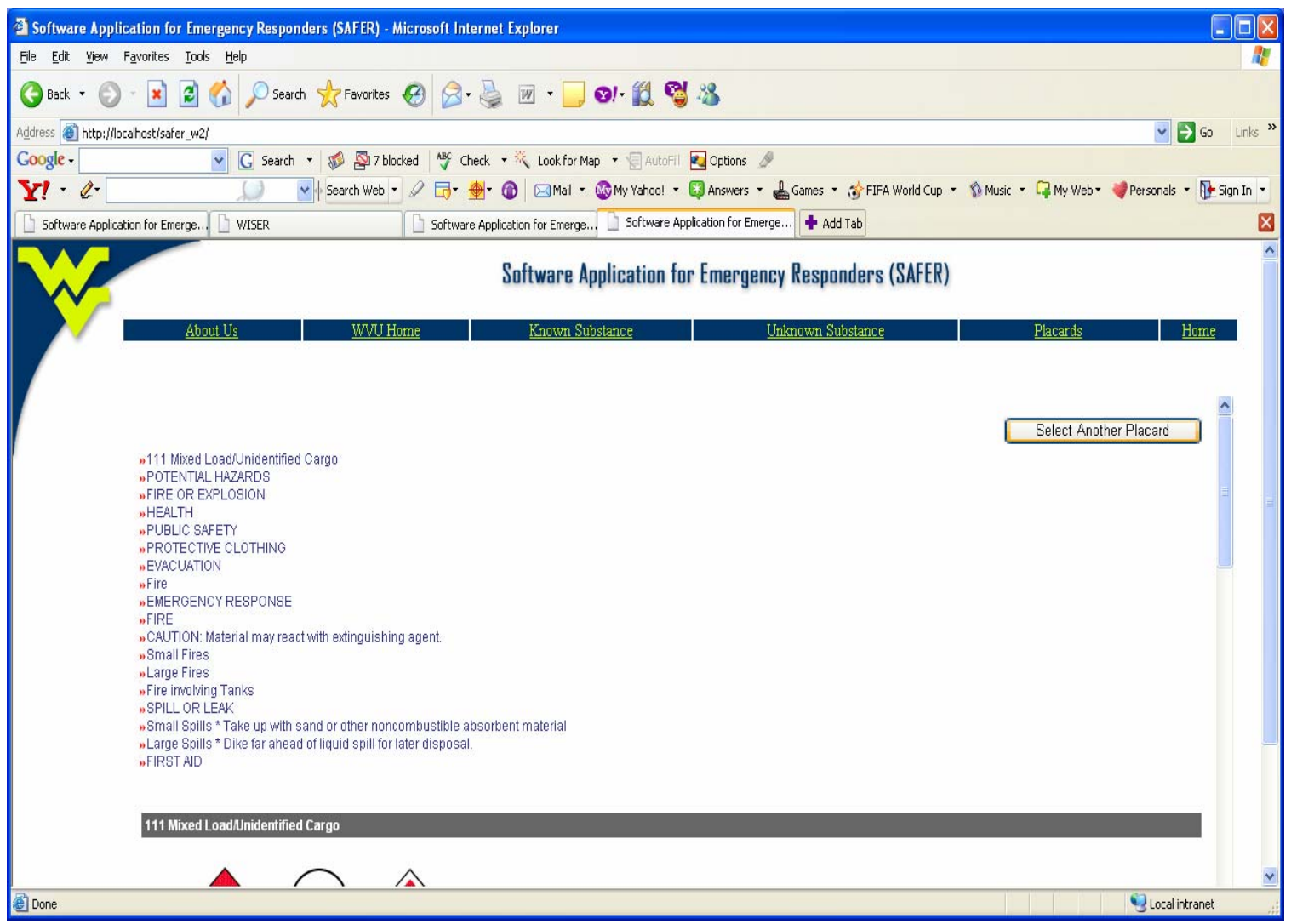

Figure 5.35: Select another Placard button 
This will take the user back to the placards home page as shown in figure 5.36.

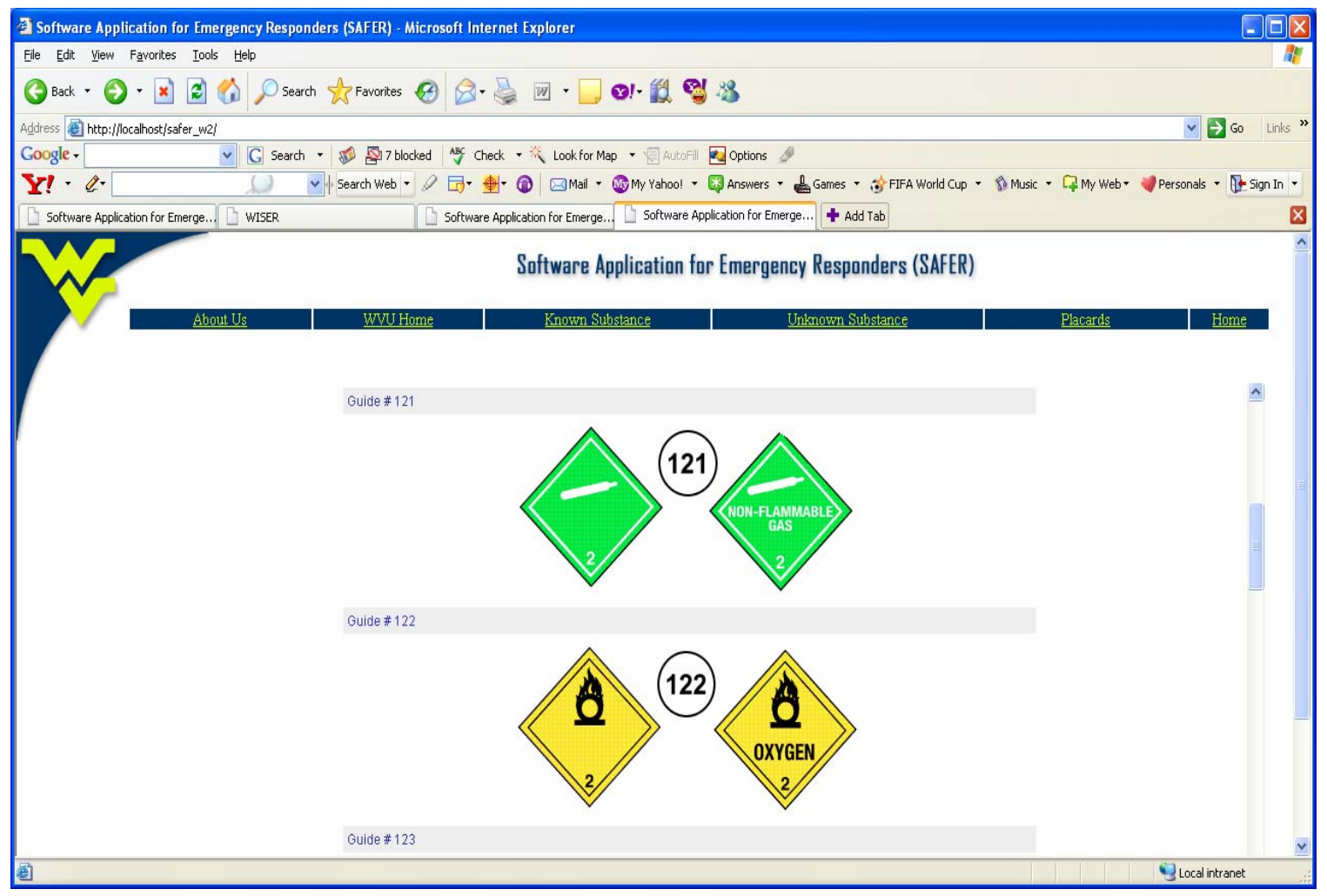

Figure 5.36: Placards homepage 


\section{CHAPTER 6}

\section{CONCLUSIONS AND FUTURE WORK}

\subsection{Conclusions}

The focus of this research was on the design and implementation of a web based software application for emergency responders, SAFER 2.0. The software was developed with ASP.NET 2.0 as the front end and MS SQL Server 2005 as the database. The system can be accessed online via any Internet browser.

This system was designed to assist Emergency Responders in hazardous material incidents. It provides rapid access to the most important information about a hazardous substance. The system expedites the ability to transition from observation to action, when seconds really count. This tool literally replaces a stack of books, so you can always have the information you need. It provides comprehensive decision support, including assistance in identification of an unknown substance. It provides guidance on immediate actions necessary to save lives and protect the environment. The system is Intuitive, simple, and easy to use.

The key features of the system are:

- Anytime availability and rapid access to the information required during a critical situation.

- It is very user friendly.

- Provides assistance in identification of unknown substances 
- Protects the First Responders and the general public during the initial response phase of the incident.

\subsection{Contributions}

- Developed the database for SAFER in SQL Server 2005 by integrating the information from multiple sources.

- Built the web-based application SAFER in the latest version of ASP.NET 2.0.50727.

- Introduced the feature to identify the unknown substance based on the physical or chemical properties of the material.

- Added an exclusive feature to identify an unknown substance on specific parameters like color, odor and state.

- Implemented the new concept of identifying a substance based on placards.

\subsection{Future Work}

The SAFER database can be expanded to include new chemicals as they appear.

It is very easy to incorporate data into the SQL Server database and code accordingly in front-end as all tables are programmatically related and they are related to front-end. In today's world, where uncertainty rules, a handheld tool with the most up to date information is a blessing in disguise for the people (Emergency Responders) who risk their lives to protect others. The application can be developed further to run on a small hand held computer (Pocket PC, PDA), that will fit easily in a pocket. Once you have a 
device that is with you all the time, it opens up many new possibilities. SAFER can be extended to provide SATCOM (Satellite Communication) capabilities. Emergency Responders are on the move all the time. Providing them with the critical information needed in the shortest time possible opens up many possibilities to minimize the risks associated in dealing with the hazardous materials incidents. 


\section{REFERENCES}

[1] http://www.ihmm.org/dspWhatIsHazMat.cfm

[2] http://hazmat.dot.gov/enforce/spills/spills.htm

[3] http://hazmat.dot.gov/pubs/hms/hmship.pdf

[4] http://www.dhs.gov/dhspublic/interapp/editorial/editorial_0197.xml

[5] Langemo M.(1980).Records Management/word processing - a needed team effort, Records Management Quarterly, Vol. 14 No. 4, pp. 10-14.

[6] Adekeye A. (1997). The Importance of Management Information Systems, Library Review, Vol. 46 No. 5, pp. 318-327.

[7] Schwiesow D., Team Management: New Web-based management systems can dramatically improve communication, Engineering Inc., October 2004

[8] Remington J., Managing your Data in a Web-based Paperless Environment, White Paper, Saber Logic, May 2003.

[9] Georgia Research Tech News, First Responder’s Best Friend: "Chemical Companion" Helps Hazmat Teams Make Critical Decisions, Web address:

http://gtresearchnews.gatech.edu/newsrelease/chemical-companion.htm.

(Internet site accessed on $6^{\text {th }}$ June 2006.)

[10] Defense Group Inc. Emergency Response Solutions. :

http://www.defensegroupinc.com/cobra/about.htm (Internet site accessed on $9^{\text {th }}$ June 2006.)

[11] Transport Cananda. Promote public safety in the transportation of dangerous goods. http://www.tc.gc.ca/canutec/en/guide/ERGO/ergo.htm (Internet site accessed on $9^{\text {th }}$ June 2006.)

[12] united States national library of medicine. Wireless Information System for Emergency Responders: http://wiser.nlm.nih.gov/index.html (Internet site accessed on $6^{\text {th }}$ July 2006.)

[13] Pocket Mobility, Inc. Hazmat toolkit.. http://www.pocketmobility.com (Internet site accessed on $27^{\text {th }}$ June 2006.) 
14] Center for disease control (CDC) Pocket Guide to Chemical Hazards. NIOSH publication no. 2005-149. www.cdc.gov/niosh/npg (Internet site accessed on $5^{\text {th }}$ July 2006.)

[15] Center for disease control (CDC). Technology News 510 - Hazcom Helper - OSHA Version, Compliance Tool For OSHA Rule 29 CFR 1910.1200. Niosh publication no. 2006-106. www.cdc.gov/niosh/npg. (Internet site accessed on $9^{\text {th }}$ July 2006.)

[16] U.S Department of Transportation, 1978. Emergency Action Guide for Selected Hazardous Materials. Draft.

[17] Bangar P., Introduction to ASP.NET. http://www.clickfire.com/viewpoints/articles/webdevelopment/asp_net.php (Internet site accessed on 1 July 2006.)

[18] U.S Department of Transportation 2004 Emergency Response Guidebook. http://hazmat.dot.gov/pubs/erg/erg2004.pdf. (Internet site accessed on $19^{\text {th }}$ June 2006.).

[19] The Role of Hazardous Material Placards In Transportation Safety and Security http://hazmat.dot.gov/riskmgmt/hmt/0803RedactedPlacardingReportSSI.pdf . (Internet site accessed on $9^{\text {th }}$ July 2006.)

[20] Sarvanan Sundararajan., 2003, A Software Tool for Emergency Responders. Problem Report.

[21] Building a 3-Tier Application using ASP.NET. http://www.c-sharpcorner.com/Tutorials/Building3TierAppPA.asp. ((Internet site accessed on $10^{\text {th }}$ July 2006.) 


\section{APPENDIX 1: SAFETY PRECAUTIONS}

APPROACH CAUTIOUSLY FROM UPWIND. Resist the urge to rush in; others cannot be helped until the situation has been fully assessed.

SECURE THE SCENE. Without entering the immediate hazard area, isolate the area and assure the safety of people and the environment, keep people away from the scene and outside the safety perimeter. Allow enough room to move and remove your own equipment.

IDENTIFY THE HAZARDS. Placards, container labels, shipping documents, material safety data sheets, Rail Car and Road Trailer Identification Charts, and/or knowledgeable persons on the scene are valuable information sources. Evaluate all available information and consult the recommended guide to reduce immediate risks.

ASSESS THE SITUATION. Consider the following:

- Is there a fire, a spill or a leak?

- What are the weather conditions?

- What is the terrain like?

- Who/what is at risk: people, property or the environment?

- What actions should be taken: Is an evacuation necessary? Is diking necessary? What resources (human and equipment) are required and are readily available?

- What can be done immediately?

OBTAIN HELP. Advise your headquarters to notify responsible agencies and call for assistance from qualified personnel. 
DECIDE ON SITE ENTRY. Any efforts made to rescue persons, protect property or the environment must be weighed against the possibility that you could become part of the problem. Enter the area only when wearing appropriate protective gear RESPOND. Respond in an appropriate manner. Establish a command post and lines of communication. Rescue casualties where possible and evacuate if necessary. Maintain control of the site. Continually reassess the situation and modify the response accordingly. The first duty is to consider the safety of people in the immediate area, including your own.

ABOVE ALL - Do not walk into or touch spilled material. Avoid inhalation of fumes, smoke and vapors, even if no dangerous goods are known to be involved. Do not assume that gases or vapors are harmless because of lack of a smell—odorless gases or vapors may be harmful. Use CAUTION when handling empty containers because they may still present hazards until they are cleaned and purged of all residues. 


\section{APPENDIX 2: TABLE OF PLACARDS (1)}
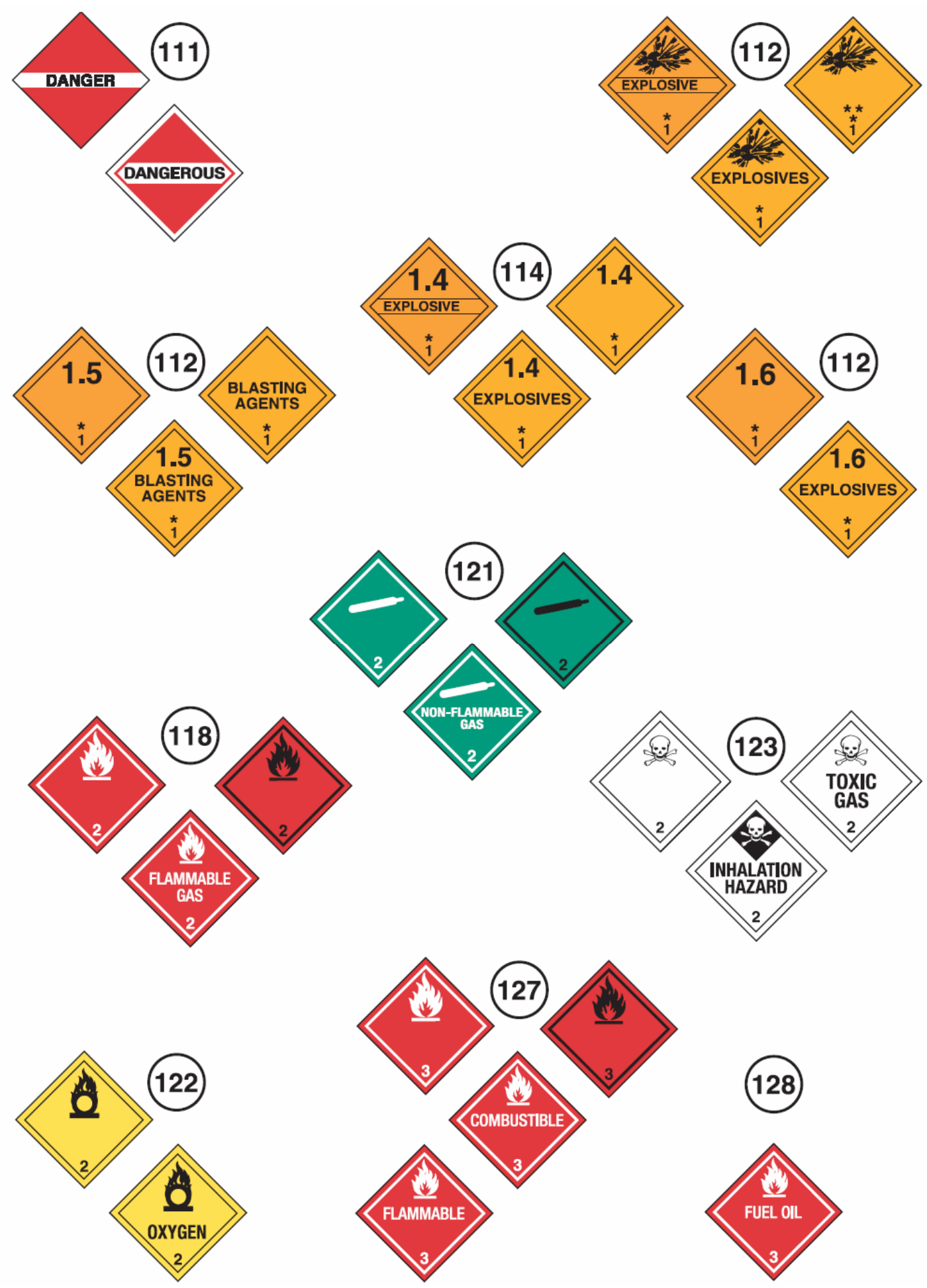


\section{APPENDIX 3: TABLE OF PLACARDS (2)}
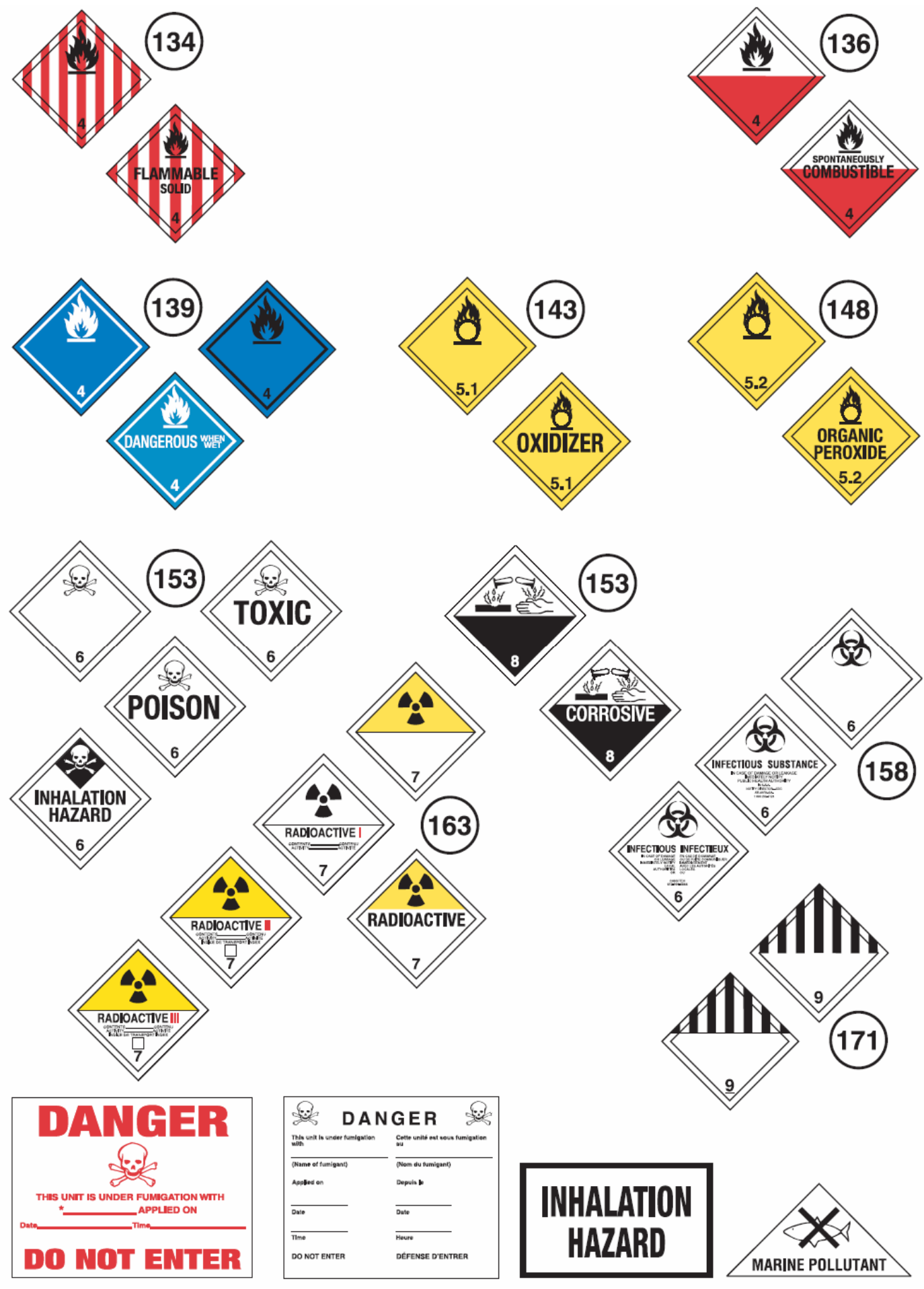

153
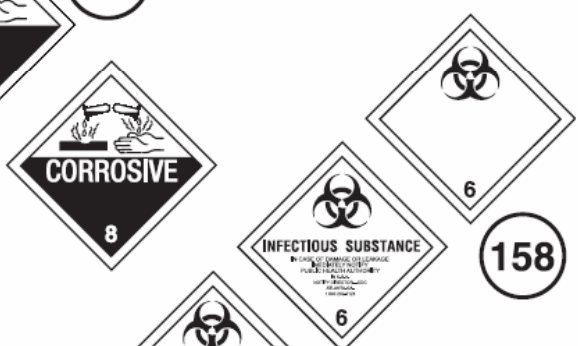

se
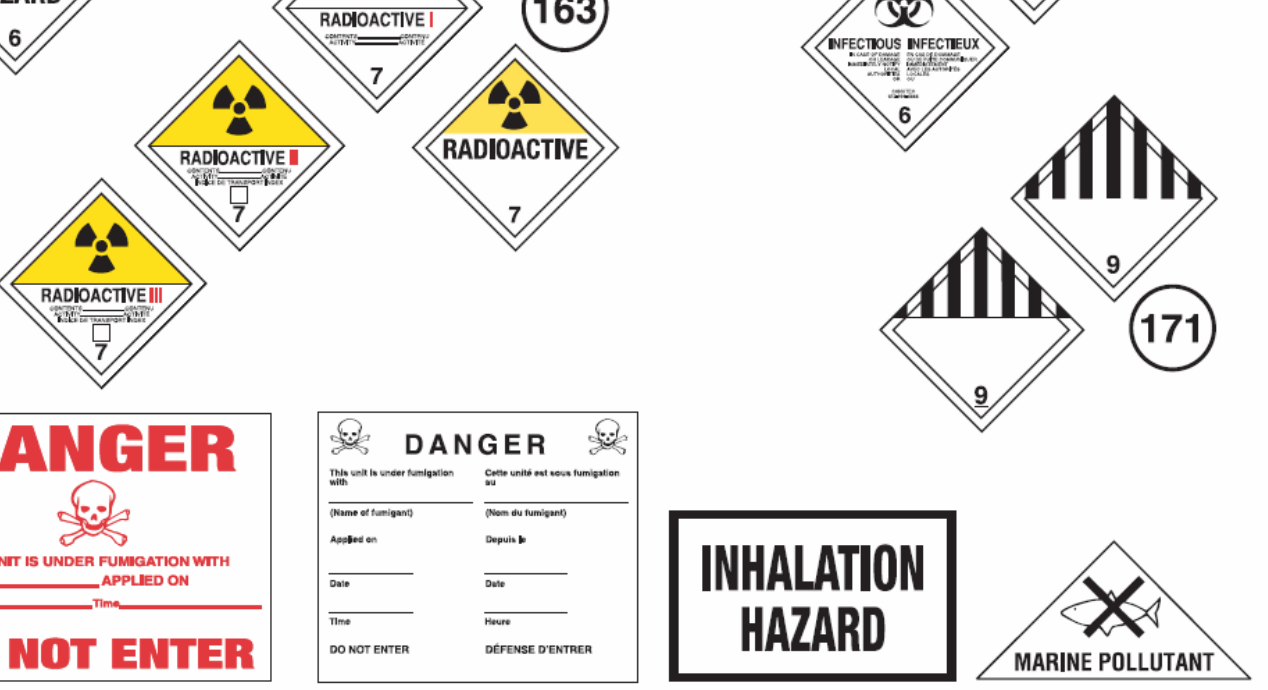


\section{APPENDIX 4: RAIL CAR IDENTIFICATION CHART}
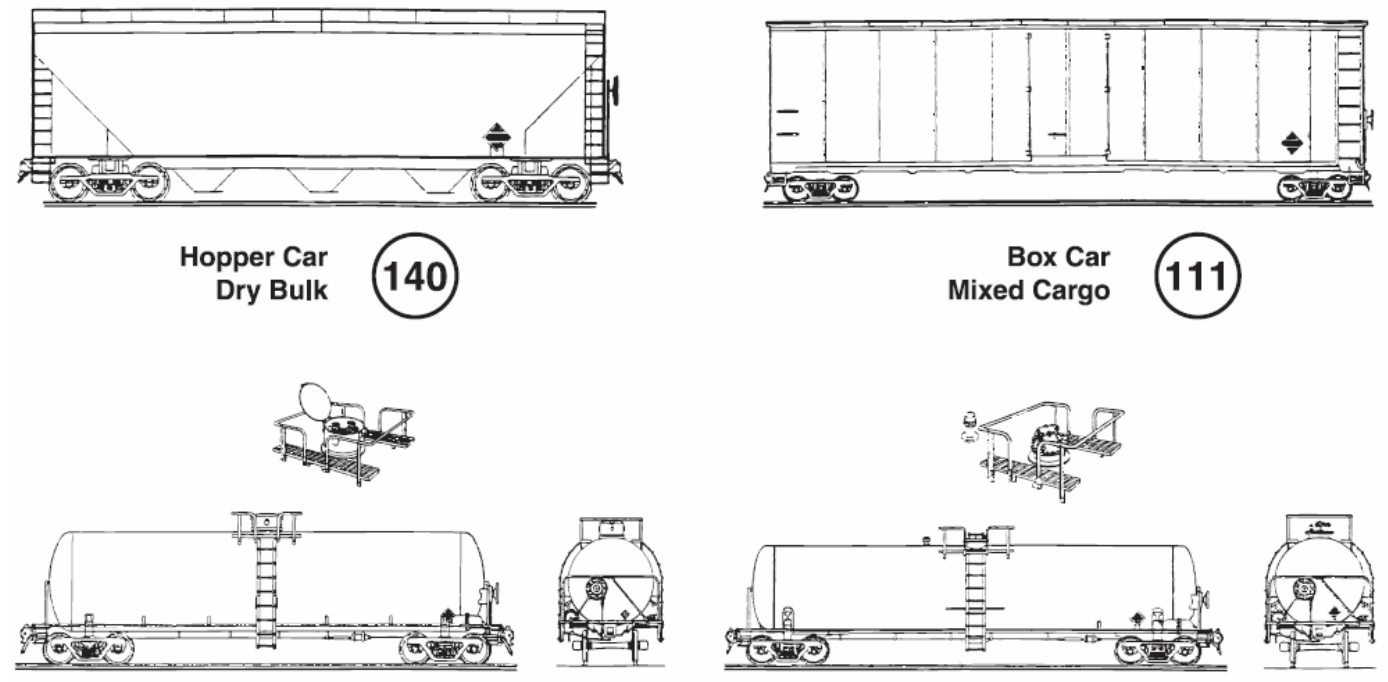

Pressure tank car

Compressed liquified gases
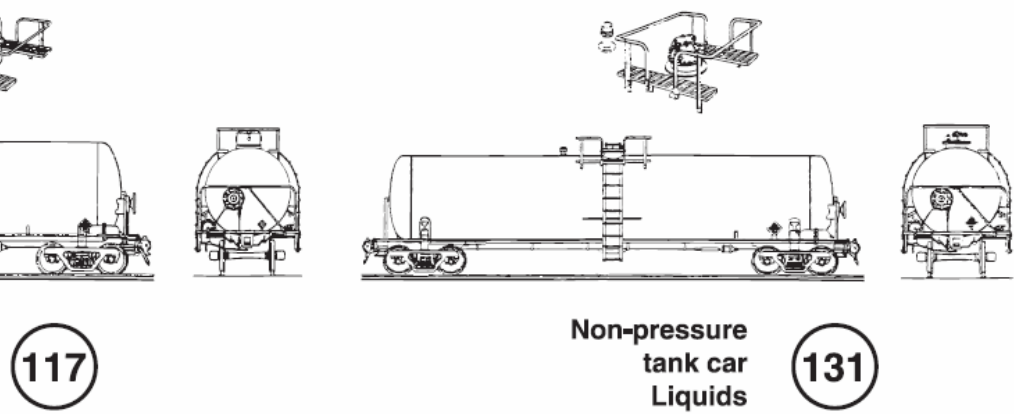

Non-pressure

tank car

Liquids

131

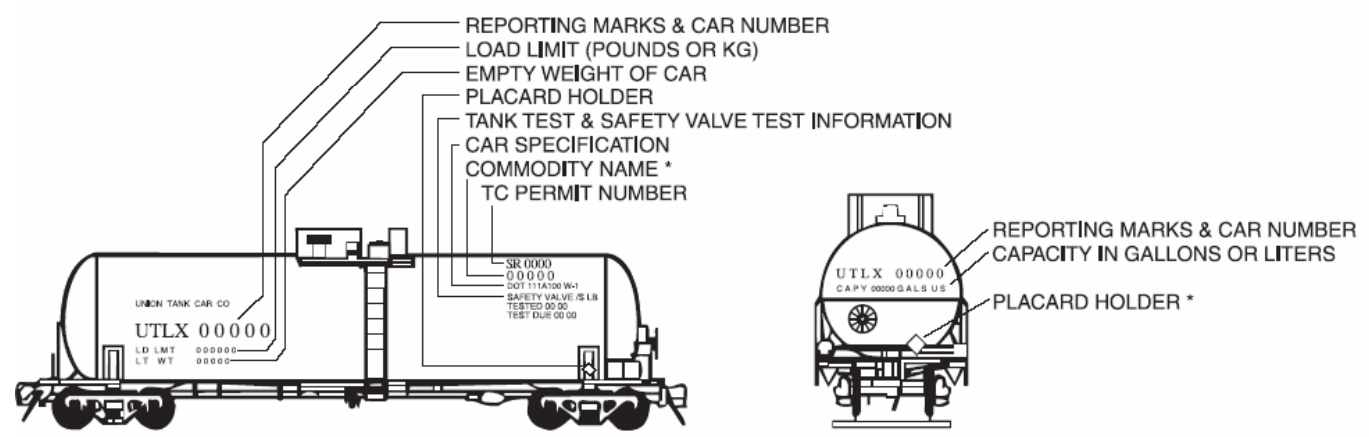

CAUTION: Emergency response personnel must be aware that rail tank cars vary widely in construction, fittings and purpose. Tank cars could transport products that may be solids, liquids or gases. The products may be under pressure. It is essential that products be identified by consulting shipping documents or train consist or contacting dispatch centers before emergency response is initiated.

The information stenciled on the sides or ends of tank cars, as illustrated above, may be used to identify the product utilizing:

a. the commodity name shown; or

b. the other information shown, especially reporting marks and car number which, when supplied to a dispatch center, will facilitate the identification of the product.

* The recommended guides should be considered as last resort if product cannot be identified by any other means. 


\section{APPENDIX 5: ROAD TRAILER IDENTIFICATION CHART}
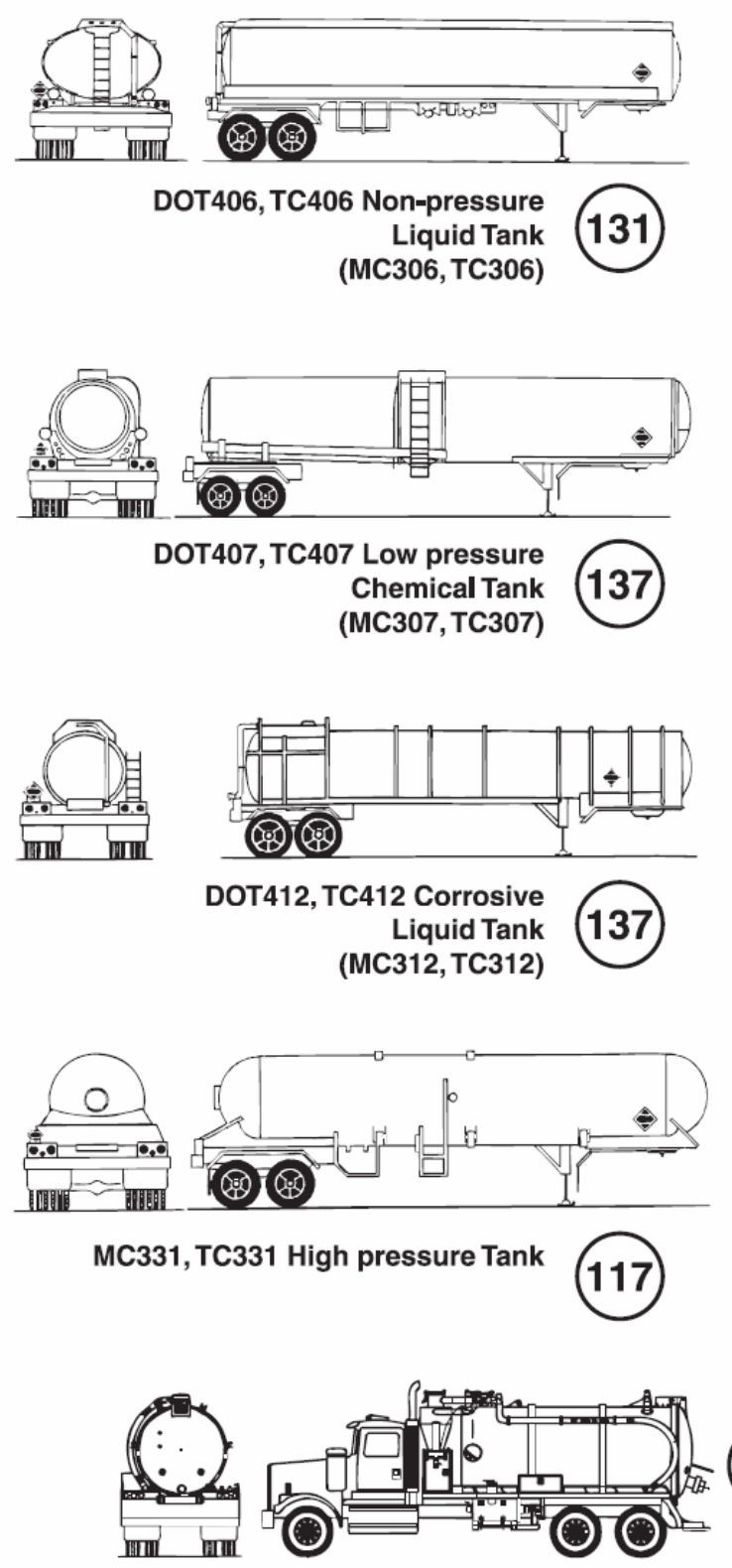
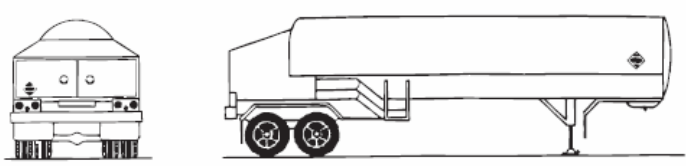

MC338, TC338 Cryogenic Liquid

Tank

(MC306, TC306)
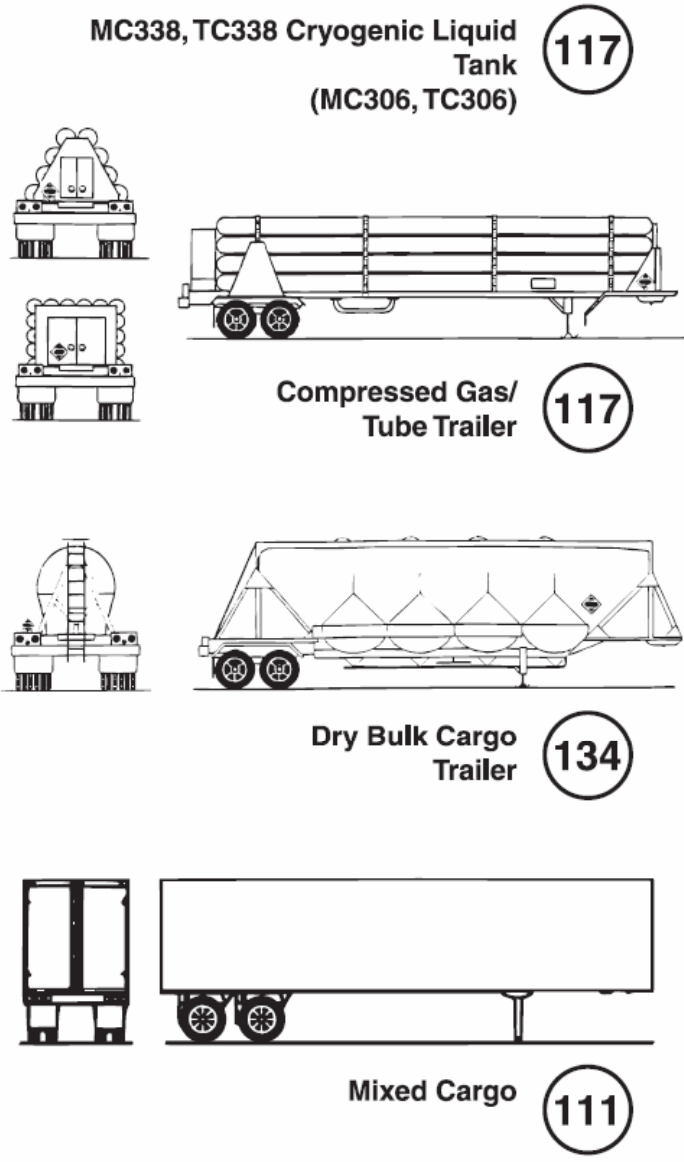

CAUTION: This chart depicts only the most general shapes of road trailers. Emergency response personnel must be aware that there are many variations of road trailers, not illustrated above, that are used for shipping chemical products. The suggested guides are for the most hazardous products that may be transported in these trailer types. 